\title{
Did Cyclic Metaphosphates Have a Role in the Origin of Life?
}

\author{
Thomas Glonek ${ }^{1}$ (i)
}

Received: 16 November 2020 / Accepted: 29 January 2021 / Published online: 15 March 2021

(c) The Author(s) 2021

\begin{abstract}
How life began still eludes science life, the initial progenote in the context presented herein, being a chemical aggregate of primordial inorganic and organic molecules capable of self-replication and evolution into ever increasingly complex forms and functions.

Presented is a hypothesis that a mineral scaffold generated by geological processes and containing polymerized phosphate units was present in primordial seas that provided the initiating factor responsible for the sequestration and organization of primordial life's constituents. Unlike previous hypotheses proposing phosphates as the essential initiating factor, the key phosphate described here is not a polynucleotide or just any condensed phosphate but a large (in the range of at least 1 kilo-phosphate subunits), water soluble, cyclic metaphosphate, which is a closed loop chain of polymerized inorganic phosphate residues containing only phosphate middle groups. The chain forms an intrinsic 4-phosphate helix analogous to its structure in Na Kurrol's salt, and as with DNA, very large metaphosphates may fold into hairpin structures. Using a Holliday-junction-like scrambling mechanism, also analogous to DNA, rings may be manipulated (increased, decreased, exchanged) easily with little to no need for additional energy, the reaction being essentially an isomerization. A literature review is presented describing findings that support the above hypothesis. Reviewed is condensed phosphate inorganic chemistry including its geological origins, biological occurrence, enzymes and their genetics through eukaryotes, polyphosphate functions, circular polynucleotides and the role of the Holliday junction, previous biogenesis hypotheses, and an Eoarchean Era timeline.
\end{abstract}

Keywords Holliday $\cdot$ LUCA $\cdot$ Metaphosphate $\cdot$ Origin of life $\cdot$ Polyphosphate $\cdot$ Progenote

Phosphate esters and anhydrides are major chemical components of the living world. The phosphate functional group is especially adapted for its various biochemical roles, particularly for genetics, because it can link two esters or form an anhydride and still ionize; the resulting negative charge serves both to stabilize these linkages against hydrolysis and to retain linked moieties within a lipid membrane. No other inorganic moiety appears to fulfill the multiple roles of phosphate in biochemistry. Phosphate is absolutely essential;

Thomas Glonek

tglonek@rcn.com

1 MR Laboratory, Midwestern University, Downers Grove, IL, USA 
therefore, it is logical to assume it was an active constituent of the first living entity at its conception.

Consider revisiting the hypothesis that a key molecule responsible for the origin of life on Earth was a condensed phosphate, a long chain of inorganic phosphate containing $\mathrm{PO}_{3}$ residues linked through $-\mathrm{P}-\mathrm{O}-\mathrm{P}-$ phosphate anhydride bonds, each of which at physiological $\mathrm{pH}$ is negatively charged, $\left(\mathrm{PO}_{3}{ }^{-}\right)_{\mathrm{n}}$. Molecules within the condensed phosphate family have several salient features:

- They are covalently-linked polymeric chains, analogous to deoxyribonucleic acid (DNA), cellulose and protein.

- They possess high-energy phosphate bonds, one for each phosphorus atom in the chain, a kind of super adenosine triphosphate (ATP), but one that is entirely inorganic.

- They are relatively stable for being such high-energy molecules.

- They can change their nature, fragment, cyclize, without losing their intrinsic energy of combination and without any assistance from any other unrelated chemical entity.

- They were there when the Earth's crust first formed and the lighter elements were belched onto its surface.

- They are water soluble.

- They sequester metal cations.

- They aggregate with and precipitate proteins but also can act as mineral chaperones.

Presented is a review of the condensed phosphate literature covering the realms of geochemistry, inorganic chemistry and biochemistry, followed by a Discussion section in which a hypothesis is presented describing how condensed phosphates, particularly the cyclic metaphosphates, may have participated in the formation of the very first living form, the germinal progenote.

\section{Definition of "Condensed Phosphates"}

"Condensed phosphate" in the context of this paper refers to any of the family of inorganic phosphate anhydrides containing a $\mathrm{P}-\mathrm{O}-\mathrm{P}$ link between two or more phosphate groups (Thilo 1965; Van Wazer 1958a). These may form open chains having two end-group phosphates, closed rings having no ends, and cage structures containing branch phosphate groups that have three $\mathrm{P}-\mathrm{O}-\mathrm{P}$ links per phosphorus atom (Van Wazer 1958a; Glonek et al. 1970, 1971b, 1974b, 1975b). $\mathrm{R}-\mathrm{O}-\mathrm{P}\left(\mathrm{O}_{2}{ }^{-}\right)-\mathrm{O}-$ $\mathrm{P}\left(\mathrm{O}_{2}{ }^{-}\right)_{\mathrm{n}}-\mathrm{O}-\mathrm{P}\left(\mathrm{O}_{2}{ }^{-}\right)-\mathrm{O}-\mathrm{R}^{\prime}$ represents the chain polymers, where $\mathrm{R}$ and $\mathrm{R}^{\prime}$ for the open chain molecules are the negative charges of the anion or protons for the acid. The cyclic metaphosphates have no end groups, $\left(\mathrm{R}-\mathrm{O}-\mathrm{P}\left(\mathrm{O}_{2}{ }^{-}\right)-\right)_{\mathrm{n}}$; they are simply anionic rings of three or more phosphate middle groups, $-\mathrm{O}-\mathrm{P}\left(\mathrm{O}_{2}^{-}\right)_{\mathrm{n}}$, where $\mathrm{n} \geq 3$. Additionally, for the anionic forms, cations, either metals or organics, may be accommodated in a charge-balanced manner. Dissolution in very strong acids, e.g., perchloric acid, produces phosphonium perchlorate salts (Glonek et al. 1974a).

In biochemistry, the nucleoside triphosphates are the outstanding representatives of chain condensed phosphates, with each containing one tripolyphosphate chain, e.g., ATP (Glonek et al. 1976b). Inorganic polyphosphates (polyP) are the other major condensed phosphates of biological origin (Kumble and Kornberg 1995; Kornberg et al. 1999; Rao et al. 2009) and are usually found as the principal constituent of intracellular electron-dense granules. 
In this review, "polyphosphate" is the generic term used by most authors to refer to a polymer of orthophosphate, and it is expressed by authors in a variety of symbols and words, particularly in the biochemical and industrial literature. Rarely are distinctions made among poly- meta- and ultra-phosphates, and often the only analytical data presented regarding polyphosphate structures are observations of stains with the appropriate properties observed under a microscope or a blue stain on a chromatogram that did not migrate. Although more recent papers also cite ${ }^{31} \mathrm{P}$ nuclear magnetic resonance (NMR), which is useful for the lower molecular weight members (Glonek et al. 1975a), ${ }^{31} \mathrm{P}$ NMR lacks resolving power, even with $11 \mathrm{~T}$ magnetic fields, for distinctions among the higher molecular weight members.

\section{Literature Review}

\section{Chemistry}

The condensed phosphates are polymers of inorganic orthophosphate, $\mathrm{Pi}\left(\mathrm{PO}_{4}{ }^{-3)}\right)$, that exist in a variety of chain, ring, and cage structures, all involving the linking $\mathrm{P}-\mathrm{O}-\mathrm{P}$ functional group. The phosphoric anhydride bond is referred to in the biological disciplines as the "high-energy" phosphate bond. For the convenience of discussion, these structures can be sorted into three molecular family groups: polyphosphates, metaphosphates, and ultraphosphates. The polyphosphates, which are open chains of phosphate groups consisting of from 2 to more than $10^{6}$ units, have two end group phosphates $\left[\left(-\mathrm{OPO}_{3}\right)^{-2}\right.$ at $\mathrm{pH}$ 9] per molecule, one on either end of the chain and, except for the smallest member, the pyrophosphate, any number of middle group phosphates, $\left(-\mathrm{O}-\mathrm{PO}_{2}-\right)^{-1}($ Kornberg et al. 1999 Fig. 1; Kulaev 1979; Kulaev et al. 2004; Thilo and Wieker 1957; Thilo 1965; Van Wazer 1958b). In general, the end groups are keys to several of the unique degradation properties of open chain phosphates. The cyclic metaphosphates, on the other hand, are rings of phosphate units, without end groups, consisting solely of anhydride-linked $\left(\mathrm{PO}_{3}\right)^{-1}$ residues (Kulaev 1979; Kulaev et al. 2004 Fig. 1; Thilo 1965; Van Wazer 1958c). These are much more stable to hydrolysis and/or rearrangement relative to their open-chain cousins. Ultraphosphates are any condensed phosphate containing the branch group phosphate, and exhibiting the constituent ratio of $\mathrm{H}_{2} \mathrm{O} / \mathrm{P}_{2} \mathrm{O}_{5}<1$ (Van Wazer 1958d). These may have any number of middle groups, occasionally one or more end groups, and may exist as cages, or fused rings, or cross-linked chains in crystalline polymers (Van Wazer 1958e). All three molecular types may be formed from Pi or its salts and esters by dehydration/dealkylation at elevated temperatures (Kulaev 1979; Kulaev et al. 2004; Van Wazer 1958f).

Geochemically, it has been demonstrated that condensed phosphate polymers are produced from the mineral phosphates of volcanic fumaroles, apparently from ultraphosphates. Approximately $5 \mu \mathrm{M}$ concentrations of pyrophosphate and tripolyphosphate were quantified in a fumarole near Mt. Usu in Hokkaido, Japan (Yamagata et al. 1991). This is by far the most convincing case for a prebiotic source of condensed phosphates (Keefe and Miller 1995). A mechanism in which $\mathrm{P}_{4} \mathrm{O}_{10}$ molecules are volatilized from rock samples is presented under Chain Polyphosphate Synthesis.

It has often been suggested that polyphosphates were involved in prebiotic evolution (Kulaev 1979; Kulaev et al. 2004; Griffith et al. 1977; Keefe and Miller 1995; FernándezGarcia et al. 2017; Prieur 2009), where a strong case advocating this molecular family has been made (Gabel 1973, 1977). There is, however, no general acceptance for the above 
<smiles>O=P1([O-])OP(=O)([O-])OP(=O)([O-])O1</smiles>

Trimetaphosphate

Open chain polyphosphates

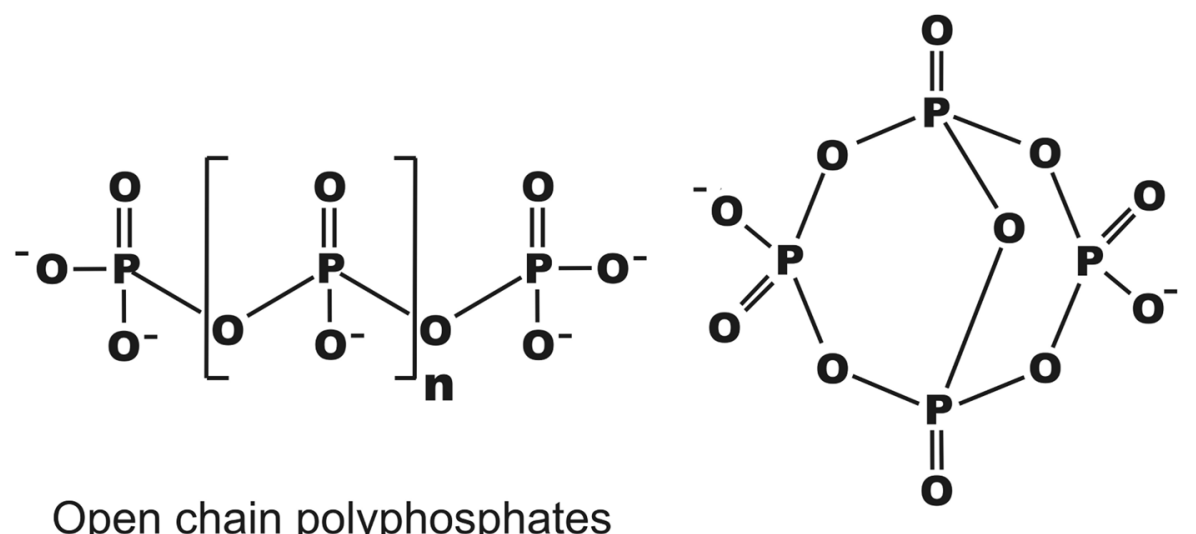

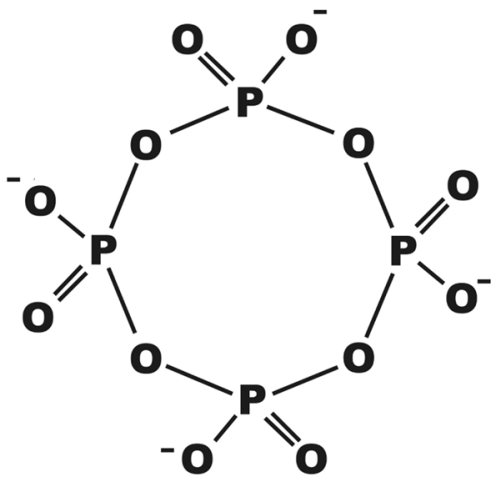

Tetrametaphosphate

\section{1,5- $\mu$-охо- Tetrametaphosphate an ultraphosphate}

Fig. 1 Known, well-characterized condensed phosphates: trimetaphosphate, a six-element ring of the family of cyclic metaphosphates; tetrametaphosphate, a larger eight-element ring; open straight-chain polyphosphates, from pyrophosphate, where $n=0$, to very large polyphosphates, where $n$ may exceed 10,000 phosphate units; 1,5- $\mu$-oxo-tetrametaphosphate, an example of a small fused-ring ultraphosphate. The polyphosphates exhibit an R-value (Van Wazer 19581) $\left(\mathrm{H}_{2} \mathrm{O} / \mathrm{P}_{2} \mathrm{O}_{5}\right)$ of $>1$ but not 3, which is the R-value of the building unit, orthophosphate; cyclic metaphosphates exhibit an R-value of exactly 1; the ultraphosphates, R-values $<1 ; 1,5$ - $\mu$-oxo-tetrametaphosphate exhibits an R-value of 0.5

rolls of condensed phosphates in prebiotic biochemistry. Keefe and Miller (1995) assumed a more negative position, concluding that the first genetic material may not have been phosphate esters and that phosphoanhydrides also are unlikely as prebiotic energy sources. Today, this issue still is not settled.

Characterization of the condensed phosphates has been and continues to be extremely difficult, particularly for those specimens derived from biological sources or those 
extracted from geological strata. Further, there are few chemically well-characterized CPgrade model compounds available for experimental identification, particularly for the large poly- and meta-phosphates, and all ultraphosphates except phosphorus pentoxide, $\mathrm{P}_{4} \mathrm{O}_{10}$. As a result, key phosphatic compounds as well as significant bioinorganic chemistry may not have been examined in work conducted to date, particularly in the world of biology, and especially when considering those events that may have occurred four-and-a-half billion years ago under a heavy, hot, and reducing atmosphere.

\section{Chemical Properties and Biological Occurrence of Condensed Inorganic Phosphates}

Except for the annealed alkali metal crystals, termed "insoluble" phosphates, inorganic condensed phosphates (Fig. 1) are water soluble and also may be dissolved as either the free acids or as aliphatic ammonium salts in certain polar organic solvents, e.g., N,N,N',N'tetramethylurea (Glonek et al. 1972, 1974b), trichloroacetonitrile (Glonek et al. 1971a, b), dioxane (Smith et al. 1958), 1-butyl-3-methylimidazolium chloride.

The chain polyphosphates, in general, exhibit two pKa values, a weak acid end-group $\left(-\mathrm{P}\left(\mathrm{OH}_{2}{ }^{-}\right) \mathrm{OH}\right)$ ionization in the range of 6.6 to 7.2 and a strong acid middle-group $\left(-\mathrm{P}\left(\mathrm{O}_{2}{ }^{-}\right) \mathrm{O}-\right)$ ionization in the range of 2.4 to 1.8 , depending on the average chain length and the quality of the preparation (Thilo 1965 Table 3). The metaphosphates exhibit only the strong acid ionization $\left(-\mathrm{P}\left(\mathrm{O}_{2}{ }^{-}\right) \mathrm{O}-\right)$, as they have no end groups, and the ultraphosphate group is not ionized. The orthophosphoric acid building unit of the condensed phosphate family also may be additionally protonated to the phosphonium cation in very strong acids, such as perchloric acid (Glonek et al. 1974a), and there is no chemical reason that this reaction isn't also possible with both the chain and the cyclic condensed phosphates (Van Wazer 1958g).

It should be noted that the inorganic polyphosphates have been found in every cell: bacterial, archaeal, fungal, protozoan, plant, and animal (Kumble and Kornberg 1995), where the cellular organelle containing the condensed phosphate has been identified using one or more of the following names: electron dense granules (particles) (Hamai and Kuwabara 1975; Lawrence et al. 1998; Remonsellez et al. 2006; Ruiz et al. 2001), volutin granules (Clark et al. 1986; Kulaev 1979; Kulaev and Vagabov 1983; Rao et al. 2009; Rudnick et al. 1990; Serafim et al. 2002), granulelike inclusion bodies (Toso et al. 2011), metachromatic granules (Kornberg et al. 1956, 1999; Kulaev 1979; Rudnick et al. 1990; Serafim et al. 2002), platelet-dense granules (Rao et al. 2009), polyphosphate granules (Eixler et al. 2005; Hupfer and Gächter 1995; Kulaev and Vagabov 1983; Mateo et al. 2006; Serafim et al. 2002; Zhang et al. 2015), cyanophycin granules (Romans et al. 1994), Babesh-Ernst bodies (Kulaev 1979), polyphosphate (polyP) bodies (Lawrence et al. 1998; Romans et al. 1994; Toso et al. 2011), and acidocalcisomes (Brown and Kornberg 2004; Docampo et al. 2005; Rao et al. 2009; Zhang et al. 2007). These sub-cellular particles are easily obtained as cell-free suspensions through $\mathrm{NaOH}$ and hot water treatments followed by filtration (Eixler et al. 2005). In the Archaeon Methanospirillum hungatei, the granules varied from roughly spherical to an angular surfaced shape (Toso et al. 2011 Fig. 1a-c). Upon higher magnification, the granules appeared to be made of smaller particles that clustered into the spherical shape (Toso et al. 2011 Fig. 1d). 


\section{Chain Polyphosphate Synthesis}

Salts of the polyphosphoric acids were first reported by Fleitman and Henneberg (1848). Bell was the first to formulate a procedure for quantifying pyro- and tripoly-phosphoric acids in the presence of each other and in the presence of Pi and the chain "metaphosphates." (Bell 1947) ["Metaphosphates," as used in (Bell 1947), is the now archaic nomenclature for highly condensed inorganic phosphates of unknown chemical structure but of known atomic ratios.]

In the laboratory, Graham's salt, $\mathrm{Na}_{\mathrm{n}} \mathrm{H}_{2} \mathrm{P}_{\mathrm{n}} \mathrm{O}_{3 \mathrm{n}+1}$, is obtained by heating $\mathrm{NaH}_{2} \mathrm{PO}_{4}$ above $620{ }^{\circ} \mathrm{C}$ and rapidly cooling the resulting melt. The melt solidifies to form a glass, about $90 \%$ of which consists of a mixture of high-molecular weight linear chain polyphosphates in the range of 1000 phosphate units per chain, the remainder being cyclic metaphosphates with molecular anions in a range of sizes (Kulaev 1979; Thilo 1965 Fig. 1). When this glass is annealed at 400 to $550{ }^{\circ} \mathrm{C}$, it is converted via a rearrangement into the pure cyclic trimetaphosphate (Thilo 1965), indicating that the thermodynamically most stable form of condensed phosphates at the metaphosphate composition, $\mathrm{P}_{2} \mathrm{O}_{5} / \mathrm{H}_{2} \mathrm{O}=1$, is the 6 element, 3 phosphate, trimetaphosphate ring (Fig. 1); however, a melt of such a sodium metaphosphate composition, when cooled to temperatures in the range of $550-600{ }^{\circ} \mathrm{C}$ and then seeded with a crystal of Kurrol's salt, will crystallize to the very long chain polyphosphate Kurrol's salt (Van Wazer 1958f).

The anion chains in Kurrol's salt, which are formed in a crystalline state with a Na/P composition of essentially unity, the pure metaphosphate composition (Van Wazer 1958f), may extend for up to $10^{6}$ units. Crystallography (Kulaev 1979; Kulaev et al. 2004; Fig. 1; Thilo 1965 Fig. 10) reveals, in addition to several counter-cation-dependant linear forms, two helical forms, Na-Kurrol-A and - B, each exhibiting four $\mathrm{PO}_{3}$ groups per turn of the helix (Thilo 1965). The length of the P-O bridges in the chains is 1.57 to $1.64 \AA$, those of the non-bridging $\mathrm{P}-\mathrm{O}$ bonds 1.44 to $1.52 \AA$. The $\mathrm{P}-\mathrm{O}-\mathrm{P}$ angles are between $124^{\circ}$ and $134^{\circ}$, and the $\mathrm{O}-\mathrm{P}-\mathrm{O}$ angles are between $98^{\circ}$ and $120^{\circ}$. The averages of these angles are practically the same for those of the cyclic metaphosphates (Thilo 1965), which is an explanation advanced to rationalize why ${ }^{31} \mathrm{P}$ NMR chemical shifts of the polyphosphates and metaphosphates converge as the molecular sizes increase (Glonek et al. 1972). As molecular size increases, the interior middle phosphate groups of both condensed phosphate molecular types are chemically and spatially essentially identical.

In the repeating $\mathrm{PO}_{3}$ unit of the condensed phosphates, four oxygens occupy the apex positions of a distorted tetrahedron, with the phosphorus approximately centered among them; the linking oxygens are shared between adjoining tetrahedra. The length of the chain-linking edge of this tetrahedron averages $\sim 2.77 \AA$, which for a linear extended 1000-phosphate residue molecule computes to $2770 \AA$ A. In a-Na-Kurrol B helix, however, four phosphates comprise one full turn of a helix, a repeating secondary conformational unit in the chain. This results in a chain-shortening of 38\%. A 1000-phosphate cyclic metaphosphate, with the constituent chain coiled into the helix conformation, would exhibit a ring diameter of $\sim 335 \AA$, a rather compact molecular arrangement.

Reviewing inorganic chemistry under geological conditions, an important finding was made by Yamagata and Watanabe (1991), who showed that acidic basalts containing apatite evolve phosphorus pentoxide $\left(\mathrm{P}_{4} \mathrm{O}_{10}\right)$ when heated to $1,200{ }^{\circ} \mathrm{C}$. The $\mathrm{P}_{4} \mathrm{O}_{10}$ molecule is thermodynamically stable even in the presence of water vapor at temperatures higher than $1,000^{\circ} \mathrm{C}$. Further, from experiments employing molten basaltic rocks that simulate magmatic conditions and from analysis of the volatile condensates in volcanic gas using 
${ }^{31} \mathrm{P}$ NMR and chromatographic analytical methodology, it was demonstrated that volcanic activity can produce water-soluble polyphosphates through partial hydrolysis of the $\mathrm{P}_{4} \mathrm{O}_{10}$ created within molten basaltic rocks (Yamagata et al. 1991).

\section{Cyclic Metaphosphate Synthesis}

The cyclic metaphosphates are present to minor degrees in all preparations of Graham's salt polyphosphate glasses, as well as the crystalline Kurrol's salt (Thilo 1965; Thilo and Schülke 1965; Thilo and Wieker 1957), where, using paper chromatography, metaphosphates up to the octametaphosphate have been identified (Mattenheimer 1956a, b; Kulaev 1979; Kura and Ohashi 1971; Thilo 1965 Fig.1; Thilo and Schülke 1965; Van Wazer $1958 \mathrm{~g}$ ). With Graham's salt, the concentrations of the individual metaphosphates decrease exponentially as the number of atoms in the ring increases (Thilo 1965 Fig. 2), indicating an equilibrium distribution. This observation of Thilo (1965) implies that metaphosphates much larger than the octametaphosphate are present in Graham's salt, although their mole fraction is small, which would be expected since the individual molecules themselves are large with regard to the number of constituent $\mathrm{PO}_{3}$ residues per molecule. The same conclusion was drawn by Glonek for the described condensation of orthophosphoric acid to the ultraphosphate composition of $0.5 \mathrm{H}_{2} \mathrm{O} / \mathrm{P}_{2} \mathrm{O}_{5}$ in polar organic media (Glonek et al. 1970, 1971a, b, 1972).

The hexa- (Griffith and Buxton 1965) and octa- (Schülke 1968) metaphosphates have been prepared in crystalline form from inorganic melts and characterized through paper chromatography (Schülke 1968; Thilo and Schülke 1965), and from carbodiimide condensation reactions characterized through ${ }^{31} \mathrm{P}$ NMR. All metaphosphates, including up to the nona- and dodeca-metaphosphates, have been purified from hydrolyzed reaction mixtures (Glonek et al. 1970, 1971a, b, 1972, 1974a, 1975a; Kulaev et al. 2004; Weimann and Khorana 1962) and characterized through ${ }^{31} \mathrm{P}$ NMR (Chen 1999; Glonek et al. 1970, 1971a, b, 1972; Figs. 3 , 4; 1974a, b, 1975b, 1976a; Kulaev and Vagabov 1983; Van Wazer and Glonek 1972; Yang et al. 1993) and/or chromatographic methods. The ${ }^{31} \mathrm{P}$ NMR chemical-shift convergence of the larger rings with the middle phosphate signal from chain polyphosphates was interpreted as arising from the propensity of phosphate chains to form helical structures in the larger molecules (Glonek et al. 1972).

Note that during the carbodiimide-mediated condensation of orthophosphoric acid in dilute solution in polar organic media, the condensation reaction proceeds through tetrapolyphosphate to eventually produce essentially pure trimetaphosphate, a counterintuitive finding (Glonek et al. 1971b). Further, in the course of this reaction, no polyphosphate greater than the tetrapolyphosphate could be detected.

Crystallography (example, tetrametaphosphate) reveals that the $\mathrm{PO}_{4}$ tetrahedra in polyand meta-phosphates are nearly regular, the edges being $2.51 \AA$. The phosphorus atoms, however, are not centrally located within the tetrahedra but are shifted away from the oxygen atoms common to two tetrahedra. This corresponds to an excess of $\pi$-character in the bonds to the unshared oxygens (Van Wazer 1958h).

\section{Chain Polyphosphate and Cyclic Metaphosphate Hydrolysis and Rearrangement}

Degradation of chain polyphosphates in water proceeds by two paths: 1. a hydrolysis reaction to form $\mathrm{Pi}$ and shorter chain polyphosphates, and 2. a rearrangement without concomitant hydrolysis to generate primarily the trimetaphosphate but also larger ring 
metaphosphates. During experimental degradation of polyphosphate chains, the main degradation products formed are $\mathrm{Pi}$ and the trimetaphosphate, with a small quantity of di- and tri- chain phosphates and the four-phosphate ring, tetrametaphosphate (Mattenheimer 1956a, b; Kulaev 1979; Thilo and Wieker 1957, 1961) This discovery of Bell (1947) seemed odd at the time, because previously the cyclization of chain-like polyphosphates had not been observed. It was shown that the ring molecules indeed were formed and that the hydrolytic degradation products depended upon the $\mathrm{pH}$ and temperature of the reaction medium (Thilo and Wieker 1957 Fig. 11). For example, at $\mathrm{pH} 8$ and $60{ }^{\circ} \mathrm{C}$, the exclusive products are $\mathrm{Pi}$ and trimetaphosphate in the molar ratio of 1:1. It was concluded that polyphosphate degradation must happen at the ends of the polyphosphate chains, and further, that the formation of $\mathrm{Pi}$ and the trimetaphosphate were connected with one another (Thilo and Wieker 1961). The reaction rates are dependent on chain lengths up to about 10 phosphate units, and the smaller the mean chain length, the more rapid the hydrolysis, i.e., the larger the number of chain ends and, therefore, the number of reactive end groups (Thilo and Wieker 1961), the greater the reaction rate. In mild acid media, $c a$. $\mathrm{pH} \mathrm{5,} \mathrm{there}$ is a propensity to generate increased short-chain fragments as well as larger metaphosphates arising from the rearrangement reaction (Thilo and Wieker 1957). With average chain lengths $>10$, the measured rates appear equivalent (Kulaev 1979; Thilo and Wieker 1957; Thilo 1965).

Later it was shown that neutral salts catalyzed increased random degradation of long chain polyphosphates, which was attributed to participation of complexed metal ions that promoted rearrangement within the length of polyphosphate chains (Thilo and Wieker 1961). This rearrangement reaction was shown by ${ }^{18} \mathrm{O}$ labeling not to involve participation of solvent water (Thilo 1965). Thus, under the experimental conditions of aqueous hydrolysis, there exists a high propensity for the long chain polyphosphates to form cyclic metaphosphates.

Considering the metaphosphates in acid media ( $\mathrm{pH} 3$ ), octametaphosphate degraded to tripolyphosphate, pyrophosphate, and orthophosphate; the higher chain phosphates up to the octapolyphosphate and intermediate sized metaphosphates were not detected, or possibly not resolved by the chromatographic procedures employed (Kura 1981). In weakly acid media in the presence of $\mathrm{Al}^{3+}$ and $\mathrm{Cu}^{2+}$ ions and using liquid chromatography as the analytical method, however, the tri-, tetra-, penta-, and hexametaphosphates were obtained as significant fractions of the hydrolyzate (Kura 1994 Table 1).

Hydrolysis of all condensed phosphates is accelerated by the cations of dissolved mineral salts (Kulaev and Vagabov 1983; Kura et al. 1974; Kura and Ohashi 1976; Kura 1994; Thilo and Wieker 1957; Thilo 1965). In general, the higher the ionic charge and the smaller the ionic radius of the cation, e.g., $\mathrm{Mg}^{2+}$ and $\mathrm{Al}^{3+}$, the more effective the cation is at catalyzing both hydrolysis and rearrangement of the condensed phosphates. Further, the rearrangement reaction to make the cyclic molecules is enhanced relative to hydrolysis (Thilo 1965). This property has been attributed to complex formation between the metal cations and the interior middle groups of the chain and ring condensed phosphates (Thilo 1965).

The very long chain, difficultly soluble, condensed phosphates Kurrol's and Graham's salts $\left(\mathrm{NaPO}_{3}\right.$ glass) can be dissolved slowly by placing them in aqueous solutions containing the dissolved salt of a cation different from $\mathrm{Na}^{+}$. When the viscosities of salt-free solutions of crude potassium Kurrol's salt preparations, which were dissolved by mixing with (Na) Graham's salt, are measured as a function of the $\mathrm{K}_{2} \mathrm{O} / \mathrm{P}_{2} \mathrm{O}_{5}$ mole ratio (Van Wazer 1958i Fig. 10.25), the viscosity passes through a maximum at the Kurrol's salt $\mathrm{K}_{2} \mathrm{O} / \mathrm{P}_{2} \mathrm{O}_{5}$ ratio of 0.9. This effect is attributed to cross-linking in those samples of potassium Kurrol's salts for which the $\mathrm{K}_{2} \mathrm{O} / \mathrm{P}_{2} \mathrm{O}_{5}$ ratio is less than unity, i.e., they contain branch phosphate 
cross-links between the long phosphate chains (see Ultraphosphates). This property is significant because appropriate fortuitous hydrolysis of such cross links would result in the generation of large cyclic metaphosphates.

Condensed phosphates complex metal cations strongly (Van Wazer 1958h). It is incorrect to assume that under all conditions of basic $\mathrm{pH}$ polyphosphates are insoluble in the presence of calcium. They are soluble in a seawater or brackish environment as long as the molar concentration of the phosphates approaches the concentration of the calcium (Gabel 1965; Griffith 1972). As has been noted by Gabel (1977), the aqueous solubility of calcium complexes of the condensed phosphates is one of their most industrially important physicochemical properties.

From dissolution studies on two forms of Maddrell's salts $\left(\mathrm{NaPO}_{3}\right.$-II and III), Van Wazer suggested that because of the difficulty in dissolving both forms of Maddrell's salt, it is possible that these materials represent rings connected by long, straight-chain segments (Van Wazer 1958e)

Enzymatic degradation is similar (see Enzymes). Using a dried brewer's yeast preparation, the $\mathrm{pH}$ optima for the hydrolysis of chain and ring phosphates were determined to lie between 7 and 8 , nearer to 7 for the pyro- and meta-phosphates and nearer to 8 for the longer chain polyphosphates (Mattenheimer 1956c). Enzymatic cleavage of polyphosphate

Table 1 Cited review articles by section headings of this work

\begin{tabular}{|c|c|}
\hline Section Heading & Reference \\
\hline Chemistry & $\begin{array}{l}\text { Fernández-Garcia et al. 2017; Gabel 1977; Harold 1966; Karki } \\
\text { et al. 2017; Kulaev 1979; Kulaev et al. 2004; Reusch 1999; } \\
\text { Serafim et al. 2002; Thilo and Wieker 1957; Van Wazer 1958g; } \\
\text { Van Wazer and Glonek } 1972\end{array}$ \\
\hline Biological Occurrence & $\begin{array}{l}\text { Dedkova and Blatter 2014; Diaz 2011; Docampo et al. 2005; } \\
\text { Chen 1999; Gabel 1977; Gabel and Thomas 1971; Harold } \\
\text { 1966; Kornberg et al. 1999; Kulaev 1979; Kulaev and Vagabov } \\
\text { 1983; Kulaev and Kulakovskaya 2000; Kumble and Kornberg } \\
\text { 1995; Moreno and Docampo 2013; Orell et al. 2012; Rao et al. } \\
\text { 2009; Reusch 1999; Serafim et al. 2002; Seviour et al. 2003; } \\
\text { Spang et al. 2017; Wood and Clark 1988 }\end{array}$ \\
\hline Enzymes & $\begin{array}{l}\text { Ault-Riché et al. 1998; Brown and Kornberg 2004; Dedkova and } \\
\text { Blatter 2014; Gray et al. 2014; Kornberg et al. 1999; Kulaev } \\
\text { 1979; Kulaev and Vagabov 1983; Kulaev and Kulakovskaya } \\
\text { 2000; Nesmeyanova 2000; Orell et al. 2012; Rao et al. 2009; } \\
\text { Wood and Clark 1988; Lichko et al. 2003; Shabalin and Kulaev } \\
\text { 1989; Shabalin et al. 1979a; Wurst et al. } 1995\end{array}$ \\
\hline Genomics & Kawakoshi et al. 2012; Kristensen et al. 2004 \\
\hline Eukaryotes & Kristensen et al. 2004 \\
\hline Polyphosphate Function, Hydrotrope & Kristensen et al. 2004; Reusch 1999 \\
\hline Circular DNA, Extrachromosomal RNA & Del Solar et al. 1998 \\
\hline Holiday Junction & Wyatt and West 2014 \\
\hline Biogenesis & $\begin{array}{l}\text { Brown and Kornberg 2004; Fernández-Garcia et al. 2017; Gabel } \\
\text { 1977; Griffith et al. 1977; Keefe and Miller 1995; Kulaev et al. } \\
\text { 2004; Kulaev and Vagabov 1983; Lazcano and Miller 1996; } \\
\text { Locker 1973; Oró 1994; Westheimer } 1987\end{array}$ \\
\hline Archaen, Eoarchaen & $\begin{array}{l}\text { Karki et al. 2017; Lazcano and Miller 1996; Maciá 2005; Spang } \\
\text { et al. 2017; }\end{array}$ \\
\hline
\end{tabular}


chains with a degree of condensation up to 10 were termed oligophosphatases and were contrasted with the polyphosphate depolymerases and metaphosphatases (cyclophosphatases) (Mattenheimer 1956a, b). The determination of large ring metaphosphates among the products of long chain polyphosphate hydrolysis was never pursued because of the lack of analytical methods capable of adequately distinguishing among the larger polyand meta-phosphate reaction products.

\section{Ultraphosphates}

Ultraphosphoric acids (Thilo and Wieker 1957; Van Wazer 1958g) can be prepared in respectable yield through condensing-agent-mediated condensations in organic polar solvents, such as N,N,N',N'-tetramethylurea (Glonek 1969; Glonek et al. 1971a, b, 1974a, 1975a, 1976b, c, 1977); by hydrating $\mathrm{P}_{4} \mathrm{O}_{10}$ in such organic solvents also containing tri-n-butylamine (Costello et al. 1974); or by melting metal oxides or salts with $\mathrm{P}_{4} \mathrm{O}_{10}$ in ratios of $\mathrm{M} / \mathrm{P}<1$ at elevated temperatures $\left(>400{ }^{\circ} \mathrm{C}\right)$ in a dry atmosphere (Van Wazer 1958d Fig 11.9).

When condensations in polar organic solvents have proceeded to completion, the phosphates remain in solution where their structures may be determined through ${ }^{31} \mathrm{P}$ NMR (Costello et al. 1974; Glonek et al. 1971a, b, 1974a, 1975a, b, 1976b, c, 1977; Serafim et al. 2002). Examination of these reaction mixtures in flame-sealed NMR tubes using dicyclohexylcarbodiimide as the condensing agent reveals a product consisting of mixtures of fused and conjoined ultraphosphate rings exhibiting complicated second-order ${ }^{31} \mathrm{P}$ spectra (Glonek et al. 1974a, 1975a, b, 1976b, c; Van Wazer 1958j Table 11.5). The sealed reactions are stable indefinitely; their ultraphosphate $\left(\mathrm{H}_{2} \mathrm{O} / \mathrm{P}_{2} \mathrm{O}_{5}\right)$ compositions at end-point, which can proceed only as far as an $\mathrm{H}_{2} \mathrm{O} / \mathrm{P}_{2} \mathrm{O}_{5}$ of 0.5 (metaphosphate $=1.0 ; \mathrm{P}_{4} \mathrm{O}_{10}=0.0$ ), depends on the amount of carbodiimide condensing agent added at the onset of the reaction and the amount of residual hydrogen, e.g., water, present at the beginning of the reaction (Glonek et al. 1974a, 1975a, b, 1976b, c). Hydrolysis or alcoholysis results in the formation of cyclic metaphosphates of a variety of sizes that may be purified through triethylammonium bicarbonate diethylaminoethyl (DEAE)-cellulose column chromatography (Glonek et al. 1974a), and characterized by thin-layer and column chromatography (Glonek et al. 1975b, 1976b, 1977; Tanzer et al. 1968), and ${ }^{31}$ P NMR (Glonek et al. 1974b). The essentially pure monoadenosine 5'-trimetaphosphate, a cyclic form of ATP (Weimann and Khorana 1962), along with a small amount of trimetaphosphate byproduct, may be prepared by such a method (Glonek et al. 1974b, 1975b).

\section{Nitrogen Derivatives of the Condensed Phosphates}

The nitrogen-containing ring and chain analogs of the condensed phosphates, the phosphimic acids (also phosphonitrilic acids or imidometaphosphoric acids) are known (Van Wazer 1958k), and the sodium trimetaphosphimic acid, the analog of trimetaphosphoric acid where the imido-nitrogen atoms link the constituent phosphorus atoms, is readily prepared by saponification of an ether solution of the trimer of phosphonitrilic chloride, $\left(\mathrm{PNCl}_{2}\right)_{3}$, through contact with an aqueous sodium acetate solution (Van Wazer 1958k, p. 838).

Primordial P-N compounds also are known. These may be obtained from meteoritic phosphides, which release phosphorus on geologically-short time scales. Moreover, amino acids, once phosphorylated and having formed P-N derivatives, have been shown to form peptides (Karki et al. 2017). The ease with which amidophosphates or phosphoramidate 
derivatives phosphorylate a wide variety of substrates suggests that alternative nitrogencontaining forms of phosphate could have played a role in primordial biochemistry (Karki et al. 2017).

Condensed phosphates are capable of polymerizing amino acids under mild abiotic conditions (Sibilska et al. 2017). A typical reaction mixture consisted of $200 \mathrm{mM}$ diglycine solution and sodium trimetaphosphate adjusted to $\mathrm{pH} \sim 9.5$ with $\mathrm{NaOH}$. This mixture was left open to the atmosphere while being maintained at a constant temperature of $70{ }^{\circ} \mathrm{C}$ for specific times ( 24 or $48 \mathrm{~h}$ ). The resulting dry pellet was then re-dissolved in water and analyzed by ion-pair high-performance liquid chromatography. Polymers of the diglycine building unit from the dimer to the octamer were detected (Sibilska et al. 2017 Fig. 2). The best polymerizations occurred at 70 and $80{ }^{\circ} \mathrm{C}$.

\section{Biological Occurrence}

The phosphate group is central to biological systems. It most widely occurs as phosphate diesters in the genetic materials ribonucleic acid (RNA) and DNA, in biomembrane phospholipids, as phosphoanhydrides in the cellular energy currency ATP, and as phosphomonoesters in numerous metabolic intermediates. The properties of phosphate that enable it to fulfill these many functions often have been remarked upon (Kornberg 1995; Westheimer 1987). These authors have pointed out that phosphate is trivalent and trianionic and therefore able to form a link in a chain and still retain negative charge. They also point out that the phosphoanhydride bond is a high-energy bond, yet the residual negative charge means that it is relatively stable in water. Molecules bearing phosphate groups are not soluble in lipid phases and can be retained in cells. The phosphate group also is able to act as a $\mathrm{pH}$ buffer and a chelator of metal ions, where it appears to have a special affinity for $\mathrm{Mg}^{+2}$ and $\mathrm{Ca}^{+2}$ (Keefe and Miller 1995). Further, it is now known to be the hydrophilic functional group of the hydrotropes identified as fostering protein solubility in the concentrated milieu of cells (Glonek and Greiner 2020; Patel et al. 2017). Because of this wealth of properties, it tasks the imagination to conceive of a life form that does not extensively utilize phosphates.

Polyphosphates have been known chemically as constituents of living organisms sense 1947 (Wiame 1947) and have been documented in a large number of species: bacteria (Ahn and Kornberg 1990; Ault-Riché et al. 1998; Chen 1999; Clark et al. 1986; Díaz et al. 2005; Glonek et al. 1971c; Harold 1966; Ishige and Noguchi 2001; Kornberg et al. 1956, 1999; Kowalczyk et al. 1996; Kristensen et al. 2004; Kulaev 1979; Kulaev and Vagabov 1983; Kulaev and Kulakovskaya 2000; Lawrence et al. 1998; Mateo et al. 2006; Mori et al. 2004; Nesmeyanova 2000; Nomura et al. 2004; Rao et al. 1985, 2009; Romans et al. 1994; Serafim et al. 2002; Seviour et al. 2003; Shi et al. 2004; Szymona and Widomski 1974; Tanaka et al. 2003; Wood and Clark 1988; Zhang et al. 2002, 2005, 2015), archaea (Andreeva et al. 2000; Kornberg et al. 1999; Orell et al. 2012 Table 2; Remonsellez et al. 2006; Rudnick et al. 1990; Scherer and Bochem 1983; Toso et al. 2011), and eukaryots (Bental et al. 1991; Brown and Kornberg 2004; Chen 1999; Dedkova and Blatter 2014; Diaz et al. 2009; Docampo et al. 2005; Eixler et al. 2005; Eppley 1962; Hamai and Kuwabara 1975; Gabel and Thomas 1971; Harold 1966; Kornberg et al. 1999; Kulaev 1979; Kulaev and Vagabov 1983; Kulaev and Kulakovskaya 2000; Kulakovskaya et al. 2005; Kumble and Kornberg 1995, 1996; Liebermann 1888; Miyata et al. 1986; Moreno and Docampo 2013; Niemeyer 1976; Orchard et al. 2010; Rafter 1959; Rao et al. 2009; 
Ruiz et al. 2001; Shi and Kornberg 2005; Wiame 1947; Wood and Clark 1988; Yang et al. 1993; Zhang et al. 2007, 2015). They are found in marine oxic sediments where they are involved in marine phosphate cycling (Brandes et al. 2007; Diaz et al. 2008; Diaz 2011). (For additional reviews of this topic, see Table 1; a particularly comprehensive work by Kulaev (1979) covers polyphosphate chemistry and biology literature through 1979.)

Over time, evidence has been acquired showing that polyphosphates have numerous and varied biological functions depending on where they are - species, cell, or subcellular compartment - and when they are needed (see Polyphosphate Functions). Among these functions are the following: substitution for ATP in kinase reactions; a reservoir for $\mathrm{Pi}$; a chelator of metals, e.g., $\mathrm{Mn}^{2+}, \mathrm{Mg}^{2+}, \mathrm{Ca}^{2+}, \mathrm{Cu}^{2+}, \mathrm{Fe}^{3+}$, where they also may function as detoxification agents in extremophiles (Orell et al. 2012); a buffer against alkali; the capsule of bacteria; competence for bacterial transformation; mRNA processing; and as a constituent of eukaryotic nuclei (Docampo et al. 2005; Griffith et al. 1977; Harold 1966; Kornberg et al. 1999; Kulaev et al. 2004; Liebermann 1888; Rao et al. 2009). In cells, polyphosphates are found in acidocalcisome organelles. A timeline from 1895 to 1998 featuring major acidocalcisome research developments has been published (Docampo et al. 2005).

\section{Acidocalcisomes}

Acidocalcisomes (Docampo et al. 2005 Fig. 2) are dense acidic organelles (both in terms of weight and as shown by electron microscopy), with a high concentration of phosphorus present as pyrophosphate and polyphosphate complexed with calcium and other elements. The alkaline earths $\mathrm{Mg}^{+2}$ and $\mathrm{Ca}^{+2}$ are always present in substantial quantities in acidocalcisomes, particularly $\mathrm{Ca}^{+2}$, hence the name. Acidocalcisomes also contain high concentrations of free amino acids $(1,250 \pm 297 \mathrm{nmol}$ per $\mathrm{mg}$ protein were found in epimastigotes of Trypanosoma cruzi). The basic amino acids arginine and lysine account for almost $90 \%$ of the amino acid pool of T. cruzi acidocalcisomes (Docampo et al. 2005), whereas whole-cell extracts contain high concentrations of neutral and acidic amino acids (Rohloff et al. 2003). Given the relatively low abundance of Lys and Arg in whole-cell extracts ( $<5 \%$ each of total amino acid pool) and the high concentration in the acidocalcisome fraction, it may be surmised that the major fraction of the cellular basic amino acids are concentrated within the acidocalcisomes (Rohloff et al. 2003). These, therefore, must be in association with the condensed phosphates, where an important function would be to serve as counter cations to the condensed phosphate's negative charge.

Acidocalcisomes are related to organelles that were previously known as volutin or metachromatic granules and polyphosphate vacuoles, and which were thought to contain nucleic acids and/or to function as storage granules. Metachromatic granules have been known as constituents of living organisms sense 1895 (Docampo et al. 2005 Timeline). Acidocalcisomes evolved before the prokaryotic and eukaryotic lineages diverged, and have been conserved during evolution in both bacteria and humans (Docampo et al. 2005).

By ${ }^{31} \mathrm{P}$ NMR analysis (both high-resolution and broadline), acidocalcisomes contain only polyphosphate, pyrophosphate and orthophosphate. The concentration of phosphorus in acidocalcisomes has been calculated to be 3-8 M, with most of this in the form of polyphosphate (Docampo et al. 2005; Serafim et al. 2002). Because of the resolution limitations of the chromatographic and spectroscopic analytical methods employed, "polyphosphates" in this context should be regarded as highly condensed phosphates of 


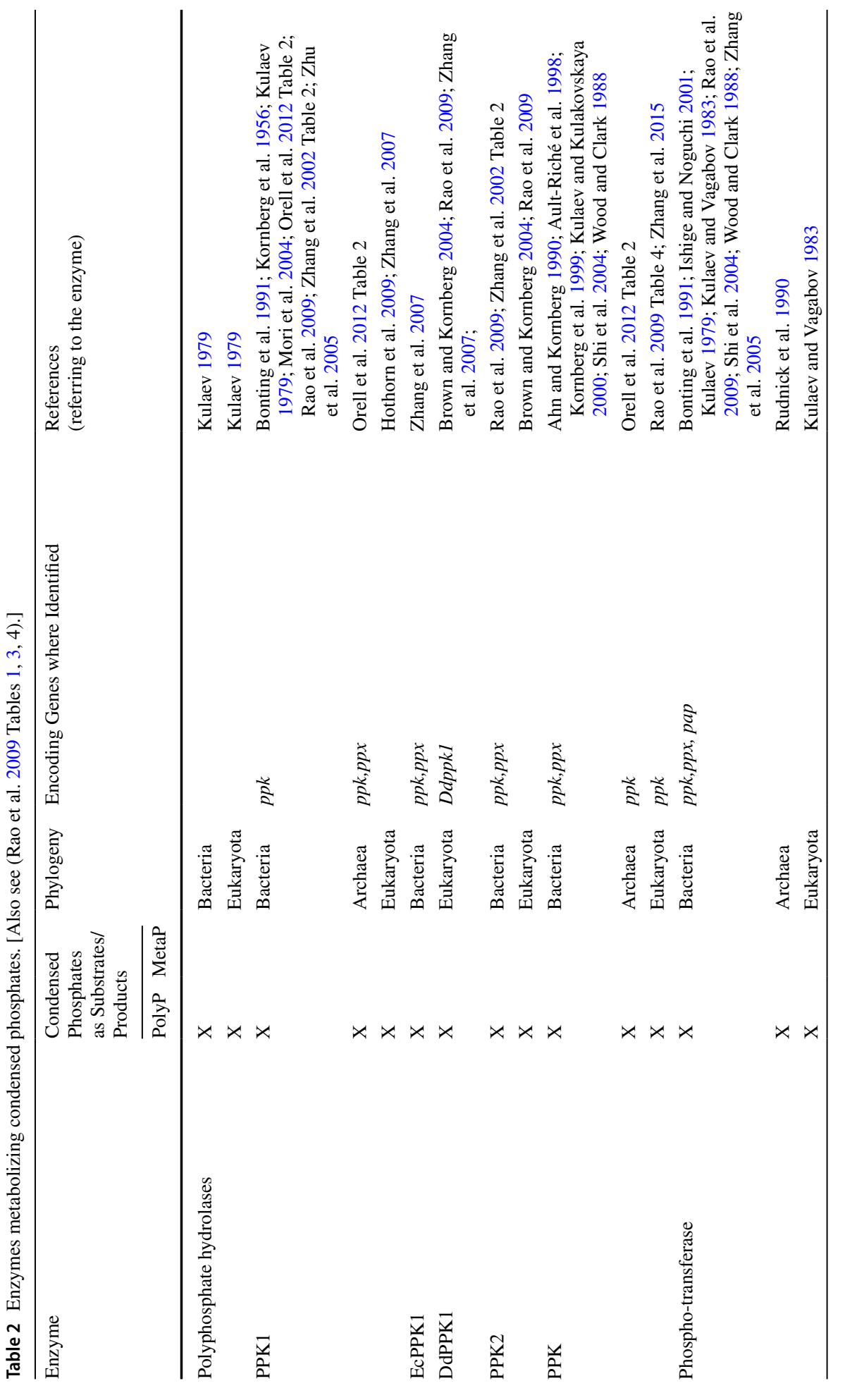




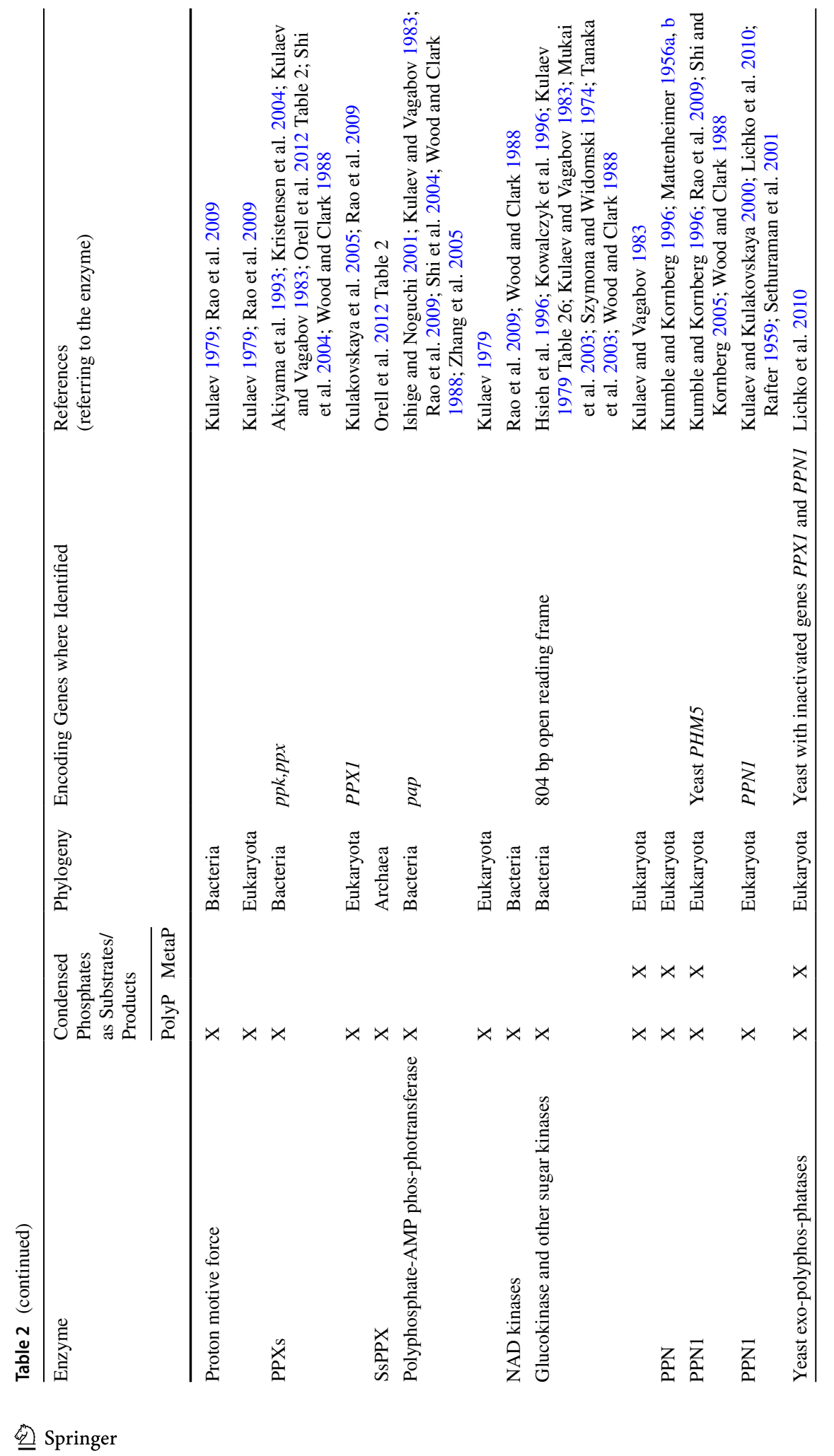




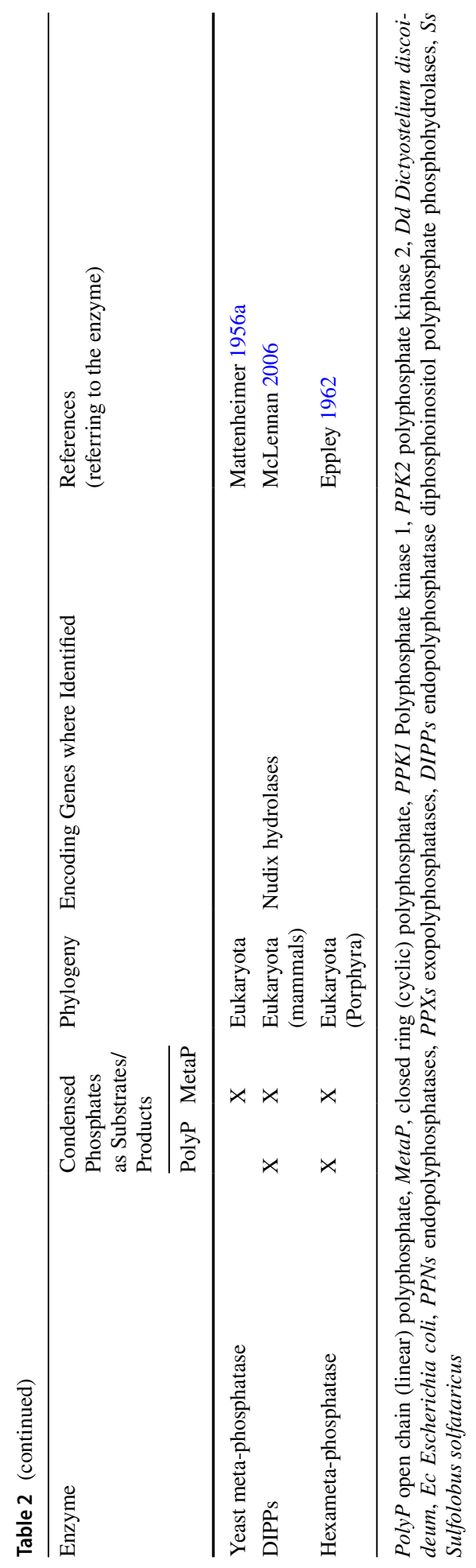



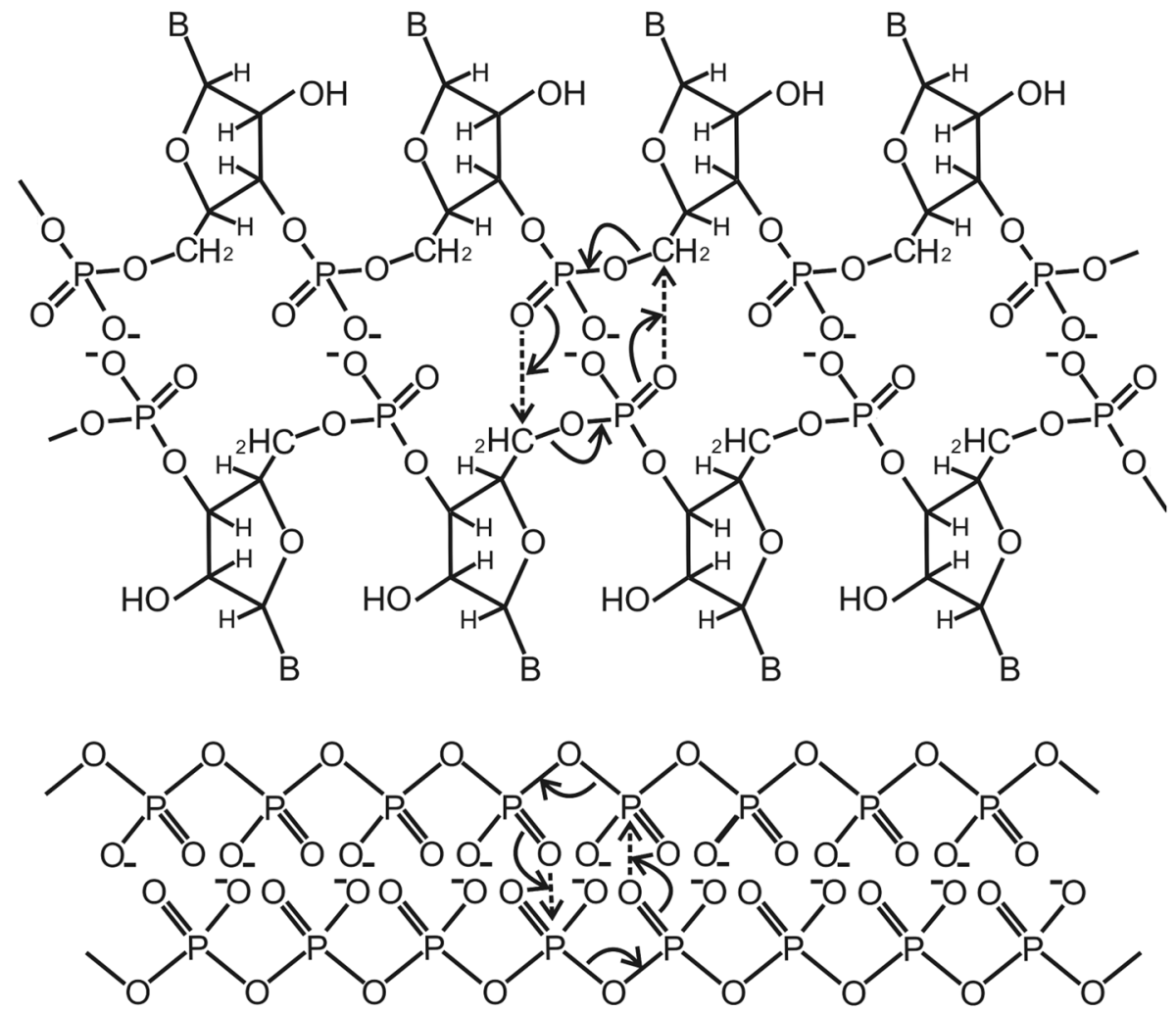

Fig. 2 The reactive center of a Holiday junction with RNA (top) and the analogous structure formed with condensed phosphate chains (bottom). The swapping of chains proceeds through a Holliday junction intermediate (top) or through an analogous condensed phosphate intermediate (bottom). (Two participating chains are shown in each half of the figure.) In both instances, the chemical $\mathrm{P}-\mathrm{O}$ bonds of either one of the oxygens of the $(\mathrm{O}-\mathrm{P}-\mathrm{O})$ moiety in one chain migrate to the adjoining chain, displacing the chain-linking oxygen in the adjoining chain, thus, rearranging the connectivity of the chains. Such a reaction probably is facilitated through the participation of the phosphorus d-orbitals in the intermediate which lower the energies of activation, in analogy to the phosphate reorganization reactions of Van Wazer (19581). An enzyme promotes juxtaposition of the reacting groups, and simple molecular vibrations are sufficient to promote the reorganization. At completion of the reaction, the number and type of functional groups remain the same as before the reaction; only the connectivity has been changed

the metaphosphate composition. It was noted that storage of cellular phosphate in the form of polyphosphate reduces the osmotic effect of large pools of this crucial nutrient anion (Docampo et al. 2005). Considering the plant Kingdom, the electron-dense vacuoles of the unicellular alga Chlamydomonas reinhardtii are very similar to acidocalcisomes with regard to their chemical composition and the presence of proton pumps (Ruiz et al. 2001).

Two intracellular pools of soluble polyphosphate were identified by in vivo ${ }^{31} \mathrm{P} N \mathrm{NM}$ spectroscopy in the cyanobacterium Synechocystis sp. strain PCC 6308. Spheroplast formation showed that polyphosphate was not present in the periplasm of the cells; it resides in two compartments in the cytosole. The majority of the polyphosphate is of a size too large to pass out of the plasma membrane and the premeabilized outer membrane (Lawrence et al. 1998). 


\section{Polyphosphate Extracts}

The amounts and chain lengths of polyphosphates extracted from Escherichia coli depend on cell growth conditions (Nesmeyanova 2000) and on the $\mathrm{pH}$ of the extraction medium (Rao et al. 1985). The acid-soluble fraction consisted mainly of a linear polymer of about $20 \pm 5$ phosphate units, whereas by gel filtration the alkali-extractable polyphosphate fraction contained at least four molecular species of higher chain length. In vivo ${ }^{31} \mathrm{P}$ nuclear magnetic resonance spectra of $E$. coli cells as a function of growth conditions were consistent with the in vitro extract results, and the two fractions (acid-soluble and alkali-soluble $\mathrm{P}_{\mathrm{i}}$ ) appeared to have independent metabolism, since the alkali-soluble fraction was synthesized when more than $85 \%$ of the acid-soluble fraction was already hydrolyzed (Rao et al. 1985).

In the presence of an inhibitor of acid phosphatase $(\mathrm{NaF})$, the level and size of the polyphosphates produced are higher. Alkali-soluble fractions exhibit polyphosphates with chain lengths ranging from 23 to over 5,000 phosphate residues (Clark et al. 1986; Gabel and Thomas 1971; Kumble and Kornberg 1995; Kulaev 1979; Lawrence et al. 1998; Nesmeyanova 2000).

Polyphosphate accounts for nearly $40 \%$ of the total phosphate content of Saccharomyces cerevisiae (Wurst et al. 1995); in mammalian brain, the length was reported to be 800 phosphate residues (Kornberg et al. 1999; Kumble and Kornberg 1995).

As was stated by Kulaev (1979), and which is still true today: "In order to obtain an accurate estimate of the degree of polymerization of polyphosphates in higher organisms, it will be necessary either to develop a sufficiently accurate micro-method for the determination of mean chain lengths, or to carry out large-scale preparative work..." (Kulaev 1979) Condensed phosphates must be obtained from the environment through alkaline extraction with ethylenediaminetetraacetic acid (EDTA) at $\mathrm{pH} \sim 8$ to keep the polymer from being cut into pieces by acid or enzymatic processes.

\section{Metaphosphate Extracts}

The occurrence of linear condensed polyphosphates and cyclic condensed metaphosphates was studied by means of pulse-labeling with ${ }^{32} \mathrm{P}$-orthophosphate $(3-5 \mathrm{~h})$ in a number of brown algae Phaeophyceae species: Pylaiella litoralis, Ilea fascia, Ectocarpus siliculosus and also in Rhodophyceae species: Ceramium deslongchampsii, C. rubrum, Rhodomela confervoides, Porphyridium purpureum and P. aerugineum. Two-dimensional cellulose thin layer chromatography revealed that in all species studied ${ }^{32} \mathrm{P}$-radioactivity was generally present in all oligopolyphosphates containing 2 to 7 phosphate residues, in cyclic metaphosphates (tri-, tetra-, penta- and hexametaphosphates) and in high-molecular-weight condensed phosphates which remained at the starting point. Among the low-molecularweight condensed inorganic phosphates, the trimetaphosphate had a significantly higher specific activity than the other oligophosphates. After previous incubation of these algae in a P-free culture medium, ${ }^{32} \mathrm{P}$ phosphorus was rapidly incorporated into high-molecularweight condensed phosphates that could not be resolved through chromatograph methods (Niemeyer 1976).

In the alga Dunaliella salina, it was estimated from the signal-to-noise ratio (of ${ }^{31} \mathrm{P}$ NMR spectra including line-widths) that a linear polyphosphate molecule that will produce an NMR signal with the observed height due to the middle phosphate residues, but none due to the terminal groups, has to be at least forty residues long (Bental et al. 1991; Serafim et al. 2002). The observations suggested that the initially formed polyphosphates may be cyclic metaphosphates (Bental et al. 1991). 
Of the large array of biological sources in which condensed phosphates have been identified, the cyclic metaphosphates have been identified in the following references (Bental et al. 1991; Chen 1999; Eppley 1962; Harold 1966; Niemeyer 1976; Rafter 1959).

\section{Enzymes}

Polyphosphate-metabolizing enzymes (Table 2) are constituents of some of the most primitive organisms examined. It, therefore, is likely that they also were a constituent of the Last Universal Common Ancestor (LUCA), and if they were, it is reasonable to suggest that their precursors were active constituents of the earliest progenotes, progenotes being replicating, evolving entities originating from the chemicals present on the early Earth. Regarding these enzymes, Shi et al. (2004) have noted that the corresponding genes of several poly-P-metabolizing enzymes that have been purified and characterized have been cloned and deleted (Ahn and Kornberg 1990; Akiyama et al. 1993; Kornberg et al. 1999; Kumble and Kornberg 1996; Sethuraman et al. 2001; Wood and Clark 1988).

\section{Polyphosphate Synthesizing Enzymes}

The polyphosphate kinase, PPK1, was the first condensed phosphate enzyme to be identified and purified (yeast) (Kornberg et al. 1956), and it is the principal source of polyphosphate in bacteria (Ahn and Kornberg 1990; Kornberg et al. 1956; Kulaev 1979; Kulaev and Vagabov 1983; Rao et al. 2009 Table 1; Wood and Clark 1988; Zhang et al. $2005,2015)$. In the reverse reaction, which ordinarily employs long-chain polyphosphates as the substrate ( $\mathrm{n}>800$ units), PPK1 acts as a nucleoside diphosphate kinase to re-generate ATP from ADP. The nucleoside diphosphate kinase activity from other organisms, however, may use different, usually shorter, polyphosphates as the highenergy substrates for this activity and different receptor nucleoside diphosphates. For example, Azotobacter vinelandii utilizes only very high molecular weight polyphosphate (Graham's salt) and only ADP, whereas the corresponding enzymes from other organisms may utilize a variety of shorter chain phosphates, but not the cyclic metaphosphates, as well as other nucleoside diphosphates, such as guanosine diphosphate (GDP) (Kulaev 1979). PPK1 is the most widely conserved of the kinases. From crystallography, the enzyme from $E$. coli contains four structural domains, with the active site located in a highly conserved structural tunnel that contains a unique ATP-binding pocket (Bonting et al. 1991; Hothorn et al. 2009 from S. cerevisiae; Mori et al. 2004 from Mycobacterium tuberculosis; Orell et al. 2012).

Most bacterial species also contain a second distinct enzyme (PPK2), which is similar to PPK1 but with a propensity to generate guanosine triphosphate (GTP) from GDP (Kulaev et al. 2004 from Microlunatus phosphovorus; Rao et al. 2009; Zhang et al. 2002 from Pseudomonas aeruginosa). Isolated from an acidocalcisome sub-cellular particle using strong salt, a PPK2 from Dictyostelium discoideum is an actin-related protein complex that is polymerized into an actin-like filament concurrent with its reversible synthesis of a polyphosphate chain from ATP (Brown and Kornberg 2004).

There are other sources of polyphosphate kinase activities that do not involve the PPK-1 and -2 kinases. For example, the main source of polyphosphates from $D$. discoideum, DdPPK1, contains the conserved residues for ATP binding and autophosphorylation as in Escherichia coli, EcPPK1, but has an N-terminal extension of 370 
amino acids lacking homology with any known protein (Zhang et al. 2007). Neurospora crassa possesses a phosphotransferase that utilizes 1,3-diphosphoglycerate to extend polyphosphate chains (Kulaev 1979; Kulaev and Vagabov 1983; Wood and Clark 1988), as does the archaeon Methanosarcina frisia (Rudnick et al. 1990). There are instances where polyphosphates have been found in organisms but where there are no apparent homologous kinase enzymes present for synthesis. This has raised the possibility that polyphosphates can be created directly by a proton motive force, bypassing ATP as an intermediate (Kulaev 1979; Rao et al. 2009). Most of these other kinase activities have not been characterized beyond their activities or partial purification. A cladogram based upon PPK sequences has been presented by Kornberg et al. (Kornberg et al. 1999 Fig. 4), as has been a table of PPK homologs among eukaryota (Rao et al. 2009).

In general, bacteria (Rao et al. 2009) and archaea (Orell et al. 2012) subjected to nutritional, osmotic or heavy metal stresses, or to nitrogen exhaustion, accumulate polyphosphate, under certain conditions to prodigious quantities, which is the basis for activated sludge phosphate removal from municipal wastewater (Kulaev and Kulakovskaya 2000). For example, in Acinetobacter strain 210A, these polymers may accumulate to $30 \%$ of dry biomass (Bonting et al. 1991). By contrast, carbon exhaustion, changes in $\mathrm{pH}$, temperature upshifts, and oxidative stress had no effect on polyphosphate levels (Ault-Riché et al. 1998; Kornberg et al. 1999). The complete genome of the sludge bacterium M. phosphovorus, an organism that may accumulate $>10 \%$ of cell mass as polyphosphate phosphorus, has been sequenced; its chromosome is a single closed circle (Kawakoshi et al. 2012).

\section{Polyphosphate Utilizing Enzymes (Table 2)}

Endopolyphosphatases, PPNs, cleave long polyphosphate chains distributively to generate shorter chains and trimetaphosphate in partial digests (Mattenheimer 1956a, b) and Pi and trimetaphosphate in limit digests (Kumble and Kornberg 1996). Exopolyphosphatases, PPXs (Akiyama et al. 1993; Wood and Clark 1988), hydrolyze and processively release the terminal phosphate from linear polyphosphates containing four or more phosphate residues (Kulaev and Vagabov 1983; Orell et al. 2012); these are classified into two groups based on their primary structure. Crystallography demonstrates that the PPX dimers from $S$. solfataricus and E. coli each contain an S-shaped canyon extending along the dimer interface and lined with positively charged residues; this cleft feature is postulated to be the putative polyphosphate binding site (Orell et al. 2012). Crystallography of the related exopolyphosphatase/guanosine pentaphosphate phosphohydrolases from the hyperthermophilic bacterium Aquifex aeolicus similarly demonstrates an interdomain cleft (Kristensen et al. 2004). In yeast it should be noted that a high activity of both exopolyphosphatases does not prevent the accumulation of polyphosphate (Kulakovskaya et al. 2005).

There also exists a polyphosphate-AMP phosphotransferase (PAP) that generates ADP from AMP (Ishige and Noguchi 2001; Kulaev 1979; Kulaev and Vagabov 1983; Rao et al. 2009; Shi et al. 2004; Wood and Clark 1988; Zhang et al. 2005). The phosphotransferase activity is used in conjunction with the polyphosphate kinases to re-generate ATP (Ishige and Noguchi 2001; Kulaev 1979; Rao et al. 2009). The phosphotransferase from Acinetobacter strain 210A, which catalyzes the phosphorylation of AMP to ADP at the expense of long-chain polyphosphate, was purified more than 1,500-fold (Kulaev and Vagabov 1983; Shi et al. 2004; Wood and Clark 1988). The mechanism of polyphosphate degradation was processive, and the polyphosphate chain was degraded 
completely to generate ADP. No activity was obtained with ortho- or pyro-phosphate, or tri-, and tetra-polyphosphates; however, the enzyme was inhibited by pyrophosphate, and tri-, and tetra-polyphosphates (Bonting et al. 1991).

The nicotinamide adenine dinucleotide (NAD) kinases (Wood and Clark 1988) of $M$. tuberculosis, Micrococcus flavus, and Bacillus subtilis synthesize nicotinamide adenine dinucleotide phosphate (NADP) using either polyphosphate or ATP as the phosphate donor (Rao et al. 2009). A glucokinase from M. tuberculosis uses polyphosphate as a substrate to generate glucose-6-phosphate (Hsieh et al. 1996; Kowalczyk et al. 1996 from Propionibacterium shermanii; Kulaev 1979; Kulaev and Vagabov 1983; Szymona and Widomski 1974; Tanaka et al. 2003 from M. phosphovorus), and there are polyphosphateD-fructose 6-phosphotransferases and similar enzymes (Kulaev 1979). Arthrobacter sp. strain KM exhibits activities of several inorganic polyphosphate- and ATP-dependent kinases, including glucokinase, NAD kinase, mannokinase, and fructokinase. Alignment of these homologous polyphosphate-utilizing enzymes revealed seven conserved regions (Mukai et al. 2003). Further, there was homology with the poly(P)/ATPglucokinase of $M$. tuberculosis (45\%), Corynebacterium glutamicum (45\%), Renibacterium salmoninarum (45\%), and B. subtilis (35\%) (Mukai et al. 2003).

An assay for polyphosphate has been developed that uses the enzyme polyP kinase (PPK1, PPK2) to generate ATP from polyphosphate (Rao et al. 2009), which is subsequently converted to light by the enzymatic luciferin-luciferase reaction (Ault-Riché et al. 1998).

The endopolyphosphatase (Wood and Clark 1988), PPN1, is widely distributed in ani mal cells and is most abundant in yeast, from which it was purified and shown to be a homotetramer of a $35 \mathrm{KDa}$ subunit (Kumble and Kornberg 1996; Shi and Kornberg 2005); the encoding yeast gene is PHM5 (Rao et al. 2009). Subsequently, a partially purified endopolyphosphatase $(\sim 20 \mathrm{KDa})$, from a yeast with inactivated genes $P P X 1$ and PPN1 encoding exopolyphosphatases, was obtained that cleaved polyphosphates without the release of orthophosphate, even after $24 \mathrm{~h}$. This enzyme degrades long-chain polyphosphate, $\mathrm{P}_{208}$, to the $\mathrm{P}_{15}$ chain in $60 \mathrm{~min}$. The enzyme was inhibited by heparin and insensitive to fluoride. $\mathrm{Mg}^{2+}, \mathrm{Mn}^{2+}$, and $\mathrm{Co}^{2+}(1.5 \mathrm{mM})$ stimulated the activity; $\mathrm{Ca}^{2+}$ was ineffective (Lichko et al. 2010). Mattenheimer (1956a) isolated an activity (metaphosphatase) from yeast that specifically opened tri- and tetra-metaphosphates to their corresponding 3- and 4-unit polyphosphate chains (Mattenheimer 1956a, b). Also in yeast, metabolism of the inositol phosphates and pyrophosphates are linked through the family of endopolyphosphatase diphosphoinositol polyphosphate phosphohydrolases (DIPPs). In mammals, four putative DIPPs have been characterized that possess a 23 -amino acid catalytic domain denominated the MutT motif or Nudix box (McLennan 2006).

In yeast, specifically, an endopolyphosphatase has been purified that is free of the kinases, transferases and endopolyphosphatases mentioned above. The enzyme requires $\mathrm{Pi}$ to open the trimetaphosphate ring, generating tetrapolyphosphate as a product. Water does not participate in the reaction, and inorganic orthophosphate is essential for ring opening (Rafter 1959). This cleavage of a cyclic metaphosphate by a material other than water is unique. (The author did not report testing this endopolyphosphatase activity on higher cyclic metaphosphates.) Note how similar this reaction is to the laboratory condensation of inorganic phosphate to trimetaphosphate in polar solvents, which also proceeds through the formation of tetrapolyphosphate to generate trimetaphosphate as the final product (Glonek et al. 1971b).

In the marine environment, there is a large amount of metabolic activity associated with polyphosphates. Liberation of inorganic phosphate from hexametaphosphate by Porphyra 
blades appears to involve hydrolysis to the corresponding open-chain polyphosphate by a metaphosphatase and subsequent attack by polyphosphatase (Eppley 1962).

In summary, the exopolyphosphatases (PPX1, PPX2) (Kulaev 1979; Orell et al. 2012; Rao et al. 2009) and related enzymes hydrolyze polyphosphates from their chain ends to form $\mathrm{Pi}$; the endopolyphosphatases cleave polyphosphates and metaphosphates internally to generate shorter chain phosphates (Rao et al. 2009; Kulaev 1979) and cyclic metaphosphates (Mattenheimer 1956a, b), particularly the trimetaphosphate (Rao et al. 2009).

\section{Poly- $\beta$-Hydroxybutyrate Complexes with Polyphosphates, Voltage-Activated Calcium Channels}

The poly- $\beta$-hydroxybutyrates (Reusch 2000 Fig. 2) are the simplest primitive macromolecules that associate with polyphosphates to form ion channels (Reusch 2000 Figs. 1, 2). Medium-chain-length poly- $\beta$-hydroxybutyrate has been found associated with inorganic polyphosphate in non-covalent complexes that are postulated to play a role in transbilayer transport of cations (Dedkova and Blatter 2014; Das et al. 1997; Rafter 1959; Reusch and Sadoff 1988; Reusch et al. 1995) and DNA (Castuma et al. 1995; Huang and Reusch 1995; Reusch 2000). They have been isolated from plasma membranes, mitochondria, and microsomes of animal cells (Reusch 1992 Table 1). Further, mechanisms of polyphosphate involvement in cell wall biosynthesis have been described (Kawakoshi et al. 2012; Reusch et al. 1997; Shabalin and Kulaev 1989; Shabalin et al. 1979a, b).

This macromolecular complex also has been shown to form voltage-activated calcium channels in the plasma membranes of $E$. coli and other bacteria. The ability of these complexes to form voltage-activated calcium channels was shown in a synthetic planar lipid bilayer and in membrane vesicles from $E$. coli (Reusch 1992, 1999). In bacterial membranes, poly- $\beta$-hydroxybutyrate also has been found complexed to single stranded DNAs (Reusch 1992). The material is most often obtained as a high molecular mass polymer within the cytoplasm of certain bacteria and archaea (Reusch 1992 structure Fig. 2). A model of the E. coli complex, based on its molar composition and including $\mathrm{Ca}^{2+}$ ions, has been computed. The complex is a cylinder with a lipophilic shell composed of alternating linear arrays of methyl and methylene groups that contains a helical polyphosphate core of from 60-70 phosphate residues. The coordinated calcium ions (Huang and Reusch 1995) link the polyphosphate core to the helical polyhydroxybutyrate shell (Reusch and Sadoff 1988; Reusch et al. 1995; Reusch 2000 Figs. 4 and 12). The molar ratio of the shell to its contained polyphosphate is 2:1 (Castuma et al. 1995).

The complex with polyphosphates is essentially that of a polyanionic salt solvated by an amphiphilic polymer. The stoichiometry for the polyphosphate/poly- $\beta$-hydroxybutyrate channel complex is as follows: The polymer lengths for poly- $\beta$-hydroxybutyrate range from 130-150 residues ( $c a$. 12,000 Da), while the polyphosphate chains range from 55-70 residues ( $c a .1995 \mathrm{Da})$. The molecular weight of the channel complex is estimated as $17,000 \pm 4000 \mathrm{Da}$. By these molecular weight estimates, the ratio of poly- $\beta$-hydroxybutyrate monomer to the polyphosphate chain is 2:1 (Reusch 1999), as mentioned above.

It is postulated that poly- $\beta$-hydroxybutyrate forms a helical sleeve, with a lipophilic exterior of methyl and methylene groups and a hydrophilic lining of ester carbonyl oxygens that afford solvation for $\mathrm{Ca}^{2+}$ ions (Reusch 1992 Fig. 6). It was postulated further that the cellular function of poly- $\beta$-hydroxybutyrate-polyanionic complexes is to transport polyanionic salts, e.g., single stranded DNA, through membranes (Reusch 1992). 
The $\mathrm{Ca}^{2+}$-ATPase purified from human erythrocytes contains the above two homopolymers, amphiphilic poly(3-hydroxybutyrate) and inorganic polyphosphate, which form voltage-activated calcium channels. It was shown that this plasma membrane $\mathrm{Ca}^{2+} \mathrm{ATPase}$ may function as a polyphosphate kinase, i.e., it exhibits ATP-polyphosphate transferase and polyphosphate-ADP transferase activities (Reusch et al. 1997).

These findings suggest that poly- $\beta$-hydroxybutyrate-polyphosphate complexes have a physiological role that is fundamental to life (Reusch 1999). "Simpler, more efficient, easier to assemble, calcium-selective cannels than polyphosphate/poly-R-3 hydroxybutyrate are difficult to imagine. Every atom in both polymers contributes to the task of ion selection and transport." (Reusch 1999) In the opinion of Reusch (1999), polyphosphate/ polyhydroxybutyrate channels may be the most ancient form of ionic channels, which were conserved in the evolution from prokaryotes to eukaryotes.

\section{Polyphosphate as a Chaperone}

Investigations on the folded-protein protective property of polyphosphate demonstrated that polyphosphate acts to stabilize cytoplasmic proteins in vivo, and effectively protects bacteria against stress conditions that cause protein unfolding and aggregation (Gray et al. 2014). As was shown by Kornberg and others, (Crooke et al. 1994; Gray et al. 2014; Kornberg et al. 1999; Rao et al. 2009) polyphosphate-deficient organisms exhibit increased sensitivity towards a variety of environmental stress conditions, including amino acid starvation, osmotic stress, and heat shock.

Further, wild-type bacteria actively re-direct a substantial proportion of their cellular ATP pool to form polyphosphate upon exposure to severe oxidative stress, which raises the intriguing possibility that the loss of ATP, long assumed to be a symptom of oxidative stress, may actually be part of an adaptive oxidative stress response aimed at rapidly accumulating large quantities of polyphosphate. It was concluded that polyphosphate plays a direct role in maintaining protein homeostasis in vivo (Gray et al. 2014).

In a manner similar to protein chaperones, polyphosphate does not appear to have any significant substrate specificity and stabilizes a wide variety of different proteins. While the possibility cannot be excluded that polyphosphate also has additional indirect or regulatory effects on proteostasis in vivo, it appears that polyphosphate is able directly to stabilize a wide variety of proteins against multiple forms of unfolding stresses (Gray et al. 2014). For example, polyphosphate protects citrate synthase from aggregation and completely abolishes chemically denatured luciferase aggregation. The presence of polyphosphates reduces the need for other chaperones to combat oxidative protein unfolding (Gray et al. 2014), implying that polyphosphate might function as a physiologically relevant chaperone.

Polyphosphate chains are effective at low micromolar concentrations, and their ability to protect proteins against protein aggregation increases with the length of their chains (Gray et al. 2014). It is, therefore, possible that polyphosphate functions as a chemical scaffold, keeping proteins soluble by stabilizing secondary motifs. Alternatively or in combination, ionic interactions between the negatively charged polyphosphate and positive side chains in proteins might contribute to the stabilization effect, as might the high concentrations of cations associated with polyphosphates (Kulaev et al. 2004).

Synthesis of polyphosphate does not require transcription or translation. This makes polyphosphate an excellent chaperone during stress conditions, such as $\mathrm{HOCl}$ stress, which not only causes protein unfolding but also inhibits new protein translation and inactivates 
ATP-dependent chaperones. Because of the primordial nature of polyphosphates, it was suggested that these molecules may have served as one of Nature's first chaperones (Gray et al. 2014).

\section{Genomics}

The earliest evidence for life (Bacteria and Archaea) extends to about 3.85 Ga. No generally accepted distinction has yet been made between the emergence of these in relation to the age of the Earth and the periods before the Snowball Earth glaciations of the Cryogenian (Brocks et al. 2017). Eukaryota appeared much later following the Sturtian (the later Snowball Earth) glaciation. Before then, there is little firm evidence for Eukaryota, only for Bacteria and Archaea (Brocks et al. 2017). As of this writing, LUCA appears to reside firmly with Bacteria.

It can be believed with some certainty that evolution from the progenote to Eukarya proceeded through Bacteria, then through Archaea to Eukarya. Spang et al. (2017) present a phylogenetic tree showing the major archaeal groups for which genomic data currently are available and the relationship of Archaea to Eukarya. Archaea include at least four major supergroups, the Euryarchaeota and the TAC, Asgard, and DPANN archaea, all of which comprise several different, potentially phylum-rank clades (Spang et al. 2017). Their genomes reveal the potential to perform central steps in carbon metabolism, lipid degradation, and, importantly, oxidative phosphorylation. These organisms are not restricted to extreme habitats and, in fact, are everywhere. Reconstructions of ancestral gene sets have indicated that the last common ancestor of the Archaea (LACA) may have been an anaerobic chemolithoautotroph that used the reductive acetyl-CoA or Wood-Ljungdahl pathway as their main mechanism for energy conservation and for synthesis of acetyl-CoA and cell carbon from $\mathrm{CO}_{2}$ (Ragsdale and Pierce 2008).

It has been established that most features of eukaryotic DNA compaction into nucleosomes are conserved in archaeal histone-based chromatin. Archael histones form a continuous superhelical ramp, and the histone-mediated DNA geometry within these assemblies is exactly the same as in eukaryots. Archaeal histone-DNA complexes, however, are not limited to one discrete structure. Unlike the defined eukaryotic nucleosome, archaeal histones can form complexes with variable numbers of histone dimers assembled along the DNA, and the resulting extended structure plays a role in gene regulation (Mattiroli et al. 2017). What has been shown is the superhelical chromatin ramp, a large diameter helix, containing (determined by counting the full DNA turns) 24 full turns of the helical DNA per turn of the nucleosome helix, or 120 DNA base pairs ( 5 base pairs per DNA turn).

\section{Polyphosphates Complexing Nucleic Acids}

RNA forms complexes with polyphosphate. Divalent metal ions, $\mathrm{Mg}^{+2}$ and $\mathrm{Ca}^{+2}$, are required, and EDTA will dissociate the complex. Studies have concerned the nature of the bonds that exist between high molecular weight ribonucleic acids (RNA) and polyphosphates in the RNA-polyphosphate complexes extracted from yeast. It was concluded that $\mathrm{Mg}^{2+}$ and $\mathrm{Ca}^{2+}$ form bridges between the two polymeric chains (Stahl and Ebel 1963). 


\section{Genes Encoding Polyphosphate-Metabolizing Enzymes}

The endopolyphosphatase PPN1 of $S$. cerevisiae, a homodimer of 35-kDa subunits (about $352-\mathrm{aa})$, is of vacuolar origin and requires the protease activation of a 75-kDa (674-aa) precursor polypeptide. The PPN1 gene ( $P P N 1)$ has been cloned, sequenced, overexpressed, and deleted. That PPN1 encodes PPN1 was verified by a 25 -fold increase in PPN1 when overexpressed under a $G A L$ promoter and also by several peptide sequences that match exactly with sequences in a yeast genome ORF (open reading frame), the mutation of which abolishes PPN1 activity. Null mutants in PPN1 accumulate long-chain polyphosphate and are defective in growth in minimal media (Sethuraman et al. 2001).

Other work (Lichko et al. 2008) indicates that there are enzymes besides PPX1 \& PPN1 that can degrade polyPs. In the (S. cerevisiae) double ( $P P X 1$ and PPN1) mutant, polyphosphate degradation is followed by accumulation of short-chain polyphosphates (Lichko et al. 2008). The enzyme encoded by PPN1 preferentially hydrolyzes long-chain poly Ps, while the enzyme encoded by the PPXI gene more effectively hydrolyzes short-chain poly Ps, including poly $\mathrm{P}_{3}$ (Andreeva et al. 2006; Lichko et al. 2003). Thus, the occurrence of an endopolyphosphatase not encoded by the PPN1 gene is indicated through the dynamics of polyphosphate hydrolysis (Lichko et al. 2008) or the presence of large metaphosphate rings, which are just long-chain condensed phosphates, but without the enzymatically reactive end groups.

Under special culture conditions, when stationary phase cells are passing on to new budding with glucose addition and Pi excess, the exopolyphosphatase not encoded by PPX1 is expressed (Andreeva et al. 2001; Kulakovskaya et al. 2005), i.e., the activity resulting in the production of $\mathrm{Pi}$ is stimulated by excess $\mathrm{Pi}$ in the growth medium. It was concluded from the amino acid sequence (Andreeva et al. 2006 Fig. 1) that this exopolyphosphatase was a product of the PPN1 gene, which possesses domains characteristic of potential cytoplasmic and vacuolar proteins (Andreeva et al. 2006). It should be noted that the purified PPN1 gene product contains a peptide of 605 amino acid residues that has not been observed in the amino acid sequence of endopolyphosphatase also encoded by this gene (Shi and Kornberg 2005).

When polyphosphate chain ends are masked and unavailable, the exopolyphosphatase, PPX1, fails as a reagent for characterizing chain polyphosphates. PPN1, therefore, should serve as a valuable reagent for degradation and analysis of masked polyphosphates (Sethuraman et al. 2001). One such mask may arise because there are no open end-groups on the polyphosphates that fail to react; these phosphates most probably are the cyclic metaphosphates which do not react with the exopolyphosphatases.

The requirement of extra phosphate to phosphorylate high concentrations of internalized sugars triggers PstS expression, a high-affinity phosphate-binding protein, in order for inorganic phosphate molecules to be captured from the environment. PstS accumulation was dramatically increased in a Streptomyces lividans polyphosphate kinase null mutant $(\Delta p p k)$ and was impaired in a deletion mutant lacking phoP, the transcriptional regulator gene of the two-component phoR-phoP system that controls the Pho regulon; however, a mutation in $p p k$, a polyphosphate kinase-encoding gene, elicited overexpression of the PstS protein (Díaz et al. 2005), thus, linking polyphosphate synthesis with the necessity of accumulating inorganic phosphate.

In media deficient in both $\mathrm{P}_{\mathrm{i}}$ and amino acids, E. coli transiently accumulates up to $20 \mathrm{mM}$ in inorganic polyphosphate (polyP) phosphate residues $\left(\mathrm{P}_{\mathrm{i}}\right)$. This transient accumulation is preceded by the appearance of nucleotides ppGpp and pppGpp generated in response to 
nutritional stresses. Mutants which lack PhoB, the response regulator of the phosphate regulon, do not accumulate polyP even though they develop wild-type levels of (p)ppGpp when subjected to amino acid starvation. It was concluded that the accumulation of polyP required a functional phoB gene and elevated levels of (p)ppGpp. (Shabalin et al. 1979a).

And biosynthesis of polyphosphate and alkaline phosphatase in E. coli is under control of integrated regulatory genes (Nesmeyanova et al. 1975).

Other genes also appear to be involved in polyphosphate metabolism. Bacteria subjected to nutritional or osmotic stress or to nitrogen exhaustion have large and dynamic accumulations of polyphosphate, which depend on the E. coli genes $\ln \mathrm{D}(\mathrm{NtrC}), \operatorname{rpoS}, \mathrm{relA}$, and phoB (Ault-Riché et al. 1998). In Bacillus cereus, genes have been found that are highly homologous to E. coli PPK1 and PPX and to P. aeruginosa PAP (Shi et al. 2004).

In a selected set of 19 extremophilic microorganisms, all members of the Crenarchaeota possess $p p x$ genes but lack a $p p k$-like gene. On the other hand, in Euryarchaeota, 9 members possessed only the $p p k$ gene and one had only $p p x$ (Orell et al. 2012 Table 2). Of 8 extremophilic bacteria, most possess both $p p k$ and $p p x$ genes; however, the genome of the hyperthermophilic bacterium A. aeolicus contains only a gene coding for a single protein of the PPX/GPPA family (Rudnick et al. 1990 annotated as a PPX in Table 2). It might be assumed that all microorganisms having only a $p p x$ gene would not synthesize polyphosphate, e.g., no reports detecting polyphosphate in A. aeolicus are available; however, the crenarchaeons S. solfataricus and Metallosphaera sedula, each containing only a ppx-like gene, are able to synthesize polyphosphate (Remonsellez et al. 2006).

Other activities of polyphosphate in cells include the following: Hypoosmotic shock of $N$. crassa produces growth-dependent changes including: 1, a rapid hydrolysis of polyphosphate with a concomitant increase in the concentration of the cytoplasmic phosphate, 2 , an increase in cytoplasmic $\mathrm{pH}$, and 3, an increase in vacuolar $\mathrm{pH}$. Thus, $95 \%$ and $60 \%$ of polyphosphate in the early-log phase and mid-log phase cells, respectively, disappeared in response to hypoosmotic shock, but little or no hydrolysis of polyphosphate occurred in stationary cells (Yang et al. 1993). It was concluded that the polyphosphate was used to adjust osmolarity (Yang et al. 1993 Table 2).

When a DNA-binding protease, Lon, a highly conserved enzyme present in Archaea and Eubacteria as well as in the mitochondria of eukaryotes, binds to polyphosphate, it stimulates the degradation of free ribosomal proteins, thus, providing amino acids to cells experiencing nutritional downshift (Nomura et al. 2004). Polyphosphate can compete with DNA for binding to Lon, and equimolar amounts of polyphosphate nearly completely inhibit DNA-Lon complex formation, suggesting that Lon binds to polyphosphate with a higher affinity than it binds to DNA. The collective results obtained using E. coli, showed that polyphosphate may control the cellular activity of Lon, not only as a protease but also as a DNA-binding protein (Nomura et al. 2004).

\section{Eukaryotes}

Condensed phosphates, both poly- and meta-phosphates, are found in eukaryotes whenever one looks for them (see Chemistry, Biological Occurrence, Table 1). Apparently their metabolic machinery has been carried forward at least from LUCA and probably before. Today, much of what we have learned about the condensed biological phosphates comes from the examination of eukaryotes, particularly yeasts, often with the idea that such studies will point the way to the earliest beginnings of life (Griffith et al. 1977; Kornberg et al. 1999; Kulaev et al. 2004). 
It is well established that there is a mixed archaeal-bacterial legacy in eukaryotic genomes. It is now clear that the last eukaryotic common ancestor (LECA) was a rather complex organism already possessing major idiosyncratic features associated with extant eukaryotes. It is also recognized that endosymbiosis did play a crucial role in eukaryogenesis and that the evolution of the alphaproteobacterial endosymbiont at the origin of mitochondria contributed the basics of energy metabolism and largely shaped the eukaryotic genome, leading to innovations (López-Garcia and Moreira 2015). The most fundamental open query relates to the nature of the host that acquired the mitochondrial ancestor and the eukaryogenic process itself. The recent discovery of an archaeal lineage, the Lokiarchaeota, sharing more and seemingly more closely related genes with eukaryotes, represents a significant advance towards the understanding of eukaryotic origins (López-Garcia and Moreira 2015).

Conservative estimates suggest that the eukaryotic ancestor had a genome with at least 4.000-5,000 genes. This implies that LECA was complex, fully comparable to many modern eukaryotes, and that the toolkit for eukaryotic cell components was established very early (López-Garcia and Moreira 2015). Condensed phosphates are present across all life, in Archaea (Andreeva et al. 2000; Orell et al. 2012), Bacteria (Griffith and Buxton 1965; Harold 1966; Kornberg et al. 1999; Lawrence et al. 1998; Rao et al. 2009), and Eukaryota.

\section{Polyphosphate Functions}

The list of polyphosphate functions, presented by Kornberg et al. (1999), Kulaev and Kulakovskaya (2000) and Kristensen et al. (2004), today may be expanded as follows. Polyphosphates:

- May substitute for ATP, an energy source in many biochemical reactions, and may readily exchange high-energy phosphate bonds with this and other nucleotides.

- Are an intracellular reservoir for $\mathrm{Pi}$, cationic amino acids (arginine and lysine), and polyvalent metal cations $\left(\mathrm{Mg}^{2+}, \mathrm{Ca}^{2+}, \mathrm{Fe}^{3+}\right)$.

- Provide an intracellular buffer against alkali by supplying acid protons derived from chain end-terminal hydrolysis.

- Avidly chelate metal ions, in particular $\mathrm{Na}^{+}, \mathrm{K}^{+}, \mathrm{Mg}^{2+}$, and $\mathrm{Ca}^{2+}$.

- Form strong (charge) associations with the positive side-chains of proteins, where they may function in a manner analogous to a chaperone (Gray et al. 2014). In this capacity, they keep proteins from aggregating in a manner analogous to that of a hydrotrope, e.g., ATP (Patel et al. 2017).

- Associate with the basic amino acids arginine and lysine and are thought to store these associated amino acids in acidocalcisome organelles (Docampo et al. 2005).

- Are used to regulate buoyancy in cyanobacteria (Romans et al. 1994).

- In conjunction with $\beta$-polyhydroxybutyrate and $\mathrm{Ca}^{2+}$, provide channels enabling translocation of DNA through lipid membranes.

- Regulate cellular stress (nitrogen limitation, phosphate limitation, amino acid limitation, osmotic stress (Yang et al. 1993) and enhance cellular survival.

- Regulate development (fruiting bodies and spore formation).

- Are components of cell capsules.

- Exhibit a role in apoptosis (Rao et al. 2009). 
"Surely, a molecule likely conserved from a prebiotic time and now found in every cell in nature must be doing something essential." (Kornberg et al. 1999 pp. 121-122).

\section{Circular DNA, Extrachromosomal RNA}

Circular DNA (Del Solar et al. 1998), RNA and other polynucleotide forms are legitimate models for a large primordial cyclic metaphosphate that is herein postulated to serve as a scaffold for the first functional progenote. Both polymers are large, but not excessively so. They are polyanionic, possessing one unit of negative charge for each phosphate residue in the polymer, implying that they cannot pass through a vesicular membrane without assistance from other membrane-permeable molecules. They are both helical in aqueous media. The moiety that repeats along the backbone of the polymer is a unit of phosphate - for the polynucleotides a phosphodiester, for the polyphosphates, a phosphoanhydride, both linking their chains through the $-\mathrm{O}-\mathrm{P}-\mathrm{O}-$ functional group. Polynucleotides possess a suite of different functional groups along their length; polyphosphates, particularly when enhanced by coordinated divalent metal cations, bind a large number of organic residues along their lengths, especially the cationic amino acids lysine and arginine. Examination of the biochemistry of circular polynucleotides, therefore, may provide insights as to how negatively charged polyanions containing $(-\mathrm{O}-\mathrm{P}-\mathrm{O}-$ )-linking functional groups may provide a scaffold for the origins of life.

\section{The Bacterial Chromosome as a Circle}

In his 1963 paper, John Forster (Hugh) Cairns demonstrated by autoradiography that the DNA of the bacterium E. coli is a single circular molecule that is replicated at a moving locus (the replicating fork) at which DNA strands are being synthesized using each branch of the fork (Cairns 1963). At the time, such a possibility was never anticipated. Subsequently, it was found that there were in fact two moving forks, traveling simultaneously in opposite directions around the chromosome. Hugh had this to say about his work: "Rather than being innovative, the work was really an act of tidying (a bit like washing-up, in fact) because it showed that the bacterial chromosome was simply a molecule of DNA - albeit one organized in a rather unexpected way. If my paper has been often quoted, that is probably because it describes something very simple." (Cairns 1963).

Since then, circular DNA has been found to be ubiquitous. For example, trypanosomatids contain a kinetoplast housing $5-20 \%$ of the total cellular DNA. Kinetoplast DNA is a large network of several thousand similar copies of minicircles and a few dozed copies of maxicircles. The maxicircle DNA encodes ribosomal RNAs and a few mitochondrial proteins; the minicircles encode for small guide RNAs that control the specificity of editing (Docampo et al. 2005).

Endogenous DNA circles derived from canonical linear chromosomal loci, known as extrachromosomal circular DNA (eccDNA or circulomes), were first detected in nuclear fractions of plant cells in the 1980s by electron microscopy (wheat and tobacco) (Kinoshita 1985 Fig. 1). Since then, eccDNAs have been detected in human cell lines (Assum et al. 1989; Cohen et al. 2008; Kuttler and Mai 2007; Misra et al. 1989) and cells of various organisms (Gaubatz 1990). Different cell types harbor different repertoires of circular DNAs (Shoura et al. 2017), and eccDNA copy number can be modulated by chromatin remodeling machinery (Peng and Karpen 2007). (Circulomes are not to be confused with circular bacterial chromosomes or circular RNA.) 
Although circular RNA molecules were first described a long time ago, it was not until recently, that it was discovered how widespread their expression is. Circular RNAs typically arise through splicing of a splice donor to an upstream localized splice acceptor, thus forming a closed circle consisting of regular $3^{\prime}-5^{\prime}$ carbon linkages throughout (Werfel et al. 2016). The genome of the bacteriophage $\mathrm{P} 1$ is a $90-\mathrm{Kbp}$ circular molecule.

A majority of mammalian cell types examined for the presence of extrachromosomal DNA contain, in addition to their mitochondrial DNA, a fraction of small polydisperse circular DNAs (Assum et al. 1989; Piwecka et al. 2017).

\section{DNA Loop Extrusion by Condensin}

May the size of a circular DNA be modified? It has been hypothesized that the SMC (structural maintenance of chromosomes) family of protein complexes, including condensin, cohesin, and the Smc5/6 complex, play vital roles in restructuring genomes during the cellular life cycle by extruding DNA into large loops. Recently, the extension of DNA loops by yeast condensin has been directly visualized in real time, providing unambiguous evidence for loop extrusion. A single condensing complex is capable of extruding tens of kilobase pairs of DNA at up to 1500 base pairs per second using the energy of ATP. The DNA loop extrusion is strictly asymmetric, which demonstrates that condensin anchors onto DNA and reels it in from only one side (Ganji et al. 2018).

Using an analogous mechanism, long-chain polyphosphates (with end groups) could be converted into large metaphosphate rings (no end groups). A primordial version of such a complex could provide a method for generating large (kilophosphate size) rings of cyclic metaphosphates from long chain polyphosphates, particularly when combined with an endophosphatase activity to close the loop.

\section{Stabilized Liposomes}

Cells and, presumably, a viable progenote, require a containment vessel, the plasma membrane for cells and viruses within cells, in order to perform non-random biochemistry. Ordered biochemistry is the only process through which evolution can progress, and vesicles (liposomes) provide the vehicle in which such biochemistry may take place and be sustained, because the liposome separates the inside from the outside permitting $\mathrm{pH}$, ionic, and particle gradients to be established.

Liposomes that are quite stable have been created using an artificial cytoskeleton comprised of DNA. The DNA serves as a template upon which a layer of positively charged lipids is laid. The polyanionic DNA stabilizes the liposome (Kurokawa et al. 2017). In the laboratory, negatively charged DNA interacts with positively charged lipids in liposome membranes to form a shell at the interior surface of the liposomes. Such liposomes are sturdier than ones without the cytoskeletons (Kurokawa et al. 2017). For example, they are better able to withstand osmotic shock (Kurokawa et al. 2017). In an analogous manner, a similar complex could be generated containing the polyanionic condensed phosphates (either poly- or meta-phosphates) in lieu of the DNA. 


\section{Holliday Junction}

In this section, the mechanism by which large circular polynucleotide molecules (DNA, RNA) are manipulated by cells is presented to provide insight as to how a primitive organism may have manipulated a primitive circular metaphosphate-containing chromosome. No such mechanism has been identified anywhere, and the existence of large, $c a$. 1000-orgreater-residue circular metaphosphate molecules has not been demonstrated, only alluded to because of the appearance of chromatographic and spectroscopic data. Consider, however, that both metaphosphates and DNA are polyanionic molecules; exhibit a secondary helical structure; vigorously bind $\mathrm{Mg}^{2+}$ and $\mathrm{Ca}^{2+}$ cations; and bind proteins. Moreover, DNA and polyphosphates both complex with poly- $\beta$-hydroxy butyrates, the purpose of which is to translocate DNA (or other polynucleotides) across biomembranes. Further, condensed phosphates can form chemical ring systems involving branch points that, in a manner analogous to a Holiday junction formed from DNA, permit the intermolecular exchange of molecular chain segments without the requirement for additional energy. The scrambling reactions of the condensed phosphoric acids, whereby molecules equilibrate into a series of related chain molecules governed by an R-value $\left[\mathrm{R}=\left(\mathrm{P}_{2} \mathrm{O}_{5}\right) /\left(\mathrm{H}_{2} \mathrm{O}\right)\right]$, are well-documented (Van Wazer 19581), and phosphates can contain branch groups (Glonek et al. 1970, 1975a; Thilo 1965; Van Wazer 1958j) that permit one molecular ring or chain to be linked to, and exchanged with or fuse to, another (Glonek 1969; Glonek et al. 1974a).

DNA forms circular polynucleotide regulating factors as does RNA (Piwecka et al. 2017). A Holliday junction (Holliday 1964; Wyatt and West 2014) linking two such circular polynucleotide molecules also contains branching points that permit segments of polynucleotide chains to be exchanged (or released) without the requirement for additional energy, and both molecular types perform these scrambling reactions without creating additional end-groups, i.e., the molecular chains remain circular throughout.

The X-ray crystal structures of two DNA Holliday junctions bound by Cre recombinase have been determined. The Holliday junction is a four-way branched structure that occurs as an intermediate in the genetic recombination pathways (Fig. 2) (Gopaul et al. 1998 Figs. 1-3). A Holliday junction is formed when a single strand from each of two duplex DNA segments involved in recombination is exchanged in a region of sequence homology to yield a branched cruciform structure that has four duplex arms (Gopaul et al. 1998). Two DNA strands are exchanged in a two process reaction that probably follows in sequence.

For all replicated circular chromosomes, the two closed and topologically-linked circular daughter molecules must be decatenated following replication (Scott 1968; Sternberg 1979; Sternberg et al. 1981). A large number of proteins are involved (Jayaram et al. 2002, 2004; Ma et al. 2009; Rice 2002; Sternberg et al. 1981; Van Duyne 2002), key among which is the Cre recombinase. The electrostatic features of DNA strand cleavage and strand joining steps catalyzed by these proteins have been determined (Ma et al. 2009; Wyatt and West 2014). The enzymatic reaction progresses in two distinct stages - an initial round of strand cleavage followed by DNA strand exchange to form a stable recombinase-bound Holliday junction (Ghosh and Van Duyne 2002; Gopaul et al. 1998; Ma et al. 2009; Shoura and Levene 2014). This junction is resolved by a second set of cleavage and strandexchange steps, yielding recombinant products (Shoura and Levene 2014). The use of Cre recombinase to carry out conditional mutagenesis of transgenes and insert DNA cassettes into eukaryotic chromosomes is widespread. The simplicity of this system, requiring only a single recombinase enzyme and short recombination sequences for robust activity in a variety of contexts, has been an important factor in both cases (Van Duyne 2014). 
Decatenation is not needed when two polyphosphate chains are reorganized to make cyclic metaphosphates or when smaller metaphosphates are fused to make larger metaphosphates; the condensed phosphate chains are not replicating, that would come later within the context of a biological process. Although branch groups are formed - or previously exist in a crystalline mineral structure analogous to Kurrol's salt - the overall process re-generates the middle groups in adjacent chains, and no large net energy flux is encountered.

\section{Biogenesis}

\section{Primordial Molecules}

Sutherland (2016) proposed a scenario for generating three essential classes of life-molecules based upon HCN and a closely related system of HCN chemistries assembled in a single geological setting. Nucleic acid precursors, e.g., pentamerisation of $\mathrm{HCN}$ to form adenine (Roy et al. 2007), were created starting with just the elements hydrogen, carbon, nitrogen, and sulfur, and ultraviolet light. The same conditions also created the starting materials for a large number of amino acids. Phosphorus, as inorganic orthophosphate, was found to catalyze selected components of this HCN system, generating known biomolecules and their precursors. The choice of orthophosphate as a catalyst was made on the basis of system chemistry considerations. As it developed, "Inclusion of phosphate in the reaction once again turned out to be the key" (Sutherland 2016).

Phosphorus, being an element, must be supplied from the mineral component of the environment and cannot be synthesized chemically. In most ancient rocks, phosphorus exists as phosphate, $\mathrm{PO}_{4} \mathrm{M}$, with $\mathrm{M}$ being any convenient charge-balancing cation(s), or an ester group(s), or an anhydride linkage(s). Significantly, meteoritic phosphides in interstellar analog ices exposed to ionizing radiation at temperatures as low as $5 \mathrm{~K}$ produce key phosphorus oxyacids, including the condensed phosphate pyrophosphoric acid (Turner et al. 2018).

Organic compounds identified as nitriles have been detected in material surrounding a young star. The finding suggests a reservoir of ice and volatile species that can seed the surfaces of young rocky planets or moons (Blake and Bergin 2015; Öberg et al. 2015). [Such a phenomenon has now been confirmed with an image of a newborn planet caught with the European Southern Observatory's Very Large Telescope (Müller et al. 2018).] These interstellar organic molecules and their higher molecular weight reaction products are incorporated into interstellar dust that aggregates eventually forming meteors. There are at least thirteen amino acids locked in meteorites (Cobb et al. 2015), solidly confirmed by several laboratories, the best example being the $20 \mathrm{lb}$ rock retrieved from the moon and now kept in a glove box.

\section{Terrestrial Synthesis Reactions}

Considering the terrestrial synthesis of early genetic molecules, the Murchison and Lonewolf Nunataks 94,102 meteorites were found to contain a diverse suite of nucleobases, which included three unusual and terrestrially rare nucleobase analogs: purine, 2,6-diaminopurine, and 6,8-diaminopurine. These nucleobase analogs could not be detected above parts-per-billion detection limits in any of the procedural blanks employed. The results 
demonstrated that the purines detected in meteorites are consistent with products of ammonium cyanide chemistry, which provides a plausible mechanism for their synthesis in the asteroid parent bodies and strongly supports their extraterrestrial origin. The discovery of these nucleobase analogs in meteorites expands the molecular inventory available for constructing the first genetic molecules (Callahan et al. 2011). These molecules released into the terrestrial environment, when allowed to react with endogenous terrestrial trimetaphosphate (Yamagata et al. 1995), could be the mechanism by which the first polynucleotides were generated. In other work employing a simulated hydrothermal environment containing trimetaphosphate and borate salts, ribose was phosphorylated to ribose-5-phosphate (Prieur 2009).

Trimetaphosphate, which is readily derived from $\mathrm{P}_{4} \mathrm{O}_{10}$, is capable of condensing glycylglycine to oligoglycine in aqueous solutions containing $\mathrm{Mg}^{2+}$ (Yamagata and Inomata 1997). Magnesium ion also was found to have a catalytic effect on the phosphorylation of adenosine by trimetaphosphate in an aqueous solution under mild conditions at $\mathrm{pH} 7.0$ and $41^{\circ} \mathrm{C}$ (Yamagata et al. 1995). The synthesis of polypeptides and the phosphorylation of nucleotides would certainly rank among the essential primordial activities required for a progenote. Moreover, the role of $\mathrm{Mg}^{2+}$ as a catalytic cation for such reactions is evident and appears to be required.

\section{Early Microorganism Biochemical Activities}

Polyphosphate hexokinase activity has been detected only in phylogenetically ancient organisms that are closely related to each other (Kulaev et al. 2004 Table 10.1). In the more ancient representatives of this group of microorganisms, such as the Micrococci, Tetracocci, Mycococci, and the propionic bacteria, polyphosphate hexokinase activity exceeded that of ATP hexokinase, whereas in the phylogenetically younger representatives, ATP hexokinase activity was substantially higher than that of polyphosphate hexokinase. The utilization of polyphosphate as a donor of active phosphate in the phosphorylation of glucose, therefore, is apparently more ancient from the evolutionary point of view than phosphorylation through ATP. Thus, at the earliest stages of the evolution of energy systems in living organisms, the function of linking exoenergetic and endoenergetic processes, which is normally accomplished in contemporary organisms by ATP, would be carried out by the more primitively structured high-energy compounds, inorganic condensed phosphates (Kulaev et al. 2004).

\section{The Roll of Condensed Phosphates in Primitive Biological Reactions}

All the enzymatic machinery needed to synthesize, degrade, and utilize polyphosphates have been identified and isolated (Kulaev and Vagabov 1983). Principally high molecularweight polyphosphates are involved in regulating prokaryote intracellular concentrations of both phosphate anions and cell-absorbed cations, especially in blue-green algae (Kulaev and Vagabov 1983). Polyphosphates may have acted as a scaffold for the organization of the initial replication molecule, and they have been found in close proximity to nucleic acids in prokaryotes (Kulaev and Vagabov 1983).

Regarding early life, Kulaev and Vagabov stated: "It is possible that, on the early Earth, initial high-energy phosphates were represented by high molecular-weight polyphosphates synthesized at high temperatures during volcanic and other processes (Belozersky 1959; Kulaev 1971, 
1979) and by inorganic pyrophosphate produced either from orthophosphates (Beck and Orgel 1965; Calvin 1963; Lipmann 1965; Miller and Parris 1964) or non-biologically from polyphosphates in an aqueous medium (Kulaev and Skryabin 1974; Mansurova et al. 1973). It can be assumed that, when the Earth was surrounded by a reducing atmosphere with a low concentration of oxygen, both high molecular-weight polyphosphates and pyrophosphate were major components of the energy system in primordial organisms." (Kulaev and Vagabov 1983).

\section{Gabel's Hypothesis}

Within the context of a symposium on the origins of life entitled Biogenesis Evolution Homeostasis (Locker 1973), Gabel presented his hypothesis of "structuralization", which involves condensed phosphate as an energy source and as an organizational scaffold (Gabel 1973). In this context "excitability" is defined as the property of an organized group of particles to transfer environmental information along its parts resulting in the maintenance of its structural integrity (Gabel 1965). "Structuralization" was differentiated from "organization" and explicitly defined as organizational schemata imbued with survival potential. More recently, Glonek and Nelson (2017) have proposed that the agent(s) of excitability are natural geophysical oscillations encompassing an enormous range of documented discrete frequency bands, with each specific band addressing biological functions of the same frequency, i.e., resonance. [For related rhythm references see (Aschoff 1981; Daan 1981; Lydic 1989; Moore-Ede et al. 1984)].

It was suggested by Gabel, while discussing the role of circular nucleic acids in evolution, that a more likely primordial condensing agent, namely inorganic circular polyphosphate, could have served as the template and the condensing agent for cyclic polynucleotides, because thermally produced polyphosphate mixtures are known to contain a broad range of cyclic (metaphosphate) rings (Locker 1973).

[That a large (cyclic) metaphosphate may have been the progenitive "structuralization" entity is the raison d'être of this review and hypothesis.]

\section{Eoarchaen Era}

\section{Timeline}

The Eoarchean is the first era of the Archean Eon of the geologic record for which the Earth has a solid crust. It spans 400 million years from the end of the Hadean Eon 4 billion years ago $(4 \mathrm{Ga})$ to the start of the Paleoarchean Era 3.6 Ga. The beginnings of life on Earth have been dated to this era or just before (Table 3). Evidence for cyanobacteria dates to $3.5 \mathrm{Ga}$, just outside this era. At that time, the atmosphere was without oxygen and the pressure values ranged from 10 to 100 bar (around 10 to 100 atmospheres). Volcanoes and volcanic islands were present, and the thin surface crust was continually being reworked through meteoric bombardment.

Metamorphic garnet crystals in rocks from Isua, West Greenland (over 3.7 Ga) contain trails of carbonaceous inclusions that are contiguous with carbon-rich sedimentary beds in the host rock, where carbon is fully graphitized. It is shown that infrared absorption spectra are consistent with carbon bonded to nitrogen and oxygen and also to phosphorus (probably phosphates). The results are consistent with biogenic organic material isolated for billions of years and thermally matured at temperatures of around $500{ }^{\circ} \mathrm{C}$. The preservation of 
these Eoarchean organic residues within sedimentary material corroborates earlier claims for the biogenic origins of carbon in Isua metasediments (Hassenkam et al. 2017).

Zircon crystals from Jack Hills, Australia, are only 150 million years younger than the Earth itself and were formed soon after the Moon-forming impact event (Theia) (Bottke et al. 2015). This implies that, just 100 million years after the moon impact event, Earth cooled sufficiently for surface water and continental-type rocks to exist (Scott and Lindsey 2017; Valley et al. 2015).

The presence of a zoo of organic compounds, including aliphatic and aromatic hydrocarbons, carboxylic acids, amino acids, phosphates (Göpel et al. 1994), ketones, aldehydes, urea, amides, alcohols, amines and nitrogen have been reported in several chondritic meteorites (Cobb et al. 2015; Wood and Chang 1985). The variety of types of compounds found and their molecular structures, exhibiting no preferred chirality, point to origins in nonbiological processes (Maciá 2005).

Fossils of recognizable microscopic organisms have been identified as early as $\sim 3.465 \mathrm{Ga}$. Specimens of five taxa of prokaryotic filamentous kerogenous cellular microfossils show their $\delta^{13} \mathrm{C}$ compositions to vary systematically taxon to taxon from $-31 \%$ o to $-39 \%$ o (petrographic thin sections of Apex chert from northwestern Western Australia). These in situ SIMS analyses present evidence for cellular preservation of such microorganisms and are consistent with the near basal position of the Archaea in rRNA phylogenies (Schopf et al. 2018).

\section{Geological Presence of Phosphates in the Eoarchean Eon}

So where did phosphorus, the element, come from? It came (mostly) from supernova explosions. The sufficiently high temperatures required to make the ${ }^{31} \mathrm{P}$ nucleus can only be obtained in the cores of very massive stars in the range of 15-100 solar masses. In such massive stars, several burning stages follow in succession and each is named after its principal fuel as hydrogen, helium, carbon, neon, oxygen and silicon burning. ${ }^{31} \mathrm{P}$ is formed through oxygen burning, ${ }^{16} \mathrm{O}+{ }^{16} \mathrm{O} \rightarrow{ }^{31} \mathrm{P}+\mathrm{p}$. However, this nuclear reaction is followed by a host of secondary ones that result in the destruction of the ${ }^{31} \mathrm{P}$ synthesized through the oxygen burning process. ${ }^{31} \mathrm{P}$, then, is re-made, subsequently, when these stars undergo a supernova explosion, whereupon the explosion-synthesized ${ }^{31} \mathrm{P}$ is blasted into the cooler interstellar medium where it does not undergo further nuclear synthesis (Maciá 2005).

The chemical nature of prevailing (interstellar) molecules, such as phosphate, $\mathrm{PO}_{4}{ }^{-3}$, its salts and esters, is determined by the physicochemical conditions at those places where interstellar molecules are formed under the constraints imposed by well-known energy and entropy optimization requirements. Within this framework, the raw materials of which living beings are made may progressively be assembled from an array of pieces interspersed in several astrophysical environments (Maciá 2005).

Volcanic activity can produce water-soluble polyphosphates through partial hydrolysis of $\mathrm{P}_{4} \mathrm{O}_{10}$ (Yamagata et al. 1991). The hydrolysis proceeds through tetra- and tri-metaphosphate (Van Wazer 1958m).

Little is known of the speciation of $\mathrm{P}$ in the lithosphere (Holm 2014), especially in melts and non-crystalline materials such as glasses and gels (Da Silva and Holm 2014); the content of $\mathrm{Al}_{2} \mathrm{O}_{3}$, however, appears to be important for phosphate lithophilic chemistry (Mysen and Cody 2001). That condensed phosphates are dissolved in glasses is supported by studies showing that pyrophosphate and trimetaphosphate are stable in 


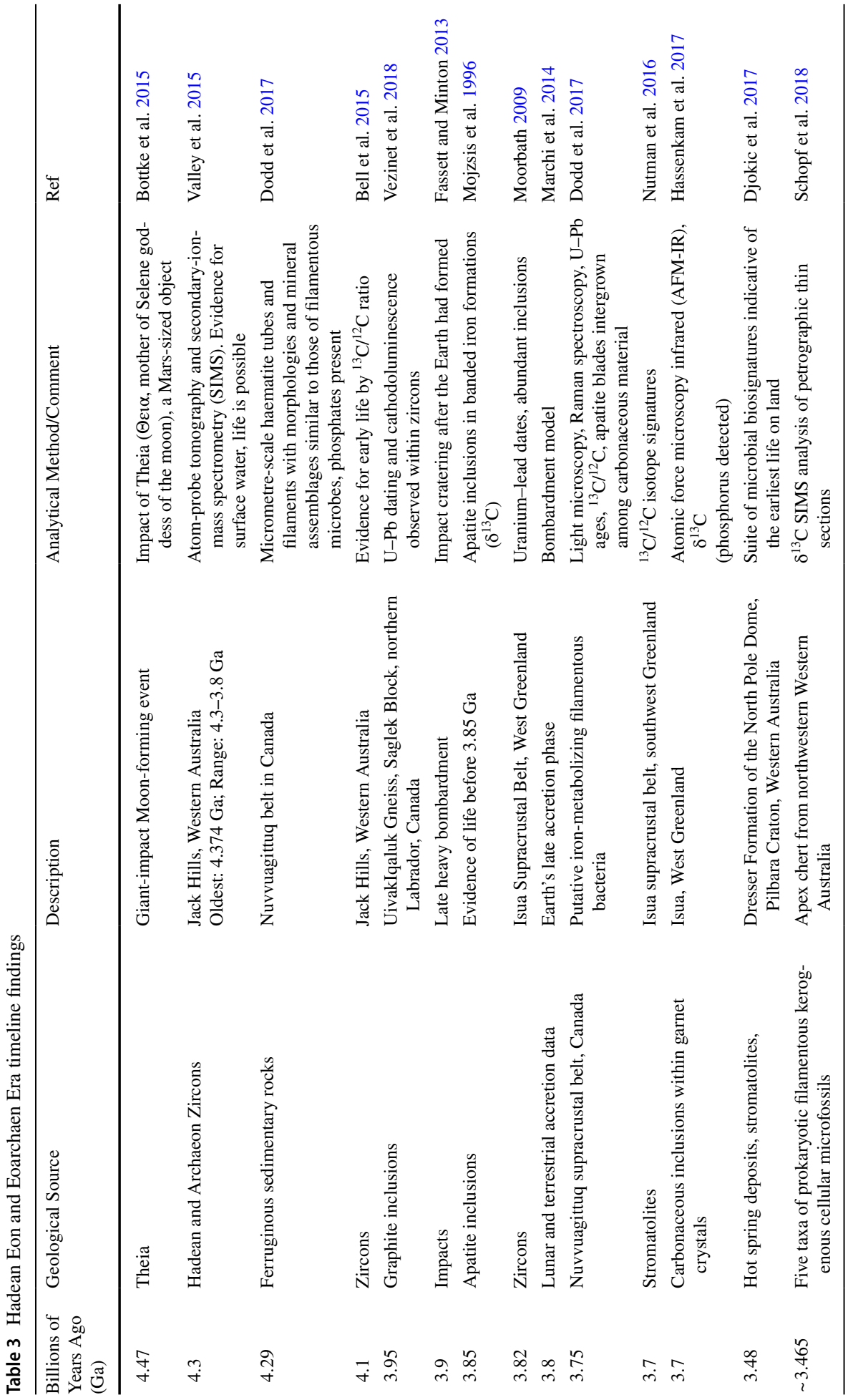


alkaline glasses at low concentrations of $\mathrm{Al}_{2} \mathrm{O}_{3}$. At about $2 \mathrm{~mol} \% \mathrm{Al}_{2} \mathrm{O}_{3}$, pyrophosphate is the dominant form; at $5 \mathrm{~mol} \% \mathrm{Al}_{2} \mathrm{O}_{3}$, it is trimetaphosphate (Cody et al. 2001; Mysen and Cody 2001; Mysen 2011). Phosphorus shows a stronger preference for the basalticmafic-member of coexisting immiscible granitic and basaltic melts (Toplis et al. 1994).

\section{Primordial Soup and Progenote Biochemistry}

In brackish primordial waters, organic molecules of the immediate environment that could be electrostatically attracted or that could coordinate with the exterior metal cations of polyphosphate complexes would form a film or envelope around this macromolecular structure. This "scavenging" effect of poly- and meta-phosphates may be one of their most efficacious properties in prebiotic chemistry in light of the scarcity of organic material in primordial waters (Gabel 1977).

Horowitz (1945) postulated 30 years ago that the first protolife entity (progenote) used for its structural network and energy metabolism those prefabricated molecules that were initially present in the environment. Inorganic polyphosphates and metaphosphates could have been produced by several different prebiotic mechanisms (Griffith et al. 1977), and they have been shown to be widely distributed within the contemporary biosphere (Gabel and Thomas 1969, 1971; Glonek et al. 1971b; Harold 1966) in a polymodal functional capacity (Deierkauf and Booij 1968; Gabel 1972; Kulaev 1971; Sutherland 2016). Two naturally occurring igneous minerals have been reported that have a condensed phosphate composition within their crystalline structures (Belov and Organova 1962; Semenov et al. 1961). These two minerals, metalomonosovite and lomonosovite, were found to occur in pegmatite granites of the Lovozero Massif adjacent to the Khibiny Massif on the Kola peninsula, Russia. Vinogradov and Tugarinov (1961) calculated that the igneous rocks of the Kola Peninsula solidified $3.6 \times 10^{9}$ years ago. Insofar as there is validity to the postulate of Horowitz, these two early Precambrian minerals could be considered as evidence for the role of inorganic poly- and metaphosphates as primordial dehydrationtype condensing agents. (Gabel 1977).

Findings from the ca. 3.48 Ga Dresser Formation of the North Pole Dome, Pilbara Craton, Western Australia extends the known geological record of inhabited terrestrial hot springs on Earth by 3 billion years. Data include hot spring deposits containing geyserite, sinter terracettes and mineralized remnants of hot spring pools/vents, all of which preserve a suite of microbial biosignatures indicative of the earliest life on land. These include stromatolites, newly observed microbial palisade fabric and gas bubbles preserved in inferred mineralized, exopolymeric substance. These observations suggest that early life in the Dresser Formation thrived off the chemical energy in hot springs (Djokic et al. 2017).

The discovery of catalytic RNA gave credibility to prior suggestions that the first living organisms were self-replicating RNA molecules with catalytic activity, a situation called the RNA world (Gesteland and Atkins 1993). It is unlikely, however, that a complicated polymer such as RNA with AUGC and a ribose phosphate backbone is a prebiotic molecule (Lazcano and Miller 1996). In the prebiotic environment, polyphosphate could have played the role later assumed by RNA. Like RNA, polyphosphate is a polyanion that coordinates metal ions and absorbs organic molecules. The amounts of polyphosphates produced geochemically, however, are small. To be effective prebiotic reagents, it could be argued that they would need to be concentrated locally, as at the foot of a volcano, or incorporated within a vesicle. 


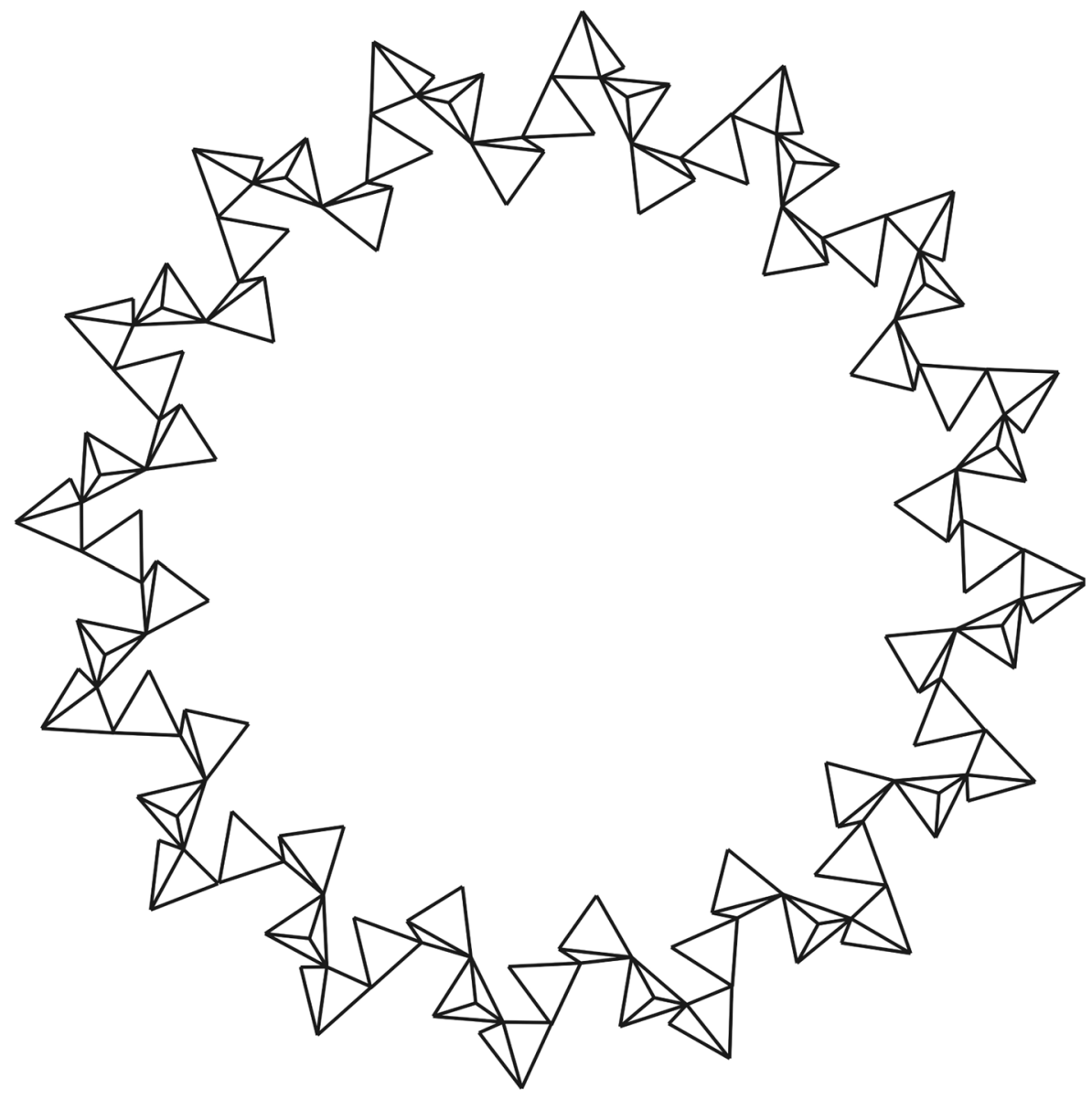

Fig. 3 A postulated 64-mer-metaphosphate exhibiting a helical conformation of the constituent condensed phosphates of the ring structure [after Thilo (1965)]. In this illustration, the constituent $\mathrm{PO}_{3}$ groups of the condensed phosphate ring are represented as tetrahedra, which is the atomic structure of the $\mathrm{PO}_{3}$ groups in crystalline sodium condensed phosphates. Such a phosphate would be capable of binding organic entities and cations

Regarding the synthesis of polyphosphates in progenotes, it was noted that the lack of a kinase activity in some organisms and the lack of a sequence to encode it has raised the possibility that polyphosphate can be made directly by a proton motive force, bypassing ATP as an intermediate (Rao et al. 2009).

It is clear that polyphosphates evolved to be used in diverse ways because these polymers have been present in all cells from early in evolution, and plausibly from the beginning. Polyphosphates of geological origins could have provided a polyanionic, high-energy scaffold of varying polymer lengths to orient or assemble macromolecules (Brown and Kornberg 2004). For example, another PPK in D. discoideum (PPK2) is an actin-related protein complex that is polymerized into an actin-like filament, concurrent with its reversible synthesis of a polyphosphate chain from ATP (Brown and Kornberg 


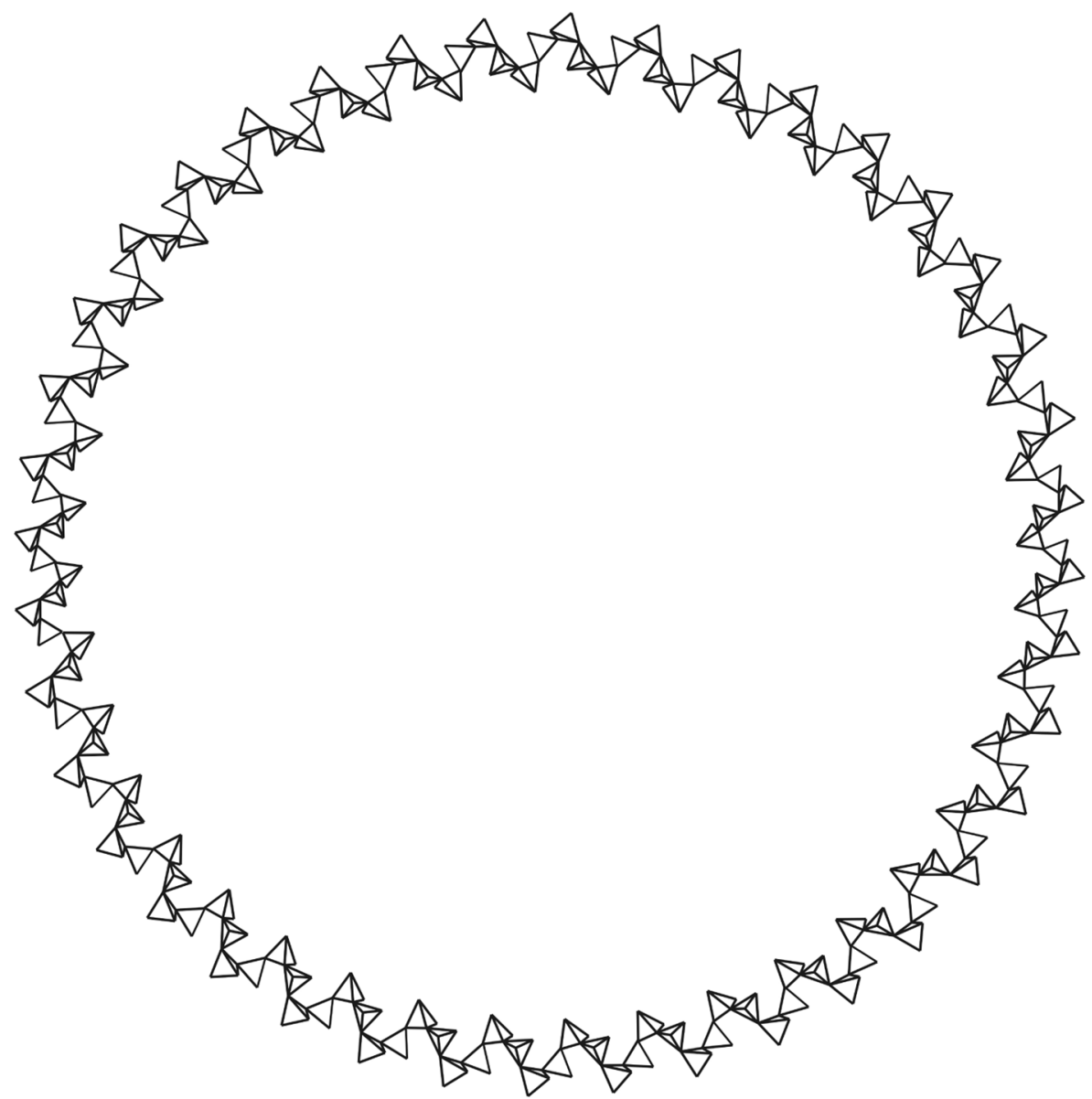

Fig. 4 A postulated 160-Mer-metaphosphate similar to the 64-mer molecule of Fig. 3. At this scale, the illustrated molecule begins to resemble small RNA and DNA cyclic polynucleotides. Note that such large condensed phosphate anions derived through dissolution of Kurrol's salt could contain thousands of constituent phosphate units

2004). It has $60 \%$ homology in sequence to the common muscle actin and similar properties and globular-filamentous transitions (Gómez-Garcia and Kornberg 2004).

In extremophiles, which probably evolved from LUCA, it was suggested that polyphosphate may provide mechanistic alternatives in tuning microbial fitness for the adaptation under stressful environmental situations and may be of crucial relevance among extremophiles. The enzymes involved in polyphosphate metabolism show structure conservation among bacteria and archaea (Orell et al. 2012), and it is reasonable to assume that such activities, or the enzymes themselves, were developed in evolved progenotes.

After having presented a strong case for the existence of condensed phosphates on the primitive Earth, Griffith et al. (1977) presented the following arguments in their thesis regarding a key to life: 
It can further be expected that in primordial waters organic molecules of the immediate environment that could be electrostatically attracted or could coordinate with exterior metal cations would form a film or envelope around this macromolecular polyphosphate complex. Through this 'scavenging' effect, the organic molecules would be brought into contact with the phosphorylating reagent, and the phosphorylation reaction would not be subject to the kinetic control of random collisions in a dilute solution (Gabel 1965).

They stated further that:

Condensed phosphates have a high negative free energy of hydrolysis, and they are unique among oxo-anions in their ability to resist drastic changes in their aqueous environment. Furthermore, the ability of condensed phosphates to form water soluble calcium complexes which can further complex with dissolved organic molecules, and thereby scavenge their immediate environment, makes the condensed phosphates capable of acting as template and phosphorylating agents in a dilute aqueous solution. The problems associated with an understanding of the function of condensed phosphates on the primitive Earth are of collection and storage, rather than synthesis. (Griffith et al. 1977).

Evolution proceeds in the direction of more highly structuralized matrices, but the organic monomers of the prebiotic milieu could not have given rise to functional biopolymers and emerging life forms without a pre-existing template and condensing agent. (Griffith et al. 1977).

\section{Amidophosphates and Phosphoramidates}

The ease with which amidophosphates or phosphoramidate derivatives phosphorylate a wide variety of substrates in water suggests that these alternative forms of phosphate might have played a role in pre-biotic phosphorylation of primordial organics (Karki et al. 2017).

Nitriles have been detected around a young star, a finding that hints at a vast reservoir of ice and volatile species that can seed the surfaces of young rocky planets or moons (Blake and Bergin 2015). Similar findings are reported from the comet-like composition of a protoplanetary disk (Öberg et al. 2015), and a diverse suite of purine nucleobases have been determined as constituents of the Murchison and Lonewolf Nunataks 94,102 meteorites. These results demonstrate that the purines detected in meteorites are consistent with products of ammonium cyanide chemistry, which provides a plausible mechanism for their synthesis in the asteroid parent bodies and strongly supports their extraterrestrial origin (Callahan et al. 2011).

It was shown that glycolaldehyde (Gull 2014) was phosphorylated by amidotriphosphate, in the presence of divalent metals in water at room temperature and near neutral $\mathrm{pH}$, to form glycolaldehyde phosphate (Pasek 2008) in quantitative yields. Glycolaldehyde, $\mathrm{HOCH}_{2}-\mathrm{CHO}$, is the smallest possible molecule that contains both an aldehyde group and a hydroxyl group. It is highly reactive and occurs both in the biosphere and in the interstellar medium (Karki et al. 2017). Primordial P-N compounds may be obtained from meteoritic phosphides, which release phosphorus on geologically short time scales. Moreover, amino acids, once phosphorylated and having formed P-N derivitives, have been shown to form peptides (Karki et al. 2017).

In a pervasively reducing primordial ocean, the Fe-P trap (Hou et al. 2018) dominates Earth's surface $\mathrm{P}$ cycle, greatly reducing overall nutrient $\mathrm{P}$ availability in the 
surface ocean. At the same time, oxygen-dependent fixed $\mathrm{N}$ loss through the microbial nitrification-denitrification cycle is minimized within the strongly reducing ocean interior because of muted microbial oxidation of ammonium $\left(\mathrm{NH}_{4}^{+}\right)$. The ultimate result is an ocean system that accumulates $\mathrm{NH}_{4}{ }^{+}$, making it more likely to be P-limited on long timescales (Reinhard et al. 2017).

\section{LUCA}

The single-cell bacterium-like ancestor of all living things on Earth, known as LUCA, the Last Universal Common Ancestor, is estimated to have lived some four billion years ago, when Earth was a mere 560 million years old (Wade 2016). Some, this author included, believe that LUCA already was a highly sophisticated organism that had evolved far beyond the original life form, the progenote. Life in the form of a bacterium is so complex it seems that a progenote would have needed hundreds of millions of years to evolve to a LUCA. Yet evidence for the earliest life dates to 4.1 billion years ago, as if it emerged almost the moment the Late Heavy Bombardment ceased (Table 3) [or before, but after Theia (Glonek and Nelson 2017)]. There still exists a gap between descriptions of prebiotic events and LUCA. Intermediate stages must have involved simpler organisms containing much smaller and simpler genome-like molecules (Lazcano and Miller 1996).

\section{Discussion}

The thesis presented herein is that a mineral scaffold containing phosphate units was present in primordial seas which provided the initiating factor responsible for the sequestration and organization of primordial life's constituents. The key phosphate scaffold was not a polynucleotide or just any condensed phosphate but a large (in the range of 1 kilo-phosphate subunits), water soluble, cyclic metaphosphate (a closed loop, no end groups), complexed with $\mathrm{Mg}^{2+}$ and/or $\mathrm{Ca}^{2+}$ and/or alkali metal cations (Figs. 3, 4).

\section{Condensed Phosphate Inorganic Chemistry}

Polymeric phosphates that are ordinarily found dissolved in aqueous solutions consist of chains of $\mathrm{PO}_{3}$ functional groups that may be as short as two units (pyrophosphate) or that may extend for the length of macroscopic crystals, as in Kurrol's salt. There are two sub-families of these polymers: the open chains in which the two end group phosphates share only one anhydride $\mathrm{P}-\mathrm{O}-\mathrm{P}$ linkage and posses a weak-acid dissociation, and the cyclic metaphosphates which are closed loops of $\mathrm{PO}_{3}$ chains in which each and every phosphate group shares two anhydride linkages.

The $\mathrm{P}-\mathrm{O}$ inter-atomic distance (radial distribution) in phosphate glass is $\sim 1.61 \AA$; an extended 1000 residue chain phosphate, therefore, computes to $\sim 2770 \AA$ in length (Thilo 1965). This distance is reduced by 38\%, if the chain assumes the structure of a four-phosphate-per-turn helix. Further, such a chain could readily form supercoils, further reducing the volume of space it occupies.

The pyrolytic synthesis of polyphosphates at or near the metaphosphate composition, $\mathrm{H}_{2} \mathrm{O} / \mathrm{P}_{2} \mathrm{O}_{5}=1$, always results in the formation of $\sim 10 \%$ cyclic metaphosphates in a range 
of ring sizes. The cyclic molecules also are found as side products of chain polyphosphate hydrolysis reactions, both acidic and alkaline. The key functional group in these reactions appears to be the end-group phosphates of the chains. Hydrolytic opening of cyclic metaphosphate rings under similar conditions is much lower, although it does take place to form the corresponding linear chain phosphate that subsequently undergoes a more rapid hydrolysis.

Considering chain phosphate hydrolysis reactions, the mole fraction of the cyclic molecules is enhanced by the presence in the reaction mixture of polyvalent cations that are hypothesized to form complexes with the phosphate groups. In such cationenhanced reactions to the metaphosphates, the small cations, e.g., $\mathrm{Mg}^{+2}$ and $\mathrm{Al}^{+3}$ are the most effective rearrangement catalysts.

Condensation of chain phosphates in organic solutions through an organic condensing agent results in the synthesis of cyclic and ultraphosphate caged and conjoined molecules.

In the crystalline state and in solutions, the condensed phosphates, depending on conditions, may form helical conformations that superficially look rather similar to that of a polynucleotide backbone.

Clearly, there is a propensity for the linear chain condensed phosphates to rearrange and form cyclic condensed phosphate molecules. Further, hydrolysis of very long chains, e.g., Kurrol's salt, could generate large metaphosphates. Consider the following:

If, as has been suggested (Van Wazer 1958e), there are branch groups within Kurrol's salt crosslinking the long middle-group phosphate chains within the crystal, then, when the crystal surface comes into contact with water (during aqueous dissolution of the crystal), hydrolysis of a reactive branch group has two possibilities: 1 . The branch link to the parallel polyphosphate chain could hydrolyze, resulting in two longer-chain linear polyphosphates. 2. The branch link along the linear axis of the polyphosphate chain could hydrolyze, resulting in the formation of a long-chain polyphosphate linked through the branch group on the parallel neighboring polyphosphate chain. This group (on the parallel chain) could then undergo hydrolysis, again with two possibilities, one of which would result in the connection of two parallel polyphosphate chains and the release of a polyphosphate chain having an end-group in the position of the previous branch-group link. A similar set of reactions anywhere along either constituent polyphosphate chain could result in the formation of a large ring molecule, a cyclic metaphosphate.

Aqueous solutions of Kurrol's salt exhibit a high viscosity that maximizes when the mole ratio of $\mathrm{K}_{2} \mathrm{O} / \mathrm{P}_{2} \mathrm{O}_{5}$ is 0.9 (Van Wazer 1958e; Fig. 10-25), that is, when the mole ratio is in the range of the ultraphosphate branch-group-containing composition. The high viscosity (500 centipoise for a $0.2 \%$ solution) indicates that hydrolysis results in the release of very long chains that may include very large rings.

\section{Biological Condensed Phosphates}

Condensed phosphates are ubiquitous in Nature being found in primitive bacteria and archaea all through the phylogenetic tree to man, where they are often contained in subcellular phosphate-containing organelles. They are found in the seas to the deepest sediments. Within these life forms, a system of metabolizing enzymes has been created for manipulating condensed phosphate molecules. The condensed phosphates function as substitutes for ATP in kinase reactions, as energy sources, as a buffering agent for alkali, as chelating agents and reservoirs for polyvalent cations, and as constituents of polynucleotide 
translocation systems. They are involved as constituents of the bacterial capsule, in bacterial transformation, in mRNA processing, and as constituents of eukaryotic nuclei.

The chain polyphosphates of a variety of lengths, some quite long, have been isolated from biological sources as has been the cyclic trimeta- and tetrameta-phosphates (Glonek 1980); larger rings from biological sources have not yet been identified. The branch phosphate group also has yet to be detected in biological sources. Branch groups hydrolyze very rapidly (Van Wazer 1958c, d). If branch groups existed biologically, they most probably would take the form of reaction intermediates on or within enzymes. Ultraphosphates, which contain branch groups, exhibit a propensity to contain four-phosphate rings. Thus, a four-phosphate ring structure may be the most probable form for an ultraphosphate intermediate in a biological system, and the presence of the tetrametaphosphate in biological isolates (Glonek 1980 Fig. 21) may indicate the existence of such an intermediate.

\section{Polyphosphate Enzymes}

Polyphosphate kinases are known to exist throughout the biosphere, and it is probable that every living cell contains such a kinase or the code for this kinase in its genome (Table 2). The condensed phosphate chains that are produced for, or are substrates for, this family of enzymes can be very long, in the range of 800 to 1000 phosphate residues, although within polyphosphate granules (acidocalcisomes) the phosphate chains, which are degraded upon chemical extraction, may be an order-of-magnitude larger. In yeast, it should be noted, a high activity of exopolyphosphatases, PPX, does not prevent the accumulation of polyphosphate (Kulakovskaya et al. 2005). Is this, perhaps, because the polyphosphate that does accumulate is really a cyclic metaphosphate? The exopolyphosphatases require end groups to be present for hydrolysis. The metaphosphates have no end groups and, therefore, do not react.

The exopolyphosphatases, the various PPKs and PPXs, have been detected in a large number of primitive organisms, suggesting that polyphosphate origins could date back to the progenote stage of life development.

While examining the effects of yeast endopolyphosphatases, PPNs, on polyphosphates prepared using purified E. coli polyP kinase, a residual was observed in the developed $6 \%$ urea-polyacrylamide gel electrophoresis (Kumble and Kornberg 1996 Fig. 4) that could be a metaphosphate in the size range of sixty-units. This occurs in two of Kornberg's papers (Kumble and Kornberg 1996; Shi and Kornberg 2005). In the follow-up paper (Shi and Kornberg 2005), he settles on a linear $\mathrm{P}_{60}$ and never mentions the possibility that this material could be a large closed ring which, although it still undergoes further hydrolysis, resists hydrolysis and persists sufficiently to accumulate in the reaction mixture and make a noticeable spot in the chromatogram (Shi and Kornberg 2005 Fig 4b). In these studies, affinities of PPN for the polyphosphates were measured using Km. For chain lengths of 100-750 residues, the $\mathrm{Km}$ was $185 \mathrm{nM}$; however, no activity was detected with the poly $\mathrm{P}_{60}$, one of the two main end products of the reaction (Kumble and Kornberg 1996). Such a result could be explained if the endopolyphosphatases employed were specific for chain and not ring phosphates.

The various endopolyphosphatases cleave polyphosphate chains into shorter chains. These enzymes, which attack the inner-chain phosphate middle groups, do not require the presence of end groups, and such activities are capable of opening metaphosphate rings, producing open chains. 
The presence of PPNs in archaea and other primitive organisms should be re-examined. Such an enzymatic activity should be capable of opening the cyclic metaphosphate rings as well as of cleaving dissolved Kurrol's salt into shorter chain polyphosphates. It is suggested by this author that most primitive organisms available today should contain active PPNs. Detecting these enzymatic activities, however, is difficult because it is necessary first to be sure possible PPN preparations are free of PPXs and other condensed phosphate hydrolase activities. A potential method to mitigate this problem would be to use as a substrate a larger crystalline metaphosphate. PPN from any organism should be capable of opening cyclic octa- and hexa-metaphosphates to the octa- and hexa-(chain)polyphosphates, which, using these substrates, would result in hydrolytic polyphosphate products no longer than the octa- or hexa-polyphosphates.

The exopolyphosphatases do not degrade metaphosphates but degrade very long chain polyphosphates, e.g., dissolved Kurrol's salt phosphates, and, significantly, polyphosphates of biological origins, such as those contained in electron dense particles, etc. The hydrolysis proceeds slowly, usually with a large fraction of such material apparently remaining un-degraded. It should be noted in this context, that hydrolytic experiments may perturb the polyphosphate within living cells, but never all of it. Is this, then, evidence for unreactive cyclic molecules? One such mask may arise because there are no open end-groups on the polyphoshates that fail to react. Such phosphates, most probably, are the cyclic metaphosphates in samples of purely mineral origins, and, by this same criterion, unreactive polyphosphates of biological origins. PPN1's action is to open these metaphosphate rings, creating linear polyphosphates having the same number of phosphate residues per molecule as the original ring molecules but with two of these residues now transformed into end groups. Subsequently, PPX1, the chain-end hydrolytic enzyme, then degrades the released chain polyphosphates into smaller chain phosphates and/or inorganic orthophosphate.

It has been observed that an overplus of Pi in incubation media results in an increase of exopolyphosphatase activity. Why should this be, when this enzyme's activity is to make additional Pi? Could it be that the enzyme in situ is not a polyphosphatase but an essential co-enzyme complex that synthesizes metaphosphates?

\section{Condensed Phosphate Complexes with Organic Cations}

Consider the possibility of salt formation between long condensed phosphate chains and large organic cations, e.g., a lysine-and/or-arginine-rich polypeptide: If a cation involved in such a phosphate complex is the size of a protein and the phosphate chain is wrapped around it as DNA is wrapped around the histone units of chromatin, a rearrangement reaction of the $\mathrm{PO}_{3}$ groups at a point where the chain overlaps itself would yield a large metaphosphate, the diameter of which might be equivalent to that of the protein-template circumference, or larger. Such a reaction would be similar to the formation of small cyclic polynucleotides through Holliday junctions.

Consider a primordial polyphosphate enshrouded with the amino groups of primordial organic molecules, the aggregate forming a neutral complex having a hydrophobic surface that can pass across a lipid membrane. These amines could be arginine and lysine, that are found in very high concentrations (ca. 90\%) in acidocalcisomes (Rohloff et al. 2003; 284), and that can be polymerized by polyphosphates into peptides (Fondi et al. 2007; Karki et al. 2017; Kornberg 1995; Sibilska et al. 2017). 


\section{Poly- $\beta$-Hydroxybutyrate Complexes with Polyphosphates, Voltage-Activated Calcium Channels}

Polyphosphates form specific complexes with $\mathrm{Ca}^{+2}$ and poly-R-3-hydroxybutyrate creating a channel through which polynucleotides may pass the plasma membrane. These channels are found in a large variety of cells from bacteria through eukaryots (Reusch 1999). They form well-regulated ion-selective channels in lipid bilayers, selecting divalent, particularly $\mathrm{Ca}^{+2}$, over monovalent cations; they play a role in DNA transmembrane transport; and they have been implicated as potential primordial regulators of $\mathrm{Ca}^{+2}$ (Reusch 1999). In the opinion of Reusch (1999), polyphosphate/polyhydroxybutyrate channels may be the most ancient form of ionic channels, which were conserved throughout evolution from prokaryotes to eukaryotes. These complexes demonstrate precisely how one type of polyphosphate-organic-moiety interaction may take place.

\section{Polyphosphate as a Chaperone}

In their review, Gray et al. (2014) make a strong case for polyphosphate serving as a chaperone. Within the crowded environment of a cell, many proteins require a cohort of molecular chaperones, proteases, and regulatory signaling pathways, the proteostasis network, to fold, to promote function, and to withstand stress conditions (Powers and Balch 2013). It was suggested that polyphosphate functions as a part of this network. For example, polyphosphate completely abolishes chemically denatured luciferase aggregation and protects citrate synthase from aggregation in vitro. Bacteria preferentially accumulate longchain polyphosphate upon stress conditions (Ault-Riché et al. 1998; Kornberg et al. 1999). Moreover, as with protein chaperones, polyphosphate does not appear to have any significant substrate specificity and stabilizes a wide variety of different proteins. It is therefore possible that polyphosphate functions as a chemical scaffold, keeping proteins soluble by stabilizing secondary motifs. In their concluding remarks, it was suggested that a universally important function of polyphosphate "...may have served as one of nature's first chaperones, a role that continues to the present day".

\section{Polyphosphates Complexing Nucleic Acids}

Polyphosphate binds tightly with RNA; however, treatment with activated charcoal revealed that covalent bonds were not involved (Harold 1966). In other work involving RNA complexes with polyphosphate, it was concluded that $\mathrm{Mg}^{2+}$ and $\mathrm{Ca}^{2+}$ form bridges between the two polymeric chains, with the tightness of the complex depending upon chain lengths (Stahl and Ebel 1963). Acidocalcisomes contain polyphosphate and are thought to contain nucleic acids (Docampo et al. 2005). Following incubation of algae in a phosphatefree medium, ${ }^{32} \mathrm{P}$ (as trace amounts of phosphate) was rapidly incorporated into polyphosphate. Column chromatography of the subsequent isolates revealed that low-molecularweight polyphosphate fractions were eluted rapidly while high-molecular-weight fractions also containing tRNA and DNA were retained and eluted together (Reinhard et al. 2017). An electron microscopic observation of polyphosphate granules in E. coli revealed chromosomal fibers seemingly oriented along chromosomal DNA fibers (Gray et al. 2014).

These data indicate that, in the presence of alkaline-earth cations, there is a propensity for polynucleotides and polyphosphates to form $\mathrm{Mg}^{+2}$-and/or- $\mathrm{Ca}^{+2}$-containing coordination complexes containing both polymeric phosphates, and it is easy to hypothesize 
polynucleotides and polyphosphates linearly complexed into a double helix as in RNA and DNA, since both molecules are helical and of approximately the same pitch. In such a complex, primordial polyphosphate would function as a scaffold for the organization of primordial double-stranded polynucleotides.

\section{Genes Encoding Polyphosphate-Metabolizing Enzymes}

A number of genes have been characterized that provide the proteins for the metabolism of poly- and meta-phosphates (Table 2). Some of these enzymes, particularly the endopolyphosphatases, which cleave interior middle-group-to-middle-group linkages, have an absolute requirement for highly condensed phosphate substrate preparations that may contain metaphosphate rings. In assessing the available $S$. cerevisiae pool of condensed phosphate metabolic activities, Lichko et al. stated: "The question of the presence of endopolyphosphatase in $S$. cerevisiae is still unclear. Such dynamics of polyphosphate hydrolysis suggests the occurrence of endopolyphosphatase not encoded by the PPN1 gene." (Lichko et al. 2008) - or, the presence of large metaphosphate rings, which are just long-chain condensed phosphates, but without the enzymatically reactive end groups required for exopolyphosphatase activities that generate short chain polyphosphate products.

It should be noted that a purified PPN1 gene product contains a peptide of 605 amino acid residues that has not been observed in the amino acid sequence of endopolyphosphatase also coded by this gene (Shi and Kornberg 2005). This gene encodes a number of enzymes that use polyphosphates as substrates. Could it be that this gene is a primordial remnant? Clearly the genetic component of polyphosphate metabolism has been just lightly touched upon. There is suggestive evidence that more genes are involved in condensed phosphate metabolism than have been identified, and these could hold the key for the role of condensed phosphates at the creation of the first progenote.

\section{Phosphate Release from Seas and Lakes and Phosphate Aquatic Mineralogy}

Considering the anoxic primordial Earth and accepting the premise that for the initial progenotes phosphorus was an essential element, what might the likely fate of Pi and condensed phosphates be in primordial lakes and seas? Free oxygen on Earth is the product of biological photosynthesis; therefore, both lakes and the seas of the primordial Earth are anoxic, contain weathering sediments and a consequential complex set of mineral equilibria. The sediments are dust and fragments created through meteoric impacts and weathering. Given that, today, volcanoes belch forth condensed phosphates as well as $\mathrm{Pi}$, one can assume that these constituents were present in the dust of the primordial Earth. In Earth's primordial lakes and seas, the mineral equilibria would exhibit properties similar to those which exist today in anoxic aquatic circumstances. What do contemporary studies teach us?

Diagenesis, the physical and chemical changes occurring during the conversion of sediment to sedimentary rock, would proceed to form precipitated orthophosphate salts, eventually forming various iron phosphates and mixed ferrous anionic minerals. Today, anoxic conditions release sediment polyphosphate phosphorus back into the water column; conversely, oxic conditions store phosphate as polyphosphate (Ingall and Jahnke 1997). These observations are consistent with studies showing that low oxygen bottom-water concentrations correlate with reduced total phosphorus burial efficiencies and enhanced organic carbon burial efficiencies (Ingall and Jahnke 1997). Thus, condensed phosphates would tend to remain in solution. 
The condensed phosphates, being highly soluble complexing agents, would find themselves dissolved in the water column, most probably as soluble polyvalent cationic complexes as is the case today. Thus, the available aquatic phosphate would be enriched in the condensed phosphate forms, resulting in a relatively abundant phosphate aquatic pool.

It is known that once life exists, phosphorus in the seas comes to equilibrium with the sediments that accumulate and the water column. One can anticipate, therefore, that before life existed there would have been a similar equilibrium, in this instance involving dispersed organics in the water column and precipitated Fe minerals in the sediments.

When progenotes arrive on the scene, one might anticipate the production of condensed phosphates in the water column to be increased due to primordial biological activity that eventually would evolve into the activities observed today. Kenney et al. (2001), in their studies on phosphorus sedimentation in hypereutrophic lakes concluded that in the water column, two common forms of biologically-available phosphorus are soluble reactive phosphorus and polyphosphate. Soluble reactive phosphorus is organic phosphates that have not been assimilated by algae; polyphosphate represents surplus storage that has been assimilated but not utilized for algal growth. In the marine environment, the dramatic increase in $\mathrm{C} / \mathrm{P}$ and $\mathrm{N} / \mathrm{P}$ ratios with depth indicates that phosphorus is preferentially regenerated from dissolved organic matter, which implies that dissolved organic phosphorus must ultimately cycle more efficiently than either dissolved organic carbon or dissolved organic nitrogen (Clark et al. 1998; Van Cappellen and Ingall 1994, 1996). [For reviews discussing polyphosphates in the marine environment, see (Benitez-Nelson 2000; Perry 1976).]

Thus, in an anoxic primordial sea, sediments would hold little polyphosphate; however, they may hold metaphosphates, which, lacking end groups, are much more stable to simple hydrolysis by water. Enzymes, such as the endonucleases, are not present until life appears. One is then driven to the conclusion that primordial cyclic metaphosphates were relatively plentiful and ubiquitous constituents of primordial aquatic environments, and not just in the water but in the sediments as well.

\section{Cyclic Metaphosphates as a Template for the Organization of the First Replicating Chemical Entities}

Synthesizing replicating molecular complexes from synthetic organic molecular tars has proved to be, thus far, too difficult. An organizing factor appears to be required. There are several candidates for such a factor: the crystal surfaces of primordial minerals; the surfaces of micells; the membrane surfaces of vesicles, either inside or outside; small polypeptides (chains of amino acids); or even polynucleotides (chains of aromatic residues); perhaps, a complex of polynucleotides and polypeptides fixed to the inner membrane of polar lipid vesicles. One can envision many more chemical combinations that may exist on a primordial planet, and since no one has been successful, we should keep trying, for example, consider a large metaphosphate or a fragment of Kurrol's salt.

\section{A Hypothetical Scaffold and Energy-Source Molecule}

It seems time to re-examine the plausible role in the origins of life of a well known and useful primordial mineral family, the condensed (polymeric) inorganic phosphates, particularly the closed-ring cyclic metaphosphates. Like DNA and RNA, which are known to exist as large cyclic polyanions, the metaphosphates also are cyclic polyanions, and for both molecular types, the charge-carrying functional group is a polymerized $\mathrm{PO}_{4}$ group. 
Such polymers can be long, literally centimeters long. Like DNA, RNA and proteins, they are coiled into a periodic helical conformation, with the links between the repeating groups being identical at all points in the molecule. Like polynucleotides and proteins, they can twist into a wide variety of looped structures, even to the point of building cage structures. And like polynucleotides, such super-coiled structures may be internally rearranged to create sizes and loops of a wide variety of molecules with little expenditure of energy above the molecular motion observed at ambient temperatures [Van Wazer's structural reorganization theory (Van Wazer 19581)].

Unlike DNA, RNA and proteins, the condensed phosphates are produced through geochemical processes that capture the Earth's energy in the form of $-\mathrm{P}-\mathrm{O}-\mathrm{P}-$ anhydride bond linkages, and condensed phosphates were present, already formed, at the birth of the Earth. Moreover, being polyanions that are readily soluble in water, and that complex metal cations and polar organic entities, they perform the function of an organizing scaffold upon which further polymerizations may occur. Further, and this may be the key property, they are capable of providing the energy needed to form ester and amide chemical bonds through reactions utilizing the energy sequestered within the $-\mathrm{P}-\mathrm{O}-\mathrm{P}-$ linkages.

Figures 3 and 4 are illustrations of hypothetical cyclic metaphosphate molecules that could perform the role of a scaffold for organizing primordial organic molecules into aggregates that potentially may possess enzyme-like activities. Illustrated are small 64- and 160-mer molecules that reveal the principal structural features of such molecules. In the figures, each phosphate group is represented as a skewed tetrahedron [after Thilo (1965)] with the oxygen atoms positioned at the apexes of the tetrahedra and the phosphorus atoms approximately face-centered within each tetrahedron. The molecule contains only phosphate groups linked through $-\mathrm{P}-\mathrm{O}-\mathrm{P}$-bonds; there are no end-group phosphates. The constituent condensed phosphate chains coil upon themselves to form helixes consisting of 4 phosphate groups per turn of the helix. Further, such molecules have sufficient flexibility to super-coil to form hairpin-like structures analogous to cyclic polynucleotides, the formation of which would be facilitated through phosphate group complexation with metal cations.

Such molecules are polyanions containing one negative charge per phosphate group that strongly associates with metal cations and the positively charged functional groups of polypeptides. Complexes with polyvalent cations, such as $\mathrm{Mg}^{+2}$ and $\mathrm{Ca}^{+2}$ would facilitate the formation of mixed complexes of organic polymers and the phosphate mineral polyanions to generate aggregates not unlike polyphosphate-poly- $\beta$-hydroxybutyrate complexes and nucleohistones.

Further, as DNA does today, the condensed phosphate chains can reorganize in a process using little energy (Fig. 2) to form loops, chains, and rings of greater or lesser lengths. Using a mechanism analogous to the features of condensin-mediated DNA loop-forming processes (Ganji et al. 2018), long-chain polyphosphates (with end groups) could be converted into large cyclic metaphosphate rings (no end groups). A primordial version of such a complex could provide a method for generating large, kilophosphate size rings of cyclic metaphosphates from long chain polyphosphates and smaller metaphosphates.

\section{Integrating Alternative Mechanisms of Polynucleotide Synthesis with that Incorporating a Metaphosphate.}

Considering organizational substrates, Cairns-Smith's (1987) suggestion that clay may have been a substrate upon which primordial organic information-carrying molecules may 
have been organized eventually lost credence as no supporting evidence emerged, although smectite-type clays can protect and promote development of diverse organic compounds that may be precursors to biomolecules (Williams et al. 2005). Clay is a silicate in which the constituent silicon atoms are tetra-connected to neighboring silicate groups forming chemically extended unreactive planer (phyllosilicate) and three-dimensional (tectosilicate) networks. Its neighbor in the Periodic Table, phosphorus, however, forms reactive twodimensional chain molecules that in aqueous solutions are partially protected from hydrolysis by negative charges on the constituent phosphate groups. This chemical structure facilitates a linear organization of organic groups along the molecular chain while permitting structural re-organizational processes along the chain without hydrolysis, thus providing a mechanism for molecular evolution.

Considering information-carrying molecular systems, Eschenmoser (1994) has shown that there are alternative structures that demonstrate the characteristic base-pairing selectivity of RNA. In these structures, ribopyranosyl ( 4 ' $\rightarrow 2$ ') isomers of RNA ('p-RNA') form viable base pairing with the same fidelity and durability of RNA (Pitsch et al. 1993). Similar alternative systems have been synthesized using members of a family of diastereoisomeric pentopyranosyl-( $\left.4^{\prime} \rightarrow 2^{\prime}\right)$-oligonucleotide systems derived from D-ribose, D-xylose, L-lyxose, L-threose (Schöning 2002) and L-arabinose, with the $\alpha$-arabinopyranosyl system showing by far the strongest Watson-Crick base pairing (Jungmann et al. 2003). These systems require that a template must be present, as no ligation reactions occur in the absence of a template (Bolli et al. 2004).

One could anticipate that such reactions would be facilitated by template structures that would impart stability to the reaction complex, as is the case for the formation of the ribopyranosyl $\left(4^{\prime} \rightarrow 2^{\prime}\right.$ ) isomers of RNA (Pitsch et al. 1993). In an analogous manner, nucleosides absorbed along the phosphate chain of a metaphosphate could serve as the template for further extension of polynucleotide chains, and such a condensation reaction would then serve as the template for further polymerization of the growing chain.

In these reactions, the energy for producing the ribopyranosyl $\left(4^{\prime} \rightarrow 2^{\prime}\right)$ isomers of RNA is provided by the opening of the cyclic monophosphoryl functional groups of the reagent nucleotides being linked into the polynucleotide chains. The analogous reaction involving a condensed phosphate would incorporate the simple nucleoside monophosphate monoesters, with the energy for creating the resultant phosphodiester links being provided by the phosphoanhydride linkages of the condensed phosphate middle groups.

If nucleosides were stacked, aligned along a condensed phosphate chain, as they are now found in association with poly- $\beta$-hydroxybutyrates, a simple scrambling reaction analogous to that shown in Fig. 2, involving the condensed phosphate chain as the energy source, would generate phosphodiester-linked nucleoside polymers. Such a reaction would result in a polynucleotide incorporated into the polymerized phosphate ring, the beginnings of a primitive RNA in cyclic form.

Clearly the key to such a process is the sequestering of nucleosides along the condensed phosphate chain. In poly- $\beta$-hydroxybutyrate/polyphosphate complexes, the poly- $\beta$ hydroxybutyrate forms an un-charged organic sleeve surrounding a condensed phosphate chain (Reusch 1992 Fig. 6). The negative charges of the condensed phosphate are neutralized by $\mathrm{Ca}^{+2}$ cations that, through the formation of coordination complexes at locations between the two polymers, establish the structure of this mixed polymer complex. It is proposed that in an analogous manner, nucleosides would stack along the polyphosphate chain, a process that would be facilitated by mineral counter cations through the formation of coordination complexes analogous to those found for the ATP-sodium and -magnesium dimers in crystals and simple aqueous solutions (Glonek 1992). This author's prejudice 
for the counter cation is not $\mathrm{Ca}^{+2}$, however, but $\mathrm{Mg}^{+2}$. Thus, the reactive complex is proposed to be a helix consisting of a string of condensed phosphate enclosed in an organic sheath of nucleoside-like molecules held together through coordination complexes involving $\mathrm{Mg}^{+2}$ cations. Formal linkages would then proceed through scrambling esterification reactions utilizing the energy provided by the phosphate anhydride linkages of the condensed phosphate chain to generate a primitive polynucleotide.

\section{Primordial Vesicles}

Cells, and, presumably, a viable progenote, require a containment vessel, the plasma membrane for cells and viruses within cells, in order to perform non-random, purposeful biochemistry. Ordered biochemistry, presumably facilitated by some form of scaffold system, is the only mechanism through which evolution can progress, i.e., in accord with the second law of thermodynamics, order progresses within the vessel at the expense of increasing disorder outside the vesicle. The vessel, therefore, must be permeable to the movement of particles but sufficiently sturdy to maintain itself while permitting the translocation of particles selectively, i.e., to retain large particles while permitting the free diffusion of small particles.

In the laboratory, negatively charged DNA interacts with positively charged lipids in liposome membranes to form a shell at the interior surface of the liposomes. Such liposomes are sturdier than ones without such cytoskeletons. For example, they are better able to withstand osmotic shock (Kurokawa et al. 2017). A quite similar complex could be generated containing the polyanionic condensed phosphates (either poly- or meta-phosphates).

Missing from the above discussion is the need for energy. By simple diffusion, vesicles will rapidly equilibrate with their environment, curtailing evolution. A source of energy, therefore, is needed to maintain a gradient across vesicle plasma membranes. Condensed phosphates, whose origins are geological, store whopping amounts of chemical energy in the form of their acid anhydride linkages, and, like ATP, another condensed phosphate, the energy stored in the anhydride linkages can be utilized for the maintenance of chemical gradients. Thus, a vesicle containing within itself a large cyclic metaphosphate has a reasonable probability of evolving to a more complex and ordered state.

\section{A Role in Evolution}

Consider two particles colliding in a primordial sea, each composed of a metaphosphate ring bonded to both mineral and organic counter cations of various types, including absorbed small polypeptides and possessing some simple primitive catalytic activity. Through an inorganic phosphate scrambling reaction requiring only the energy inherent in molecular motion, the two phosphate rings fuse, creating a single phosphate ring containing the absorbed complement from both of the interacting particles. The new larger particle now contains the capabilities of both of the original interacting particles. Thus, evolution begins. Since this is chemistry, not biology, such scrambling interactions would occur countless times all over the primordial seas where the requisite materials could be found, resulting in particles possessing sufficient catalytic activity to be considered the initial progenotes. At this point natural selection begins. 


\section{Geological Rhythms as a Facilitating Factor}

In a review featuring a focus on oscillator interactions, Lydic (1989) stated: "The ubiquity of biological rhythms suggests that the continuous influence of abiotic, environmental cycles contributed to their evolutionary selection and development (Daan 1981). Solar, lunar, tidal, and even stellar cycles can strongly influence species-specific biological rhythms such as feeding, migratory, and reproductive cycles. Such environmental influence is referred to as entrainment and can alter the period, amplitude, or phase characteristics of a biological rhythm. Although rhythmic physiology and behavior can be entrained, biological rhythms are endogenously generated and not merely a passive product of environmental cycles (Aschoff 1981; Moore-Ede et al. 1984)."

It is suggested here that primordial rhythms of geological origins facilitated the organization of molecular species within a progenote vesicle. Considering those geological rhythms that correlate with biological rhythms (Glonek and Nelson 2017), rhythms within the frequency range of $(0.01$ to 1000$) \mathrm{Hz}$ are believed to be the most promising candidates for such a facilitating factor, particularly the rhythm at $0.1 \mathrm{~Hz}$, which is ubiquitous in Nature (Glonek and Nelson 2017).

Abbreviations ATP ADP AMP: Respectively, adenosine tri-, di, mono-phosphate; DEAE: Diethylaminoethyl; DIPP: Diphosphoinositol polyphosphate phosphohydrolase; DNA: Deoxyribonucleic acid; DOC: DON, DOP, respectively, dissolved organic: phosphorus, nitrogen, carbon; DOP: Dissolved organic phosphorus; EDTA: Ethylenediaminetetraacetic acid; GDP: Guanosine diphosphate; GTP: Guanosine triphosphate; LACA: Last common ancestor of the Archaea; LECA: Last eukaryotic common ancestor; LUCA: Last Universal Common Ancestor; NMR: Nuclear magnetic resonance; NAD: Nicotinamide adenine dinucleotide; NADP: Nicotinamide adenine dinucleotide phosphate; PAP: Phosphotransferase; Pi: Inorganic orthophosphate; PPN: Endopolyphosphatase; PPX: Exopolyphosphatase; RNA: Ribonucleic acid; SIMS: Secondary-ion-mass spectrometry; SMC: Structural maintenance of chromosomes; SRP: Soluble reactive phosphorus

Acknowledgement Edward J. Griffith, who encouraged me to write this a long time ago.

Author Contribution Article has only a single author.

Funding Author funded.

Data Availability All data are present in the text.

\section{Declarations}

Ethics Approval No approvals required.

Consent for Publication No consents required.

Open Access This article is licensed under a Creative Commons Attribution 4.0 International License, which permits use, sharing, adaptation, distribution and reproduction in any medium or format, as long as you give appropriate credit to the original author(s) and the source, provide a link to the Creative Commons licence, and indicate if changes were made. The images or other third party material in this article are included in the article's Creative Commons licence, unless indicated otherwise in a credit line to the material. If material is not included in the article's Creative Commons licence and your intended use is not permitted by statutory regulation or exceeds the permitted use, you will need to obtain permission directly from the copyright holder. To view a copy of this licence, visit http://creativecommons.org/licenses/by/4.0/. 


\section{References}

Ahn K, Kornberg A (1990) Polyphosphate kinase from Escherichia coli. J Biol Chem 265(20):11734-11739

Akiyama M, Crooke E, Kornberg A (1993) An exopolyphosphatase of Escherichia Coli. J Biol Chem 268:633-639

Andreeva NA, Kulakovskaya TV, Kulaev IS (2000) Inorganic polyphosphatases from Halobacterium salinarium. Microbiology 69(4):411-416

Andreeva, NA, Kulakovskaya TV, Kulaev IS (2001) Two exopolyphosphatases of the cytosol of the yeast S. cerevisiae: Comparative characteristics. Biochemistry (Moscow) 66(2):147-153

Andreeva NA, Kulakovskaya TV, Kulaev IS (2006) High molecular mass exopolyphosphatase from the cytosol of the yeast Saccharomyces cerevisiae is encoded by the PPN1 gene. Biochemistry (Moscow) 71(9):975-977

Aschoff J (ed) (1981) Handbook of Behavioral Neurobiology, vol 4. Plenum Press, New York, Biological Rhythms. https://doi.org/10.1007/978-1-4615-6552-9

Assum G, Böckle B, Fink T, Dmochewitz U, Krone W (1989) Restriction analysis of chromosomal sequences homologous to single-copy fragments cloned from small polydisperse circular DNA (spcDNA). Hum Genet 82:249-254

Ault-Riché D, Fraley CD, Tzeng CM, Kornberg A (1998) Novel assay reveals multiple pathways regulating stress-induced accumulations of inorganic polyphosphate in Escherichia coli. J Bacteriol 180:1841-1847

Beck A, Orgel LE (1965) The formation of condensed phosphate in aqueous solution. Proc Natl Acad Sci USA 54:664-667

Bell EA, Boehnke P, Harrison TM, Mao WL (2015) Potentially biogenic carbon preserved in a 4.1 billion-year-old zircon. Proc Nat Acad Sci, PNAS Early Edition. https://doi.org/10.1073/pnas. 1517557112

Bell RN (1947) Estimation of triphosphoric and pyrophosphoric acids in presence of ortho- and metaphosphoric acids. Anal Chem 19(2):97-100

Belov NV, Organova NI (1962) Crystallochemistry and mineralogy of lomonosovite as related to its crystal structure. Geokhimiya 1:6-14

Belozersky AN (1959) On species specificity of nucleic acids in bacteria. In: Oparin AI, Pasynskii AG, Braunshtein AE, Pavlovskaya TE, Clark F, Synge RLM (eds) The Origin of Life on the Earth. Pergamon Press, London, pp 322-331

Benitez-Nelson CR (2000) The biogeochemical cycling of phosphorus in marine systems. Earth Sci Rev 51:109-135

Bental M, Pick U, Avron M, Degani H (1991) Polyphosphate metabolism in the alga Dunaliella salina studied by ${ }^{31}$ P-NMR. Biochim Biophys Acta Mol Cell Res 1092(1):21-28

Blake GA, Bergin EA (2015) Prebiotic chemistry on the rocks Nature 520:161-162

Bolli M, Micura R, Pitsch S, Eschenmoser A (2004) Pyranosyl-RNA: Further observations on replication. Helv Chim Acta 80(6):1901-1951

Bonting CFC, Kortstee GJJ, Zehnder AJB (1991) Properties of polyphosphate: AMP phosphotransferase of Acinetobacter Strain 210A. J Bacteriol 173(20):6484-6488

Bottke WF, Vokrouhlicky D, Marchi S, Swindle T, Scott ERD, Weirich JR, Levison H (2015) Dating the Moon-forming impact event with asteroidal meteorites. Science 348(6232):321-323

Brandes JA, Ingall E, Paterson D (2007) Characterization of minerals and organic phosphorus species in marine sediments using soft X-ray fluorescence spectromicroscopy. Mar Chem 103(3-4):250-265

Brocks JJ, Jarrett AJM, Sirantoine E, Hallmann C, Hoshino Y, Liyanage T (2017) The rise of algae in Cryogenian oceans and the emergence of animals. Nature. https://doi.org/10.1038/nature23457

Brown MRW, Kornberg A (2004) Inorganic polyphosphate in the origin and survival of species. Proc Natl Acad Sci USA 101(46):16085-16087

Cairns JF (1963) The bacterial chromosome and its manner of replication as seen by autoradiography. J Mol Biol 6:208-213

Cairns-Smith AG (1987) Clay minerals and the origin of life. Hartman H (ed) Cambridge University Press, Cambridge

Callahan MP, Smith KE, Cleaves II HJ, Ruzicka J, Stern JC, Glavin DP, House CH, Dworkin JP (2011) Carbonaceous meteorites contain a wide range of extraterrestrial nucleobases. PNAS 108(34):1399513998. https://doi.org/10.1073/pnas.1106493108

Calvin M (1963) Evolution of photosynthetic mechanisms Graduate Journal 5:319-348

Castuma CE, Huang R, Kornberg A, Reusch RN (1995) Inorganic polyphosphates in the acquisition of competence in Escherichia coli. J Biol Chem 270:12980-12983. https://doi.org/10.1074/jbc.270.22.12980 
Chen KY (1999) Study of polyphosphate metabolism in intact cells by 31-P nuclear magnetic resonance spectroscopy. In: Schröder HC, Müller WEG (eds) Prog Mol Subcell Biol, Vol 23. Springer-Verlag, Heidelberg

Clark JE, Beegen H, Wood HG (1986) Isolation of intact chains of polyphosphate from "Propionibacterium shermanii" grown on glucose or lactate. J Bacteriol 168(3):1212-1219

Clark LL, Ingall ED, Benner R (1998) Marine phosphorus is selectively remineralized. Nature 393(6684):426-EOA

Cobb AK, Pudritz RE, Pearce BKD (2015) Nature's starships II: simulating the synthesis of amino acids in meteorite parent bodies. 809(6). https://doi.org/10.1088/0004-637X/809/1/6

Cody GD, Mysen B, Sághi-Szabó G, Tosell JA (2001) Silicate-phosphate interactions in silicate glasses and melts: I. A multinuclear $\left(27 \mathrm{AL}, 29 \mathrm{SI},{ }^{31} \mathrm{P}\right)$ MAS NMR and ab initio chemical shielding $\left({ }^{31} \mathrm{P}\right)$ study of phosphorus speciation in silicate glasses. Geochim Cosmochim Acta 65(14):2395-2411. https://doi. org/10.1016/S0016-7037(01)00597-X

Cohen S, Houben A, Segal D (2008) Extrachromosomal circular DNA derived from tandemly repeated genomic sequences in plants. The Plant Journal: for Cell and Molecular Biology 53:1027-1034. https:// doi.org/10.1111/j.1365-313X.2007.03394.x

Costello AJR, Glonek T, Myers TC, Van Wazer JR (1974) Structure and properties of the condensed phosphates. XVII. Ring-chain and other equilibria in organic solvents. Inorg Chem 13:1225-1230

Crooke E, Akiyama M, Rao NN, Kornberg A (1994) Genetically altered levels of inorganic polyphosphate in Escherichia coli. J Biol Chem 269(9):6290-6295

Da Silva JAL, Holm NG (2014) Borosilicates and silicophosphates as plausible contributors to the origin of life. J Colloid Interface Sci 431:250-254. http://www.sciencedirect.com/science/article/pii/ S0021979714001179.

Daan S (1981) Adaptive daily strategies in behavior, Chap. 15. In: Aschoff J (ed) Handbook of Behavioral Neurobiology, Vol. 4, Biol Rhythms. Plenum Press, New York. https://doi.org/10.1007/978-1-4615-6552-9

Das S, Lengweiler UD, Seebach D, Reusch RN (1997) Proof for a nonproteinaceous calcium-selective channel in Escherichia coli by total synthesis from R-3-hydroxybutanoic acid and inorganic polyphosphate. Proc Natl Acad Sci USA 94:9075-9079. https://doi.org/10.1073/pnas.94.17.9075

Dedkova EN, Blatter LA (2014) Role of $\beta$-hydroxybutyrate, its polymer poly- $\beta$-hydroxybutyrate and inorganic polyphosphate in mammalian health and disease. Front Physiol. https://doi.org/10.3389/fphys. 2014.00260

Deierkauf FA, Booij HL (1968) Changes in the phosphatide pattern of yeast cells in relation to active carbohydrate transport. Biochim Biophys Acta 150:214-225

Del Solar G, Giraldo R, Ruiz-Echevarria MJ, Espinosa M, Diaz-Orejas R (1998) Replication and control of circular bacterial plasmids. Microbiol Molec Biol Rev 62(2):434-464

Diaz J, Ingall E, Benitez-Nelson C, Paterson D, de Jonge MD, McNulty I, Brandes JA (2008) Marine polyphosphate: A key player in geologic phosphorus sequestration. Science 320(5876):652-655

Diaz J, Ingall E, Vogt S, de Jonge MD, Paterson D, Rau C, Brandes JA (2009) Characterization of phosphorus, calcium, iron, and other elements in organisms at sub-micron resolution using X-ray fluorescence spectromicroscopy. Limnol Oceanogr: Methods 7:42-51

Diaz JM (2011) Inorganic Polyphosphate in the Marine Environment: Field Observations and New Analytical Techniques. Dissertation, Georgia Institute of Technology, Atlanta, GA. https://smartech.gatech. edu/handle/1853/3739

Díaz M, Esteban A, Fernández-Abalos JM, Santamaría RI (2005) The high-affinity phosphate-binding protein PstS is accumulated under high fructose concentrations and mutation of the corresponding gene affects differentiation in Streptomyces lividans. Microbiology 151:2583-2592. https://doi. org/10.1099/mic.0.27983-0

Djokic T, Van Kranendonk MJ, Campbell KA, Walter MR, Ward CR (2017) Earliest signs of life on land preserved in ca. $3.5 \mathrm{Ga}$ hot spring deposits. Nat Commun 8 pages. https://doi.org/10.1038/ncomms 15263

Docampo R, de Souza W, Miranda K, Moreno RPSM (2005) Acidocalcisomes-Conserved from bacteria to man. Nat Rev Microbiol 3:251-261

Dodd MS, Papineau D, Grenne T, Slack JF, Rittner M, Pirajno F, O'Neil J, Little CTS (2017) Evidence for early life in Earth's oldest hydrothermal vent precipitates. Nature 543(7643):60-64

Eixler S, Selig U, Karsten U (2005) Extraction and detection methods for polyphosphate storage in autotrophic planktonic organisms. Hydrobiologia 533:135-143

Eppley RW (1962) Hydrolysis of polyphosphates by Porphyra and other seaweeds. Physiol Plant 15:246-251

Eschenmoser A (1994) Towards a chemical etiology of nucleic acid structure. Cell Chem Biol. https://doi. org/10.1016/1074-5521(94)90019-1

Fassett CI, Minton DA (2013) Impact bombardment of the terrestrial planets and the early history of the Solar System. Nat Geosci 6:520-524. https://doi.org/10.1038/ngeo1841 
Fernández-Garcia C, Coggins AJ, Powner MW (2017) A chemist's perspective on the role of phosphorus at the origins of life. Life 7:31. https://doi.org/10.3390/life7030031

Fleitmann TH, Henneberg W (1848) Notiz uber einige pyrophosphorsaure Doppelsalze. Justus Liebigs Ann Chem 65:387-391

Fondi M, Brilli M, Emiliani G, Paffetti D, Fani R (2007) The primordial metabolism: an ancestral interconnection between leucine, arginine, and lysine biosynthesis. BMC Evol Biol 7(Suppl 2):S3. https://doi. org/10.1186/1471-2148-7-S2-S3

Gabel NW (1965) Excitability and the origin of life: A hypothesis. Life Sci 4(21):2085-2096

Gabel NW (1972) Could those rapidly exchangeable phosphoproteins be polyphosphate-protein complexes? Perspect Biol Med 15:640-643

Gabel NW (1973) Abiogenic aspects of biological excitability. A general theory of evolution. In: Locker A, Ed. Biogenesis Evolution Homeostasis, A Symposium by Correspondence. Springer-Verlag, New York, pp 85-91. ISBN 13: 978-3-540-06134-2 e-ISBN 13: 978-3-642-95235-7. https://doi. org/10.1007/978-3-642-95235-7

Gabel NW (1977) Chemical evolution: A terrestrial reassessment. In: Hahn FE, Kersten H, Kersten W, Szybalski W (eds) Prog Mol Subcell Biol, Volume 5. Springer-Verlag, Berlin, pp 147-172, p 157

Gabel NW, Thomas V (1969) Occurrence of inorganic polyphosphates in excitable tissue. Fed Proc 28:2663-EOA

Gabel NW, Thomas V (1971) Evidence for the occurrence and distribution of inorganic polyphosphates in vertebrate tissues. J Neruochem 18:1229-1242

Ganji M, Shaltiel IA, Bisht S, Kim E, Kalichava A, Haering CH, Dekker C (2018) Real-time imaging of DNA loop extrusion by condensin. Science 360(6384):102-105

Gaubatz JW (1990) Extrachromosomal circular DNAs and genomic sequence plasticity in eukaryotic cells. Mutat Res 237(5-6):271-292

Gesteland RF, Atkins JF (eds) (1993) The RNA World. Cold Spring Harbor Laboratory Press, Cold Spring Harbor, New York

Ghosh K, van Duyne GD (2002) Cre-loxP biochemistry. Methods 28:374-383

Glonek T (1969) Phosphoric Acid Condensations with Trichloroacetonitrile. Dissertation, University of Illinois at the Medical Center, Chicago

Glonek T, Myers TC, Han PZ, Van Wazer JR (1970) Evidence for a small ultraphosphate molecule in solution. J Am Chem Soc 94:7214-7216

Glonek T, Lunde M, Mudgett M, Myers TC (1971c) Studies of biological polyphosphate through the use of phosphorus-31 nuclear magnetic resonance. Arch Biochem Biophys 142:508-513

Glonek T, Myers TC, Van Wazer JR (1971a) ${ }^{31} \mathrm{P}$ nuclear magnetic resonance studies of phosphate condensations with trichloroacetonitrile. II: Condensation and hydration in the ultraphosphate region. Bioinorg Chem 1:23-34

Glonek T, Van Wazer JR, Myers TC (1971b) ${ }^{31} \mathrm{P}$ nuclear magnetic resonance studies of phosphate condensations with trichloroacetonitrile. I: Condensation to the meta composition. Bioinorg Chem 1:1-22

Glonek T, Van Wazer JR, Mudgett M, Myers TC (1972) Cyclic metaphosphates from hydrolysis of the products from phosphoric acid condensation with carbodiimides. Inorg Chem 11:567-570

Glonek T, Van Wazer JR, Kleps RA, Myers TC (1974a) Cyclic phosphates with substitution or with conjoined or fused rings. Inorg Chem 13:2337-2345

Glonek T, Kleps RA, Myers TC (1974b) Cyclization of the phosphate side chain of adenosine triphosphate: Formation of monoadenosine 5'-trimetaphosphate. Science 185:352-355

Glonek T, Costello AJR, Myers TC, Van Wazer JR (1975b) P-31 nuclear magnetic resonance studies on condensed phosphates. III Polyphosphate spectra J Phys Chem 79:1214-1218

Glonek T, Myers TC, Van Wazer JR (1975a) Synthesis of an organic adduct of the P4O10 cage structure. J Am Chem Soc 97:206-207

Glonek T, Kleps RA, Van Wazer JR, Myers TC (1976b) Carbodiimide-intermediated esterifications of the inorganic phosphates and the effect of tertiary amine base. Bioinorg Chem 5:283-310

Glonek T, Kleps RA, Van Wazer JR, Myers TC (1976c) Cyclization of the phosphorus chain of the methylene-bridged analogs of adenosine triphosphate. Bioinorg Chem 6:295-304

Glonek T, Wang PJ, Van Wazer JR (1976a) Phosphorus-31 spin-lattice relaxation: 2. Inorganic ring and chain phosphates. J Am Chem Soc 98:7968-7973

Glonek T, Van Wazer JR, Myers TC (1977) Carbodiimide-mediated esterifications and condensations of phosphoric acids dissolved in various alcohols. Phosphorus Sulfur 3:137-150

Glonek T (1980) Applications of ${ }^{31} \mathrm{P}$ NMR to biological systems with emphasis on intact tissue determinations. In: Stec WJ (ed) Phosphorus Chemistry Directed Towards Biology. Pergamon Press, New York, pp $157-174$ 
Glonek T (1992) ${ }^{31} \mathrm{P}$ NMR of Mg-ATP in dilute solutions: Complexation and exchange. Int J Biochem 24:1533-1559

Gopaul DN, Guo F, Van Duyne GD (1998) Structure of the Holliday junction intermediate in Cre-loxP sitespecific recombination. EMBO J 17(14):4175-4187

Glonek T, Greiner JV (2020) Hydrotropic function of ATP in the crystalline lens. Exp Eye Res 190:1-8. https://doi.org/10.1016/j.exer.2019.107862

Glonek T, Nelson KE (2017) Geological and biological oscillations: A holistic continuous spectrum. https:// www.researchgate.net/publication/318769341_Geological_and_Biological_Oscillations_a_Holistic_ Continuous_Spectrum_Geological_and_Biological_Oscillations. https://doi.org/10.13140/RG.2.2.25189. 70888

Gómez-Garcia MR, Kornberg A (2004) Formation of an actin-like filament concurrent with the enzymatic synthesis of inorganic polyphosphate. Proc Natl Acad Sci USA 101:15876-15880. https://doi. org/10.1073/pnas.0406923101

Göpel C, Manhès G, Allègre CJ (1994) U-Pb systematics of phosphates from equilibrated ordinary chondrites. Earth Planet Sci Lett 121(1-2):153-171. https://doi.org/10.1016/0012-821X(94)90038-8

Gray MJ, Wholey W-Y, Wagner NO, Cremers CM, Mueller-Schickert A, Hock NT, Krieger AG, Smith EM, Bender RA, Bardwell JCA, Jakob U (2014) Polyphosphate is a primordial chaperone. Mol Cell 53(5):689-699. https://doi.org/10.1016/j.molcel.2014.01.012

Griffith EJ, Buxton RL (1965) The preparation and properties of the twelve-membered ring hexametaphosphate anion. Inorg Chem 4(4):549-551. https://doi.org/10.1021/ic50026a023

Griffith EJ (1972) Phosphate solubility in natural water systems. Proc. 14th Water Quality Confer. University of Illinois Press, Urbana, IL pp 115-118

Griffith EJ, Ponnamperuma C, Gabel NW (1977) Phosphorus, a key to life on the primitive earth. Orig Life Evol Biosph 8:71-85

Gull M (2014) Prebiotic phosphorylation reactions on the early Earth. Geochem Trans 15:1-4

Hamai Y, Kuwabara T (1975) Early cytologic changes of Fraser cataract. An electron microscopic study. Investig Ophthalmol Vis Sci 14(7):517-527

Harold FM (1966) Inorganic polyphosphates in biology: Structure, metabolism, and function. Bacterol Rev 30(4):772-794

Hassenkam T, Andersson MP, Dalby KN, Mackenzie DMA, Rosing MT (2017) Elements of Eoarchean life trapped in mineral inclusions. Nature https://doi.org/10.1038/nature23261

Holliday R (1964) A mechanism for gene conversion in fungi. Genet Res, Camb 5:282-304. https://doi. org/10.1017/S0016672308009476

Holm NG (2014) Glasses as sources of condensed phosphates on the early earth. Geochem Trans 15:8. https:// doi.org/10.1186/1467-4866-15-8

Horowitz NH (1945) The evolution of biochemical syntheses. Proc Nat Acad Sci 31:153-157

Hothorn M, Neumann H, Lenherr ED, Wehner M, Rybin V, Hassa PO, Uttenweiler A, Reinhardt M, Schmidt A, Seiler J, Ladurner AG, Herrmann C, Scheffzek K, Mayer A (2009) Catalytic core of a membrane-associated eukaryotic polyphosphate polymerase. Science 324(5926):513-516

Hou T, Charlier B, Holtz F, Veksler I, Zhang Z, Thomas R, Namur O (2018) Immiscible hydrous Fe$\mathrm{Ca}-\mathrm{P}$ melt and the origin of iron oxide-apatite ore deposits. Nat Commun 9:1415-1423. https://doi. org/10.1038/s41467-018-03761-4

Hsieh P-C, Kowalczyk TH, Phillips NFB (1996) Kinetic mechanism of polyphosphate glucokinase from Mycobacterium tuberculosis. Biochemistry 35(30):9772-9781

Huang R, Reusch RN (1995) Genetic competence in Escherichia coli requires poly-beta-hydroxybutyrate/ calcium polyphosphate membrane complexes and certain divalent cations. J Bacteriol 177:486-490

Hupfer M, Gächter R (1995) Polyphosphate in lake-sediments: ${ }^{31} \mathrm{P}$ NMR-spectroscopy as a tool for its identification. Limnol Oceanogr 40(3):610-617

Ingall E, Jahnke R (1997) Influence of water-column anoxia on the elemental fractionation of carbon and phosphorus during sediment diagenesis. Mar Geol 139(1-4):219-229

Ishige K, Noguchi T (2001) Polyphosphate: AMP phosphotransferase and polyphosphate: ADP phosphotransferase activities of Pseudomonas aeruginosa. Biochem Biophys Res Commun 281(3):821-826. https://doi.org/10.1006/bbrc.2001.4415

Jayaram M, Grainge I, Tribble G (2002) Site-specific recombination by the Flp protein of Saccharomyces cerevisiae. Mobile DNA II ASM Press Washington DC 192-218:1555812090

Jayaram M, Mehta S, Uzri D, Voziyanov Y, Velmurugan S (2004) Site-specific recombination and partitioning systems in the stable high copy propagation of the 2-micron yeast plasmid. In: Moldave K (ed) Prog Nucl Acid Res Mol Biol 77:127-172 
Jungmann O, Beier M, Luther A, Huynh HK, Ebert MO, Jaun B, Krishnamurthy R, Eschenmoser A (2003) Pentopyranosyl oligonucleotide systems. The $\alpha$-L-arabinopyranosyl-(4' $\rightarrow 2$ ')-oligonucleotide system: Synthesis and pairing properties. Helv Chim Acta 86(5):1259-1308

Karki M, Gibard C, Bhowmik S, Krishnamurthy R (2017) Nitrogenous derivatives of phosphorus and the origins of life: Plausible prebiotic phosphorylating agents in water. Life 7:32. https://doi.org/10.3390/ life 7030032

Kawakoshi A, Nakazawa H, Fukada J, Sasagawa M, Katano Y, Nakamura S, Hosoyama A, Sasaki H, Ichikawa N, Hanada S, Kamagata Y, Nakamura K, Yamazaki S, Fujita N (2012) Deciphering the genome of polyphosphate accumulating actinobacterium Microlunatus phosphovorus. DNA Res 5:383-394. https://doi.org/10.1093/dnares/dss020;PMCID:PMC3473371:PMID22923697

Keefe AD, Miller SI (1995) Are polyphosphates or phosphate esters prebiotic reagents? Orig Life Evol Biosph 41:693-702

Kenney WF, Schelske CL, Chapman AD (2001) Changes in polyphosphate sedimentation: A response to excessive phosphorus enrichment in a hypereutrophic lake. Can J Fish Aquat Sci 58(5):879-887

Kinoshita Y, Ohnishi N, Yamada Y, Kunisada T, Yamagishi H (1985) Extrachromosomal Circular DNA from Nuclear Fraction of Higher Plants. Plant Cell Physiol 26(7):1401-1409

Kornberg A, Kornberg SR, Simms ES (1956) Metaphosphate synthesis by an enzyme from Escherichia coli. Biochim Biophys Acta 20:215-227

Kornberg A (1995) Inorganic polyphosphate: toward making a forgotten polymer unforgettable. J Bacteriol 177(3):491-496

Kornberg A, Rao NN, Ault-Riché D (1999) Inorganic polyphosphate: a molecule of many functions. Annu Rev Biochem 68:89-125

Kowalczyk TH, Horn PJ, Pan W-H, Phillips NFB (1996) Initial rate and equilibrium isotope exchange studies on the ATP-dependent activity of polyphosphate glucokinase from Propionibacterium shermanii. Biochemistry 35(21):6777-6785

Kristensen O, Laurberg M, Liljas A, Kastrup JS, Gajhede M (2004) Structural characterization of the stringent response related exopolyphosphatase/guanosine pentaphosphate phosphohydrolase protein family. Biochemistry 43(28):8894-8900

Kulaev I, Kulakovskaya T (2000) Polyphosphate and phosphate pump. Annu Rev Microbiol 54:709-734

Kulaev IS (1971) Inorganic polyphosphates in evolution of phosphorus metabolism. In: Buvet R, Ponnamperuma C, eds., Chemical Evolution and the Origin of Life, Vol. 1, Molecular Evolution. Proceedings of the Third International Conference on the Origin of Life, Pont-A-Mousson, France, April 19-25, 1970. Amsterdam: North-Holland, pp 458-465

Kulaev IS, Skryabin KG (1974) Reactions of non-enzymatic transphosphorylation through highly polymeric polyphosphates and their role in abiogenesis. Zh Évol Biokhim Fiziol 10:553-560

Kulaev IS (1979) The Biochemistry of Inorganic Polyphosphates. John Wiley \& Sons, New York. English translation, Brookes RF. ISBN 0471275743

Kulaev IS, Vagabov VM (1983) Polyphosphate metabolism in microorganisms. Adv Microbiol Physiol 24:83-171

Kulaev IS, Vagabov VM, Kulakovskaya TV (2004) Inorganic polyphosphates in chemical and biological evolution. In: The Biochemistry of Inorganic Polyphosphates. In: Kulaev IS et al. The Biochemistry of Inorganic Polyphosphates, John Wiley \& Sons, Ltd, Chichester, England, pp 193-210. ISBN: 0 470858109

Kulakovskaya TV, Andreeva NA, Trilisenko LV, Suetin SV, Kulaev IS (2005) Accumulation of polyphosphates and expression of high molecular weight exopolyphosphatase in the yeast Saccharomyces cerevisiae. Biochemistry (Moscow) 70(9):980-985

Kumble KD, Kornberg A (1995) Inorganic polyphosphate in mammalian cells and tissues. J Biol Chem 270(11):5818-5822

Kumble KD, Kornberg A (1996) Endopolyphosphatases for long chain inorganic polyphosphate in yeast and mammals. J Biol Chem 271(43):27146-27151

Kura G, Ohashi S (1971) Chromatographic separation of cyclic phosphates by means of an anion-exchange dextran gel. J Chromatogr 56:111-120

Kura G, Ohashi S, Kura S (1974) Complex formation of cyclic phosphate anions with bivalent cations. J Inorg Nucl Chem 36(7):1605-1609. https://doi.org/10.1016/0022-1902(74)80631-7

Kura G, Ohashi S (1976) Interactions between cyclic phosphate anions and various cations in aqueous solution. J Inorg Nucl Chem 38:1151-1155

Kura G (1981) Chromatographic study of the acidic hydrolysis of cyclic octametaphosphate. J Chromatog 211(1):87-94. https://doi.org/10.1016/S0021-9673(00)81176-0

Kura G (1994) Evidence for the formation of higher cyclo-polyphosphates as degradation products of linear octaphosphate. Phosphorus Research Bulletin 4:105-110 
Kurokawa C, Fujiwara K, Morita M, Kawamata I, Kawagishi Y, Sakai A, Murayama Y, Nomura S-IM, Murata S, Takinoue M, Yanagisawa M (2017) DNA cytoskeleton for stabilizing artificial cells. Proc Natl Acad Sci 114(28):7228-7233

Kuttler F, Mai S (2007) Formation of non-random extrachromosomal elements during development, differentiation and oncogenesis. Semin Cancer Biol 17:56-64

Lawrence BA, Suarez C, DePina A, Click E, Kolodny NH, Allen MM (1998) Two internal pools of soluble polyphosphate in the cyanobacterium Synechocystis sp. strain PCC 6308: An in vivo ${ }^{31} \mathrm{P}$ NMR spectroscopic study. Arch Microbiol 169(3):195-200

Lazcano A, Miller SL (1996) The origin and early evolution of life: Prebiotic chemistry, the pre-RNA world, and time. Cell 85:793-798

Lichko LP, Andreeva NA, Kulakovskaya TV, Kulaev IS (2003) Exopolyphosphatases of the yeast Saccharomyces cerevisiae. FEMS Yeast Res 3:233-238. https://doi.org/10.1016/S1576 -1356(02)00205-2

Lichko LP, Kulakovskaya TV, Kulakovskaya, EV, Kulaev IS (2008) Inactivation of PPX1 and PPN1 genes encoding exopolyphosphatases of Saccharomyces cerevisiae does not prevent utilization of polyphosphates as a phosphate reserve. Biochemistry 73(9):985-989. ISSN 0006-2979. https:// doi.org/10.1134/S0006297908090046

Lichko LP, Kulakovskaya TV, Kulaev IS (2010) Properties of partially purified endopolyphosphatase of the yeast Saccharomyces cerevisiae. Biochemistry (Moscow) 75(11):1404-1407

Liebermann L (1888) Ueber das Nucleïn der Hefe und künstliche Darstellung eines Nucleïns Eiweiss und Metaphosphorsäure. Berichte 21:598-600

Lipmann F (1965) Projecting backward from the present stage of evolution of biosynthesis. In: Fox SW (ed) The Origin of Prebiological Systems and of their Molecular Matrices. Academic Press, New York 1965, pp 259-280

Locker A (Ed) (1973) Biogenesis Evolution Homeostasis Springer-Verlag, New York A Symposium by Correspondence 13: 978-3-540-06134-2 e-ISBN 13: 978-3-642-95235-7. https://doi. org/10.1007/978-3-642-95235-7

López-Garcia P, Moreira D (2015) Open questions on the origin of eukaryotes. Trends Ecol Evol 30(11):697-708. https://doi.org/10.1016/j.tree.2015.09.005

Lydic R (1989) Central pattern-generating neurons and the search for general principles. FASEB J 3:2457-2468

Ma CH, Kachroo AH, Macieszak A, Chen TY, Guga P, Jayaram M (2009) Reactions of Cre with metlhylphosphonate DNA: Similarities and contrasts with Flp and vaccinia topoisomerase. PLoS One 4(9):e7248. https://doi.org/10.1371/journal.pone.0007248

Maciá E (2005) The role of phosphorus in chemical evolution. Chem Soc Rev 34:691-701. https://doi. org/10.1039/b416855k

Mansurova SE, Kulaev IS, Skryabin KG (1973) On a possibility of non-enzymatic transphosphorylation by high polymeric polyphosphates. In: Kulaev IS and Vagabov VM (eds) Reaction Mechanisms and control Properties of Phosphotransferases. Berlin: Akademie-Verlag, Berlin pp 75-78

Marchi S, Bottke WF, Elkins-Tanton LT, Bierhaus M, Wuennemann K, Morbidelli A, Kring DA (2014) Widespread mixing and burial of Earth's Hadean crust by asteroid impacts. Nature 511(7511):578-582. https://doi.org/10.1038/nature13539

Mateo P, Douterelo I, Berrendero E, Perona E (2006) Physiological differences between two species of cyanobacteria in relation to phosphorus limitation. J Phycol 42(1):61-66. https://doi.org/10.1111/ j.1529-8817.2006.00180.x

Mattenheimer H (1956a) Die Substratspezifität "anorganisher" Poly- und Metaphosphatasen. III. Papirchromatographische Untersuchungen beim enzymatischen Abbau von anorganischen Polyund Metaphosphaten. Z Phys Chem 303:125-139

Mattenheimer H (1956b) Die Substratspezifität “anorganisher" Poly- und Metaphosphatasen. II. Trennung der Enzyme Z Physiol Chem 303:115-124

Mattenheimer H (1956c) Die Substratspezifität "anorganisher" Poly- und Metaphosphatasen. I. Optimale Wirkungsbedingungen für den enzymatischen Abbau von Poly- und Metaphosphaten. Z Phys Chem 303:107-114

Mattiroli F, Bhattacharyya S, Dyer PN, White AE, Sandman K, Burkhart BW, Byrne KR, Lee T, Ahn NG, Santangelo TJ, Reeve JN, Luger K (2017) Structure of histone-based chromatin in Archaea. Science 357(6351):609-612

McLennan AG (2006) The Nudix hydrolase superfamily. Cell Mol Life Sci 63:123-143. https://doi. org/10.1007/s00018-005-5386-7

Miller SL, Parris M (1964) Synthesis of pyrophosphate under primitive Earth conditions. Nature 204:1248-1250 
Misra R, Matera AG, Schmid CW, Rush MG (1989) Recombination mediates production of an extrachromosomal circular DNA containing a transposon-like human element, THE-1. Nucleic Acids Res 17:8327-8341

Miyata K, Hattori A, Ohtsuki A (1986) Variation of cellular phosphorus composition of Skeletonema costatum and Heterosigma akashiwo grown in chemostats. Mar Biol 93(2):291-297

Mojzsis SJ, Arrhenius G, McKeegan KD, Harrison TM, Nutman AP, Friend CRL (1996) Evidence for life on Earth before 3,800 million years ago. Nature 384:55-59

Moorbath S (2009) The discovery of the Earth's oldest rocks. Notes Rec R Soc 63:381-392. https://doi. org/10.1098/rsnr.2009.0004

Moore-Ede MC, Sulzman FM, Fuller CA (1984) In: The Clocks that Time Us. Harvard Press, Cambridge

Moreno SN, Docampo R (2013) Polyphosphate and its diverse functions in host cells and pathogens. PLoS Pathog 9:e1003230

Mori S, Yamasaki M, Maruyama Y, Momma K, Kawai S, Hashimoto W, Mikami B, Murata K (2004) Crystallographic studies of Mycobacterium tuberculosis polyphosphate/ATP-NAD kinase complexed with NAD. J Biosci Bioeng 98(5):391-393

Mukai T, Kawai S, Matsukawa H, Matuo Y, Murata K (2003) Characterization and molecular cloning of a novel enzyme, inorganic polyphosphate/ATP-glucomannokinase, of Arthrobater sp. strain KM. Appl Environ Microbiol 69(7):3849-3857. https://doi.org/10.1128/AEM.69.7.3849-3857.2003

Müller A, Keppler M, Henning et al. (2018) Orbital and atmospheric characterization of the planet within the gap of the PDS 70 transition disk. Earth and Planetary Astrophysics. https://doi.org/10.1051/0004$6361 / 201833584$

Mysen BO, Cody GD (2001) Silicate-phosphate interactions in silicate glasses and melts: II. Quantitative, high-temperature structure of P-bearing alkali aluminosilicate melts. Geochim Cosmochim Acta 65(14):2413-2431. https://doi.org/10.1016/S0016-7037(01)00598-1

Mysen BO (2011) An experimental study of phosphorus and aluminosilicate speciation in and partitioning between aqueous fluids and silicate melts determined in-situ at high temperature and pressure. Am Mineral 96:1636-1649. https://doi.org/10.2138/am.2011.3728

Nesmeyanova MA, Gonina SA, Kulaev IS (1975) Biosynthesis of polyP and alkaline phosphatase in E. coli is under control of integrated regulatory genes. Dokl Akad Nauk SSSR 224:710-712

Nesmeyanova MA (2000) Polyphosphates and enzymes of polyphosphate metabolism in Escherichia coli. Biochemistry-Moscow 65(3):309-314

Niemeyer R (1976) Cyclic condensed metaphosphates and linear polyphosphates in brown and red algae. Arch Microbiol 108(3):243-247

Nomura K, Kato J, Takiguchi N, Ohtake H, Kuroda A (2004) Effects of inorganic polyphosphate on the proteolytic and DNA-binding activities of Lon in Escherichia coli. J Biol Chem 279(33):34406-34410. https://doi.org/10.1074/jbc.M404725200

Nutman AP, Bennett VC, Friend CRL, Van Kranendonk MJ, Chivas AR (2016) Rapid emergence of life shown by discovery of 3,700-million-year-old microbial structures Nature 537(7621):535-501. https:// doi.org/10.1038/nature19355

Öberg KI, Guzman VV, Furuya K, Qi C, Aikawa Y, Andrews SM, Loomis R, Wilner DJ (2015) The cometlike composition of a protoplanetary disk as revealed by complex cyanides. Nature 520:198-201

Orchard ED, Benitez-Nelson CR, Pellechia PJ, Lomas MW, Dyhrman ST (2010) Polyphosphate in Trichodesmium from the low-phosphorus Sargasso Sea. Limnol Oceanogr 55(5):2161-2169

Orell A, Navarro CA, Rivero M, Aquilar JS, Jerez CA (2012) Inorganic polyphosphates in extremophiles and their possible functions. Extremophiles 16(4):573-583. https://doi.org/10.1007/s00792012-0457-9

Oró J (1994) Chemical synthesis of lipids and the origin of life. J Biol Phys 20(1-4):135-147

Pasek MA (2008) Rethinking early Earth phosphorus geochemistry. Proc Natl Acad Sci USA 105:853-858

Patel A, Malinovska L, Saha S, Wang J, Alberti S, Krishmam Y, Hyman AA (2017) ATP as a biological hydrotrope. Science 356(6339):753-756

Peng JC, Karpen GH (2007) H3K9 methylation and RNA interference regulate nucleolar organization and repeated DNA stability. Nat Cell Biol 9(1):25-35

Perry MJ (1976) Phosphate utilization by an oceanic diatom in phosphorus-limited chemostat culture and in oligotrophic waters of Central North-Pacific. Limnol Oceanogr 21(1):88-107

Pitsch S, Wendeborn S, Jaun B, Eschenmoser A (1993) Why pentose- and not hexose-nucleic acids? Part VII, Pyranosyl-RNA ('p-RNA'). Helv Chim Acta 76:2161-2183

Piwecka M, Glažar P, Hernandez-Miranda LR, Memczak S, Wolf SA, Rybak-Wolf A, Filipchyk A, Klironomos F, Cerda Jara CA, Fenske P, Trimbuch T, Zywitza V, Plass M, Schreyer L, Ayoub S, Knocks C, Kühn R, Rosenmund C, Birchmeier C, Rajewsky N (2017) Loss of a mammalian circular RNA locus 
causes miRNA deregulation and affects brain function. Science 357(6357):1254-1255. https://doi. org/10.1126/science.aam8526

Powers ET, Balch WE (2013) Diversity in the origins of proteostasis networks-a driver for protein function in evolution. Nat Rev Mol Cell Biol 14(4):237-248. https://doi.org/10.1038/nrm3542

Prieur BE (2009) Phosphorylation of ribose in the presence of borate salts Orig Life Evol Biosph 39:264265 (entirespecialissue):https://doi.org/10.1007/s11084-009-9164-7

Rafter GW (1959) Studies on trimetaphosphate metabolism in yeast. Arch Biochem Biophys 81:238-248

Ragsdale SW, Pierce E (2008) Acetogenesis and the Wood-Ljungdahl pathway of CO2 fixation. Biochim Biophys Acta 1784(12):1873-1898. https://doi.org/10.1016/j.bbapap.2008.08.012

Rao NN, Roberts MF, Torriani A (1985) Amount and chain length of polyphosphates in Escherichia coli depend on cell growth conditions. J Bacteriol 162(1):242-247

Rao NN, Gómez-García MR, Kornberg A (2009) Inorganic polyphosphate: Essential for growth and survival. Annu Rev Biochem 78:605-647

Reinhard CT, Planavsky NJ, Gill BC, Ozaki K, Robbins LJ, Lyons TW, Fischer WW, Wang C, Cole DB, Konhauser KO (2017) Evolution of the global phosphorus cycle. Nature 541:386-389. https://doi. org/10.1038/nature20772

Remonsellez F, Orell A, Jerez CA (2006) Copper tolerance of the thermoacidophilic archaeon Sulolobus metallicus: possible role of polyphosphate metabolism. Microbiology 152:59-66

Reusch RN, Sadoff HI (1988) Putative structure and functions of a poly-beta-hydroxybutyrate/calcium polyphosphate channel in bacterial plasma membranes. Proc Natl Acad Sci USA 85:4176-4180. https:// doi.org/10.1073/pnas.85.12.4176

Reusch RN (1992) Biological complexes of poly- $\beta$-hydroxybutyrate. FEMS Microbiol Rev 103:119-130

Reusch RN, Huang R, Bramble LL (1995) Poly-3-hydroxybutyrate/polyphosphate complexes form voltageactivated $\mathrm{Ca} 2+$ channels in the plasma membranes of Escherichia coli. Biophys J 69:754-766. https:// doi.org/10.1016/S0006-3495(95)79958-1

Reusch RN, Huang R, Kosk-Kosicka D (1997) Novel components and enzymatic activities of the human erythrocyte plasma membrane calcium pump. FEBS Lett 412:592-596

Reusch RN (1999) Polyphosphate/poly-R-3 hydroxybutyrate in channels ion cell membranes. Inorganic Polyphosphates: Biochemistry, Biology, Biotechnology. In: Schröder HC, Müller, Eds., Prog Mol Subcell Biol. Berlin/Heidelberg/New York: Springer-Verlag 23:151-183

Reusch RN (2000) Transmembrane ion transport by polyphosphate/poly-(R)-3-hydroxybutyrate complexes. Biochemistry (Mosc) 65:280-295

Rice PA (2002) Theme and variation in tyrosine recombinases: Structure of a Flp-DNA complex. In Mobile DNA II. American Society of Microbiology Press Washington DC 219-229:1555812090

Rohloff P, Rodrigues CO, Docampo R (2003) Regulatory volume decrease in Trypanosoma cruzi involves amino acid efflux and changes in intracellular calcium. Mol Biochem Parasitol 126(2):219-230

Romans KM, Carpenter EJ, Bergman B (1994) Buoyancy regulation in the colonial diazotrophic cyanobacterium Trichodesmium tenue: Ultrastructure and storage of carbohydrate, polyphosphate, and nitrogen. J Phycology 30(6):935-942

Roy D, Najafian K, von Ragué Schleyer, (2007) Chemical evolution: The mechanism of the formation of adenine under prebiotic conditions. Proc Natl Acad Sci USA 104:17272-17277

Rudnick H, Hendrich S, Pilatus U, Blotevogel K-H (1990) Phosphate accumulation and the occurrence of polyphosphate and cyclic 2,3-diphosphoglycerate in Methanosarcina frisia. Arch Microbiol 154:584-588

Ruiz FA, Marchesini N, Seufferheld M, Docampo G, Docampo R (2001) The polyphosphate bodies of Chlamydomonas reinhardtii possess a proton-pumping pyrophosphatase and act similar to acidocalcisomes. J Biol Chem 276(49):46196-46203. https://doi.org/10.1074/jbc.M105268200

Scherer A, Bochem H-P (1983) Ultrastructural investigation of Methanosarcinae and related species grown on methanol for occurrence of polyphosphate like inclusion. Can J Microbiol 29:1190-1199

Schöning K-U, Scholz P, Wu X, Guntha S, Delgado G, Krishnamurthy R, Eschenmoser A (2002) The $\alpha$-Lthreofuranosyl-( $\left.3^{\prime} \rightarrow 2^{\prime}\right)$-oligonucleotide system ('TNA'): Synthesis and pairing properties. Helv Chim Acta 85(12):4111-4153

Schopf JW, Kitajima K, Spicuzza MJ, Kudryavtsev AB, Valley JW (2018) SIMS analyses of the oldest known assemblage of microfossils document their taxon-correlated carbon isotope compositions. PNAS 115(1):53-58

Schülke U (1968) Darstellung von Oktametaphosphaten. M8[P8O24]. Z Anorg Allg Chem 360:231-246

Scott JR (1968) Genetic studies on bacteriophage P1. Virology 36:564-574

Scott M, Lindsey R (2017) What's the hottest Earth's ever been? NOAA: Science \& Information for a Climate-Smart Nation.https://www.climate.gov/print320058 
Semenov EI, Kukharchik ONI, MV, (1961) New data on minerals of the lomonosovite-murmanite group. Kristallografiya 6:925-932

Serafim LS, Lemos PC, Levantesi C, Tandoi V, Santos H, Reis MAM (2002) Methods of detection and visualization of intracellular polymers stored by polyphosphate-accumulating microorganisms. J Microbiol Methods 51(1):1-18

Sethuraman A, Rao NN, Kornberg A (2001) The endopolyphosphatase gene: Essential in Saccharomyces cerevisiae. Proc Natl Acad Sci USA 98(15):8542-8547

Seviour RJ, Mino T, Onuki M (2003) The microbiology of biological phosphorus removal in activated sludge systems. FEMS Microbiol Rev 27(1):99-127

Shabalin YA, Kulaev IS (1989) Solubilization and properties of yeast dolichylpyrophosphate:polyphosp hate phosphotransferase. Biokhimia 54:68-75

Shabalin YA, Vagabov VM, Kulaev IS (1979a) On the coupling mechanism of biosynthesis of highmolecular polyphosphates and mannan in Saccharomyces carlsbergensis yeast. Dokl Acad Nauk SSSR 249:243-246

Shabalin YA, Vagabov VM, Kulaev IS (1979b) Dolychildiphosphatemannose-an intermediate of glycoprotein biosynthesis in yeast? Dokl Acad Nauk SSSR 283:720-723

Shi XB, Rao NN, Kornberg A (2004) Inorganic polyphosphate in Bacillus cereus: Motility, biofilm formation, and sporulation. Proc Natl Acad Sci USA 101(49):17061-17065. https://doi.org/10.1073/ pnas.0407787101

Shi X, Kornberg A (2005) Endopolyphosphatase in Saccharomyces cerevisiae undergoes post-translational activations to produce short-chain polyphosphates. FEBS Lett 579:2014-2048

Shoura MJ, Levene SD (2014) Understanding DNA looping through Cre-recombination kinetics. In: Jonoska N, Saito M, eds. Discrete and Topological Models in Molecular Biology. Berlin, Heidelberg: Springer Berlin Heidelberg 405-418

Shoura MJ, Gabdank I, Hansen L, Merker J, Gotlib J, Levene SD, Fire AZ (2017) Beyond the linear genome: Comprehensive determination of the endogenous circular elements in C. elegans and human genomes via an unbiased genomic-biophysical method. (preprint) https://doi. org/10.1101/128686

Sibilska IK, Chen B, Li L, Yin J (2017) Effects of trimetaphosphate on abiotic formation and hydrolysis of peptides. Life 7(4):50-61. https://doi.org/10.3390/life7040050

Smith M, Moffatt JG, Khorana HG (1958) Carbodiimides. VIII. Observations on the reactions of carbodiimides with acids and some new applications in the synthesis of phosphoric acid esters. J Am Chem Soc 80:6204-6212

Spang A, Caceres EF, Ettema TJG (2017) Genomic exploration of the diversity, ecology, and evolution of the archaeal domain of life. Science 357(6351), eaaf3883: https://doi.org/10.1126/science.aaf3883

Stahl AJC, Ebel JP (1963) Étude des complexes entre acides ribonucléiques et polyphosphates inorganiques dan la levure. III. Rôle des cations divalents dans la formation des complexes. Bull Soc Chim Biol 45(9-10):887-900

Sternberg N (1979) Demonstration and analysis of P1 site-specific recombination using $\lambda$-P1 hybrid phages constructed in vitro. Cold Spring Harb Symp Quant Biol 43(Pt 2):1143-1146

Sternberg N, Hamilton D, Austin S, Yarmolinsky M, Hoess R (1981) Site-specific recombination and its role in the life cycle of bacteriophage P1. Cold Spring Harb Symp Quant Biol 45(Pt 1):297-309

Sutherland JD (2016) The origin of life-out of the blue. Angew Chem Int Ed 55:104-121. https://doi. org/10.1002/anie.201506585

Szymona M, Widomski J (1974) A kinetic study on inorganic polyphosphate glucokinase from Mycobacterium tuberculosis H37RA. Physiol Chem Phys 6:393-404

Tanaka S, Lee SO, Hamaoka K, Kato J, Takiguchi N, Nakamura K, Ohtake H, Kuroda A (2003) Strictly polyphosphate-dependent glucokinase in a polyphosphate-accumulating bacterium. Microlunatus Phosphovorus J Bacteriol 185(18):5654-5656

Tanzer JM, Krichevsky MI, Chassy B (1968) Separation of polyphosphates by anion exchange thin layer chromatography. J Chromatog 38:526-531

Thilo E, Wieker W (1957) Die Anionenhydrolyse kundensierter Phosphate in verdünnter wäßriger Lösung. Z Anorg Allg Chem 291:164-185

Thilo E, Wieker W (1961) Study of degradation of polyphosphates in aqueous solution. J Polymer Sci Part A: Polymer Chem 53(158):55-59

Thilo E (1965) The structural chemistry of condensed inorganic phosphates. Angew Chem Int Ed 4(12):1061-1071. https://doi.org/10.1002/anie.196510611

Thilo E, Schülke U (1965) Zur Chemie der kondensierten Phosphate und Arsenate. XLVI. Über Metaphosphate, die mehr als vier Phosphoratome im Ringanion enthalten. Z Anorg Allg Chem 341(56):293-307 
Toplis MJ, Libourel G, Carroll MR (1994) The role of phosphorus in crystallization processes of basalt: an experimental study. Geochim Cosmochim Acta 58(2):797-810. https://doi.org/10.1016/00167037(94)90506-1

Toso DB, Henstra AM, Gunsalus RP, Zhou ZH (2011) Structural, mass and elemental analyses of storage granules in methanogenic archaeal cells. Environ Microbiol 13:2587-2599

Turner AM, Bergantini A, Abplanalp MJ, Zhu C, Góbi S, Sun BJ, Chao KH, Chang AHH, Meinert C, Kaiser RI (2018) An interstellar synthesis of phosphorus oxoacids. Nat Commun 9(3851):XXXXXX. https://doi.org/10.1038/s41467-018-06415-7

Valley JW, Reinhard DA, Cavosie AJ, Ushikubo T, Lawrence DF, Larson DJ, Kelly TF, Snoeyenbos DR, Strickland A (2015) Nano- and micro-geochronology in Hadean and Archean zircons by atom-probe tomography and SIMS: New tools for old minerals. American Mineralogist. 100:(pdf, 23 pages). https:// doi.org/10.2138/am-2015-5134

Van Cappellen P, Ingall ED (1994) Benthic phosphorus regeneration, net primary production, and ocean anoxia: A model of the coupled marine biogeochemical cycles of carbon and phosphorus. Paleoceanography 9(5):677-692

Van Cappellen P, Ingall ED (1996) Redox stabilization of the atmosphere and oceans by phosphorus-limited marine productivity. Science 271(5248):493-496

Van GD Duyne (2002) A structural view of tyrosine recombinase site-specific recombination NL Craig R Craigie M Gellert AM Lambowitz Eds Mobile DNA II ASM Press Washington DC 93-117:1555812090

Van Duyne GD (2014) Cre recombinase. Microbiol Spectrum 3(1):MDNA3-0014. https://doi.org/10. 1128/microbiolspec.MDNA3-0014-2014

Van Wazer (1958a) Phosphorus and Its Compounds, Vol. I: Chemistry. New York: Interscience Publishers, Inc., a division of Wiley \& Sons. pp. 419-477, structure and properties of the condensed phosphates.)

Van Wazer (1958b) pp 747-763. (Composition of chain polyphosphates.)

Van Wazer (1958c) pp 680-688 (Structures of the cyclic condensed phosphates)

Van Wazer (1958d) pp 706-710 (Ultraphosphate preparation and properties)

Van Wazer (1958e) pp 677-678 (Presence of branch groups in Maddrell's salts)

Van Wazer (1958f) pp 666-672 (Preparation of condensed phosphates; Kurrol's salt p 667)

Van Wazer (1958g) pp 839-840. (Imidophosphates; evidence for cross-linking in Kurrol's salt)

Van Wazer (1958h) pp 628-672 (Metal ion complexation)

Van Wazer (1958i) pp 676-678 (Evidence for cross-linking in Kurrol's salt)

Van Wazer (1958j) pp 711-713 (Ultraphosphate families)

Van Wazer (1958k) Phosphimic acids N-containing cyclic metaphosphimates 834843

Van Wazer (19581) pp 722-769 (Reorganization Theory; R value, p. 726)

Van Wazer (1958m) pp 692-695; Table 11.2; Fig. 11.4. (Hydrolysis of phosphorus pentoxide)

Van Wazer JR, Glonek T (1972) High-resolution nuclear magnetic resonance. In: Hallmann M (ed) Analytical Chemistry of Phosphorus Compounds. John Wiley \& Sons Inc, New York, pp 151-188

Vezinet A, Pearson G, Tomassot E, Stern RA, Sarkar C, Luo Y, Fisher CM (2018) Hydrothermallyaltered mafic crust as source for early Earth TTG: $\mathrm{Pb} / \mathrm{Hf} / \mathrm{O}$ isotope and trace element evidence in zircon from TTG of the Eoarchean Saglek Block, N. Labrador Earth and Planetary Science Letters 503:95-107. https://doi.org/10.1016/j.eps1.2018.09.015

Vinogradov AP, Tugarinov AI (1961) Geochronology of the Precambrian. Geokhimiya 1961:723-731

Wade N (2016) Meet Luca, the ancestor of all living things. The New York Times. July 25, 2016. http:// nyti.ms/2anJSpd

Weimann G, Khorana HG (1962) Studies on polynucleotides. XVII. On the mechanism of internucleotide bond synthesis by the carbodiimide method. J Am Chem Soc 84:4329-4341

Werfel S, Nothjunge S, Schwarzmayr T, Strom T-M, Meitinger T, Engelhardt S (2016) Characterization of circular RNAs in human, mouse and rat hearts. J Mol Cell Cardiol 98:103-107

Westheimer FH (1987) Why Nature chose phosphates. Science 235:1173-1178

Wiame J-M (1947) Yeast metaphosphate. Fed Proc 6:302-EOA

Williams L, Canfield B, Voglesonger KM, Holloway JR (2005) Organic molecules formed in a "primordial womb." Geology 33(11):913-916

Wood HG, Clark JE (1988) Biological aspects of inorganic polyphosphates. Ann Rev Biochem $57: 235-260$

Wood JA, Chang S (1985) The cosmic history of the biogenic elements and compounds. NASA SP-476, Washington DC

Wurst H, Shiba T, Kornberg A (1995) The gene for a major exopolyphosphatase of Saccharomyces cerevisiae. J Bacteriol 177(4):898-906 
Wyatt HDM, West SC (2014) Holliday junction resolvases. Cold Spring Harb Perspect Biol 6:a023192. https://doi.org/10.1101/cshperspect.a023192

Yamagata Y, Watanabe H, Saitoh M, Namba T (1991) Volcanic production of polyphosphates and its relevance to prebiotic evolution. Nature 352(6335):516-519

Yamagata Y, Inoue H, Inomata K (1995) Specific effect of magnesium ion on 2',3'-cyclic amp synthesis from adenosine and trimetaphosphate in aqueous solution. Orig Life Evol Biosph 25(1-3):47-52

Yamagata Y, Inomata K (1997) Condensation of glycylglycine to oligoglycines with trimetaphosphate in aqueous solution. II: Catalytic effect of magnesium ion. Orig Life Evol Biosph 27(4):339-344. https:// doi.org/10.1023/A:1006529421813

Yang YC, Bastos M, Chen KY (1993) Effect of osmotic stress and growth stage on cellular pH and polyphosphate metabolism in Neurospora crassa as studied by ${ }^{31} \mathrm{P}$-nuclear magnetic resonance spectroscopy. Biochim Biophys Acta 1179:141-147

Zhang F, Blasiak LC, Karolin JO, Powell RJ, Geddes CD, Hill RT (2015) Phosphorus sequestration in the form of polyphosphate by microbial symbionts in marine sponges. https://doi.org/10.1073/pnas.1423768112. Assessed Mar. 6, 2015

Zhang H, Gommez-Garcia MR, Shi X, Rao NN, Kornberg A (2007) Polyphosphate kinase 1, a conserved bacterial enzyme, in a eukaryote, Dictyostelium discoideum, with a role in cytokinesis. Proc Natl Acad Sci USA 104:16486-16491

Zhang HY, Ishige K, Kornberg A (2002) A polyphosphate kinase (PPK2) widely conserved in bacteria. Proc Natl Acad Sci USA 99(26):16678-16683

Zhang HY, Rao NN, Shiba T, Kornberg A (2005) Inorganic polyphosphate in the social life of Myxococcus xanthus: Motility, development, and predation. Proc Natl Acad Sci USA 102(38):13416-13420

Zhu Y, Huang W, Lee SS, Xu W (2005) Crystal structure of a polyphosphate kinase and its implications for polyphosphate synthesis. EMBO Rep 6:681-687

Publisher's Note Springer Nature remains neutral with regard to jurisdictional claims in published maps and institutional affiliations. 